Disturbance Measurements from Off-Road Vehicles on Seasonal Terrain

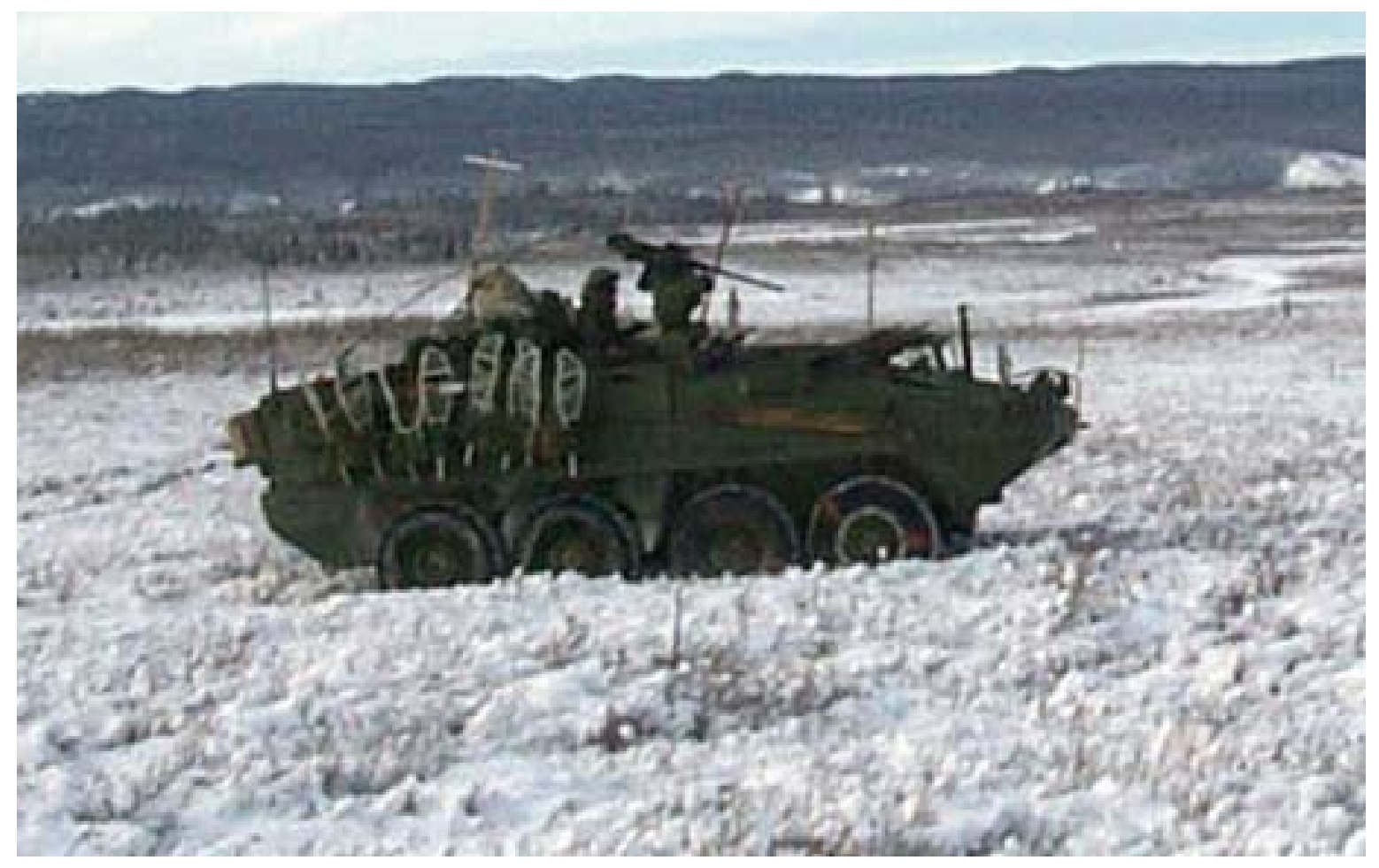




\title{
Disturbance Measurements from Off-Road Vehicles on Seasonal Terrain
}

\author{
Rosa T. Affleck \\ Cold Regions Research and Engineering Laboratory \\ U.S. Army Engineer Research and Development Center \\ 72 Lyme Road \\ Hanover, New Hampshire 03755-1290
}

Final report

Approved for public release; distribution is unlimited.

Prepared for U.S. Army Corps of Engineers

Washington, DC 20314-1000 


\begin{abstract}
Vehicle operations on cross-country terrain for military, commercial or industrial, and recreational purposes can disturb the terrain, especially during spring thaw season. Terrain disturbance from off-road vehicle operations can be measured in terms of rut depth and vegetation damage. Ruts occur when vehicle load is greater than the terrain's bearing capacity, especially in soft soils. Rutting is the physical disturbance of the soil, including compaction and deformation. Estimates of rut depth for wheeled and tracked vehicles in soft, unfrozen soils can be calculated using an empirical equation based on the vehicle and soil properties. The vehicle parameters include vehicle load, tire or tracked footprint area, and wheel slip. The terrain soil properties are very important elements for estimating rut depth, including soil type and strength. Rut depth measurements were collected from military vehicles during Stryker (wheeled) vehicle impact tests at three locations at Donnelly Training Area, Alaska, and from M6oA3 (tracked) and HEMTT (wheeled) vehicles at Fort McCoy, Wisconsin, during spring thaw seasons. These rut depth data are coupled with information about vehicle maneuvers (multiple passes and turning) and soil properties, such as soil type, moisture content, and soil strength. The scope of this report is to compare the actual rut depth measurements with the empirical equations to relate the physical disturbance of the soil and vegetation to a severity index, quantify the volumetric soil displacement, and assess disturbance on winter operations.
\end{abstract}




\section{CONTENTS}

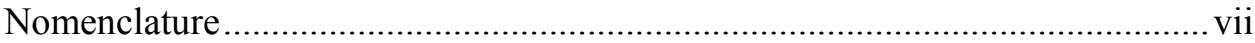

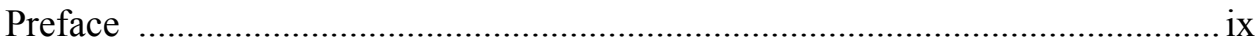

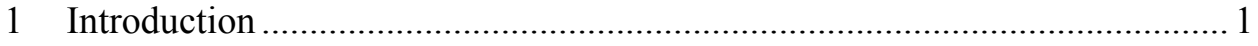

1.1 Definition of Problem-The Problem of Spring Thaw …........................ 1

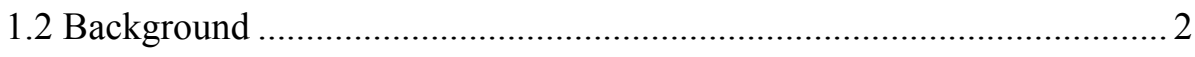

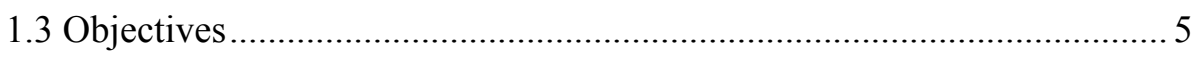

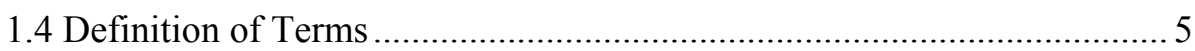

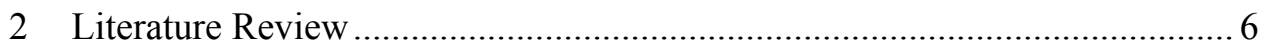

2.1 Vehicle Impact on Arctic and Subarctic Terrain ........................................ 6

2.2 Impact of Military Vehicles on Training Lands ................................... 7

2.3 Impact of Mechanized Forest Operations on Woodlands ........................ 8

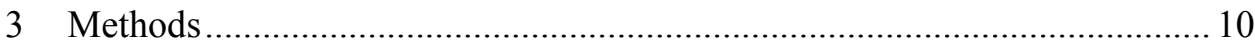

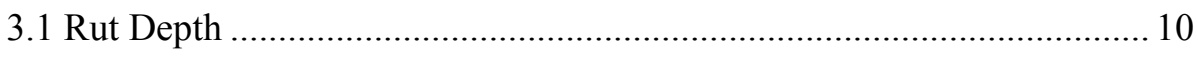

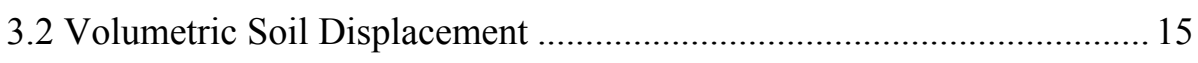

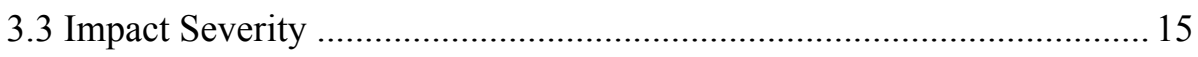

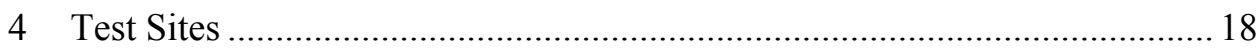

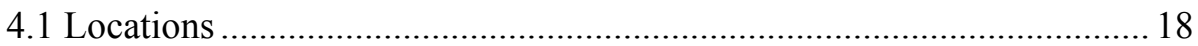

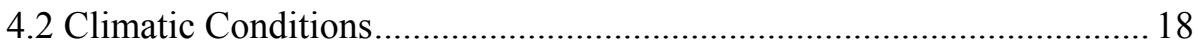

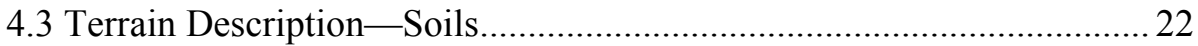

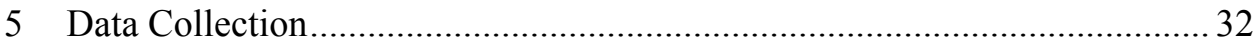

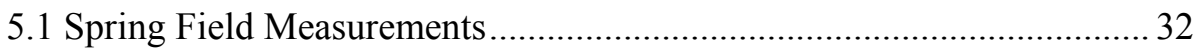

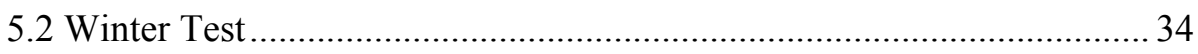

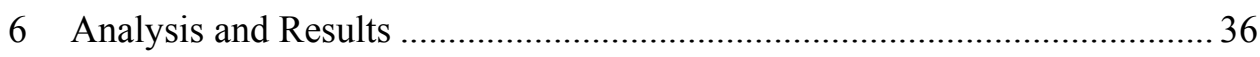

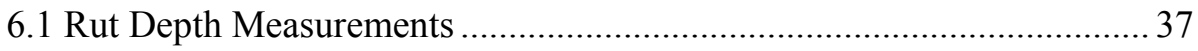

6.2 Rut Depth Model Comparison ................................................................. 41

6.3 Volumetric Soil Displacement ................................................................ 44

6.4 Cumulative Impact Width ............................................................... 46

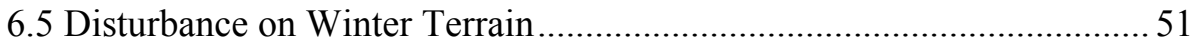

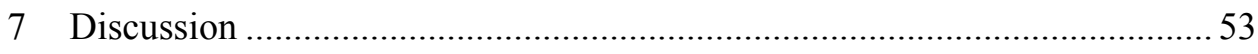

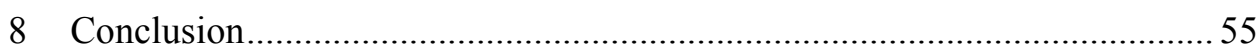




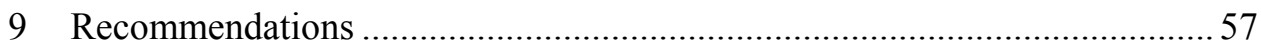

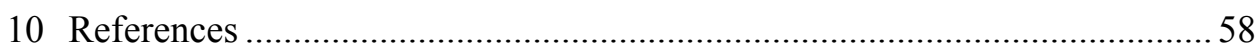

Appendix A: Summary Tables of Test Data and Example Pictures of Rut

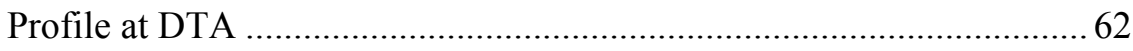

Appendix B: Calculation of Frost Depth ....................................................... 75

Appendix C: Off-Road Vehicle Guidelines and Ratings from Studies in

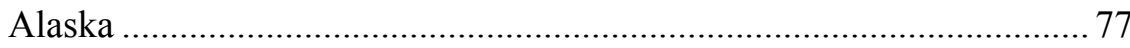

Appendix D: Methods to Calculate Vehicle Speed and Turning Radius from

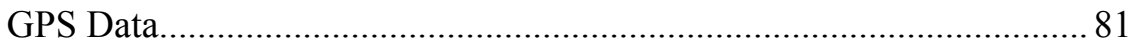

\section{ILLUSTRATIONS}

Figure 1. Locations of Stryker maneuver tests at Donnelly Training Area ........... 3

Figure 2. Location of wooded trail at Fort McCoy, Wisconsin ............................. 4

Figure 3. Rut depth measurement and determination using a profilometer ......... 12

Figure 4. Measurement of tire dimensions....................................................... 13

Figure 5. Soil displacement calculation using image processing software to determine the area of a rut ................................................................. 15

Figure 6. Disturbance categories used to determine impact severity .................. 17

Figure 7. Air freezing degree days and daily average temperatures for Delta Junction, Alaska, for four winter seasons .............................................. 19

Figure 8. Graph of air freezing degree days and daily average temperature for Sparta, Wisconsin, for the 1994-1995 winter season

Figure 9. Grain size distribution of the soil at the spiral and multi-pass test sections at Arkansas Range.

Figure 10. Photo and map of terrain at Arkansas Range showing vegetation features and pattern of maneuver impact test........................................ 24

Figure 11. Gradation curve of the soil at Eddy Drop Zone.................................25

Figure 12. Photo and map of terrain at Eddy Drop Zone showing vegetation features and pattern of maneuver impact test........................................2 26

Figure 13. Highly organic material located at the Texas Range maneuver site...27

Figure 14. Photo and map of terrain at Texas Range showing vegetation features and pattern of maneuver impact test...... 
Figure 15. Gradation curves for soils on control sections of wooded trail at Fort McCoy.

Figure 16. Control section of the wooded trail at Fort McCoy trafficked by an M60A3 in April 1995.

Figure 17. Stryker disturbance test in March 2003 at the Texas Range

Figure 18. Stryker vehicle average speed from a GPS unit at locations where rut depth data were measured at Arkansas Range, Eddy Drop Zone, and Texas Range

Figure 19. Gravimeter water content versus rut depth at Arkansas Range and Eddy Drop Zone

Figure 20. Relationship between average rut depth and thaw depth for all three sites at DTA

Figure 21. Number of passes and rut depth relationships on the dry and wet sections of the wooded trail.

Figure 22. Comparison of measured rut depth to predicted rut depth using eq 1 for two values of wheel slip at Arkansas Range and Eddy Drop Zone.....

Figure 23. Comparison of measured rut depth to predicted rut depth using eq 1 and 2 on both control sections of the wooded trail

Figure 24. Stryker vehicle turning radius versus average volumetric soil displacement for the wet section at Arkansas Range and Eddy Drop Zone

Figure 25. Rut depth versus average volumetric soil displacement at Arkansas Range, Eddy Drop Zone, and Texas Range

Figure 26. Stryker vehicle turning radius and cumulative impact width relationships for the outside tracks for Alaska sites.

Figure 27. Turning radius and cumulative impact width of single and multipass tests at Arkansas Range.

Figure 28. Right and left wheel plots of turning radius versus cumulative impact width for single and multi-pass runs at Eddy Drop Zone 50

Figure 29. Comparison of cumulative impact width versus turning radius for various military vehicles for single pass....

Figure 30. Minor vegetation disturbance and no measurable rut depth resulted from the winter disturbance test. 


\section{TABLES}

Table 1. Guidelines for impact severity based on work by Haugen and

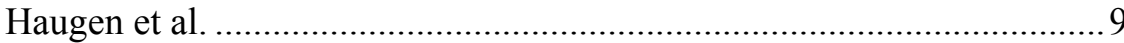

Table 2. Comparison of vehicle mobility parameters for the Stryker and other military off-road vehicles. 14

Table 3. Test site locations, terrain description, and conditions during

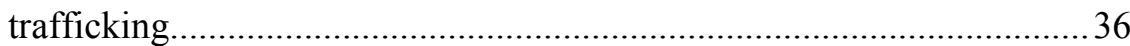

Table 4. Relationships derived between volume of soil displaced along the track and turning radius. 


\section{NOMENCLATURE}

\begin{tabular}{|c|c|}
\hline$b_{\mathrm{i}}$ & Undeflected tire or track width $(\mathrm{m}$, in.) \\
\hline CI & Cone index \\
\hline DTA & Donnelly Training Area \\
\hline GIS & Geographic Information System \\
\hline GPS & Global Positioning System \\
\hline$h_{\mathrm{i}}$ & Unloaded section height (m, in.) \\
\hline HEMTT & Heavy Expanded Mobility Tactical Truck \\
\hline HMMWV & High-Mobility Multipurpose Wheeled Vehicle \\
\hline$I_{\mathrm{af}}$ & Air freezing index or air freezing degree days $\left({ }^{\circ} \mathrm{C}\right.$-days $)$ \\
\hline$I_{\mathrm{at}}$ & Thawing index or thawing degree days $\left({ }^{\circ} \mathrm{C}\right.$-days) \\
\hline$k_{\mathrm{f}}$ & Frozen thermal conductivity $\left(\mathrm{J} / \mathrm{s}-\mathrm{m}-{ }^{\circ} \mathrm{C}\right)$ \\
\hline$k_{\mathrm{u}}$ & Unfrozen thermal conductivity $\left(\mathrm{J} / \mathrm{s}-\mathrm{m}-{ }^{\circ} \mathrm{C}\right)$ \\
\hline$L_{\mathrm{i}}$ & Track length $(\mathrm{m}$, in.) \\
\hline LAV & Light Armored Vehicle \\
\hline M1 & Abrams Tank (M1A1 or M1A2) \\
\hline$n_{\mathrm{f}}$ & Freezing surface n-factor (dimensionless) \\
\hline NCDC & National Climatic Data Center \\
\hline$r_{\mathrm{i}}$ & Tire radius $(\mathrm{m}, \mathrm{in})$. \\
\hline $\mathrm{RCI}$ & Rating cone index (kPa, psi) \\
\hline$s$ & Wheel slip \\
\hline$t$ & Length of freezing period (days) \\
\hline USCS & Unified Soil Classification System \\
\hline$v_{\mathrm{o}}$ & Mean annual air temperature $\left({ }^{\circ} \mathrm{C}\right)$ \\
\hline$V v$ & Velocity of the vehicle (mph) \\
\hline$V w$ & Velocity of the wheel (mph) \\
\hline$W_{\mathrm{i}}$ & Wheel or track load $(\mathrm{N}, \mathrm{lb})$ \\
\hline$X$ & Frost depth $(\mathrm{m}, \mathrm{ft})$ \\
\hline$Z_{\text {soil }}$ & Sinkage or rut depth $(m$, in. $)$ \\
\hline
\end{tabular}




$\begin{array}{ll}\alpha & \text { Thermal ratio (dimensionless) } \\ \delta_{\mathrm{i}} & \text { Deflection for the running gear element } i(\mathrm{~m}, \mathrm{in} .) \\ \lambda & \text { Correction coefficient (dimensionless) } \\ \mu & \text { Fusion parameter (dimensionless) } \\ \rho_{\mathrm{d}} & \text { Soil dry density }\left(\mathrm{kg} / \mathrm{m}^{3}\right) \\ \omega & \text { Soil moisture content }(\%)\end{array}$




\section{PREFACE}

This report was prepared by Rosa T. Affleck, Research Civil Engineer, Civil Engineering Research Division, Engineer Research and Development Center, Cold Regions Research and Engineering Laboratory (ERDC-CRREL), Hanover, New Hampshire.

The author gratefully acknowledges ERDC-CRREL for providing financial support to complete this report, and U.S. Army Alaska's Department of Public Works for providing funding for the Stryker maneuver study. The author thanks Jerry Reagan of the Cold Region Testing Center and his crew for conducting the Stryker maneuver tests at Donnelly Training Area. She also thanks U.S. Army Alaska Department of Public Works personnel, including Gary Larsen for funding and technical support, and Ellen Clark for assisting during site selection and field work. The author thanks Paul Ayers of the University of Tennessee for his support and for lending his equipment, including the GPS and the profilometer, and thanks Katie Simmons of the University of Tennessee for conducting the severity impact measurements.

The contributions of the following CRREL employees are greatly appreciated: Christopher Berini and Garrett Quillia, who assisted with data collection; Charles Collins, CRREL-Fairbanks, for technical and project support; and Major Douglas Anderson, Judy Strange, and Thomas Douglas, CRREL-Fairbanks, for their assistance. The author also gratefully acknowledges the support, contribution, and technical guidance of Sally Shoop on this subject.

This report was prepared under the general supervision of Stephen N. Flanders, Chief, Civil Engineering Research Division, CRREL; Dr. Lance D. Hansen, Deputy Director, CRREL; and James L. Wuebben, Acting Director, CRREL.

The Commander and Executive Director of the Engineer Research and Development Center is Colonel James R. Rowan. The Director is Dr. James R. Houston. 


\title{
Disturbance Measurements from Off-Road Vehicles on Seasonal Terrain
}

\author{
ROSA T. AFFLECK
}

\section{INTRODUCTION}

\subsection{Definition of Problem-The Problem of Spring Thaw}

Spring thaw is a critical time of year for disturbance to soil and vegetation from vehicle passage. Traffic on off-road terrain includes a variety of purposes, e.g., military vehicles conducting training exercises and operations, oil drilling and exploration, mechanized forest logging operations, and recreational purposes. Vehicle disturbance on terrain during spring thaw is more complicated, owing to the saturated and weakened thawed soil layer. Soil moisture is at its maximum levels for the year due to snowmelt, and the moisture is trapped in the thawed layer over an impermeable frozen layer (Shoop 1993, Richmond et al. 1995). The impact of vehicle traffic on shallow, thawed terrain may be severe as a result of slippage and loss of vehicle traction, causing vegetation to be sheared off at the thaw/frost interface. Likewise, the impact can be significant when thaw is deeper and vehicle travel is restricted and impractical.

Soil deformation from military vehicle operations can cause environmental damage by decreasing plant development and increasing erosion (Ayers 1994). Several studies have been conducted to determine the effects of vehicle traffic on soil and the resulting environmental damage (Braunack 1986a, b; Ayers 1994). The potential consequences of vehicle traffic on soil and vegetation include displacement of surface horizons, rut formation, soil compaction, reduction of soil strength, restriction of water movement, and physical damage to root systems. The physical soil disturbances affect not only plant vigor and mortality, but also plant recovery. The severity of disturbance to the terrain has been correlated with loss of vegetation, exposed soil, increased erosion, soil compaction, and root damage.

Military vehicle operations on training lands during spring thaw can cause significant disturbance to soil and vegetation. The training lands in Alaska have 
experienced thermokarst erosion caused by loss of insulating vegetation in permafrost zones. Evaluations and guidelines are being developed and monitored for land sustainability (Jorgenson et al. 2004; Shoop et al. 2004a, b). The need to maximize training capacities is important for the Army, but disturbance must be kept to a minimum because of environmental consequences, and to minimize the terrain reclamation or restoration needs.

In winter, however, frozen ground allows vehicles to traverse on areas of otherwise untrafficable or inaccessible lands. The impact to the terrain can be minimal as a result of the frozen soil's higher strength, and snow cover can also limit the disturbance to the vegetation.

Disturbance to the soil and vegetation generated by the vehicles can be measured in terms of rut depth and severity of the disturbance. This report, however, deals only with the disturbance generated by military vehicles.

\subsection{Background}

In order to provide a quantitative analysis of the impacts of the Stryker Brigade maneuver training on Alaska training lands, a study was conducted during spring breakup using the 20-ton Stryker wheeled vehicle. The tests were performed in May 2003 at three locations in the Donnelly Training Area (DTA, formerly Fort Greely), Alaska (Affleck et al. 2004a, b). The three locations are at Arkansas Range, Eddy Drop Zone, and Texas Range (Fig. 1). The study encompassed examination and measurements of the rut depth, soil moisture, thaw depth, soil strength, and disturbance to soil and vegetation along the vehicle tracks in the maneuver test area. The maneuver impact tests consisted of spiral and multi-pass runs to quantify the effects of the vehicle performing various maneuvers (straight versus turning). For the spiral test, the vehicle performed turning maneuvers by traversing from a small radius to larger radii to examine the disturbance generated when the vehicle is turning. The multi-pass tests were composed of lanes with one, three, eight, and thirteen passes. A preliminary data analysis on the maneuver impact tests at DTA is reported in Affleck et al. (2004a, b).

In contrast to the Alaska training sites, the other site where spring rut depth data were collected is located at Fort McCoy, Wisconsin, with moderate seasonal frost conditions (Fig. 2). The rut data used in this report are from two control sections of a wooded trail generated after trafficking using the M60A3 (tracked) and HEMTT (wheeled) vehicles in April 1995, in conjunction with a soil stabilization project (Kestler et al. 1999). The control sections of the trail were relatively straight and fairly flat, and rut depth measurements from one, ten, twenty-five, and fifty passes were taken. 


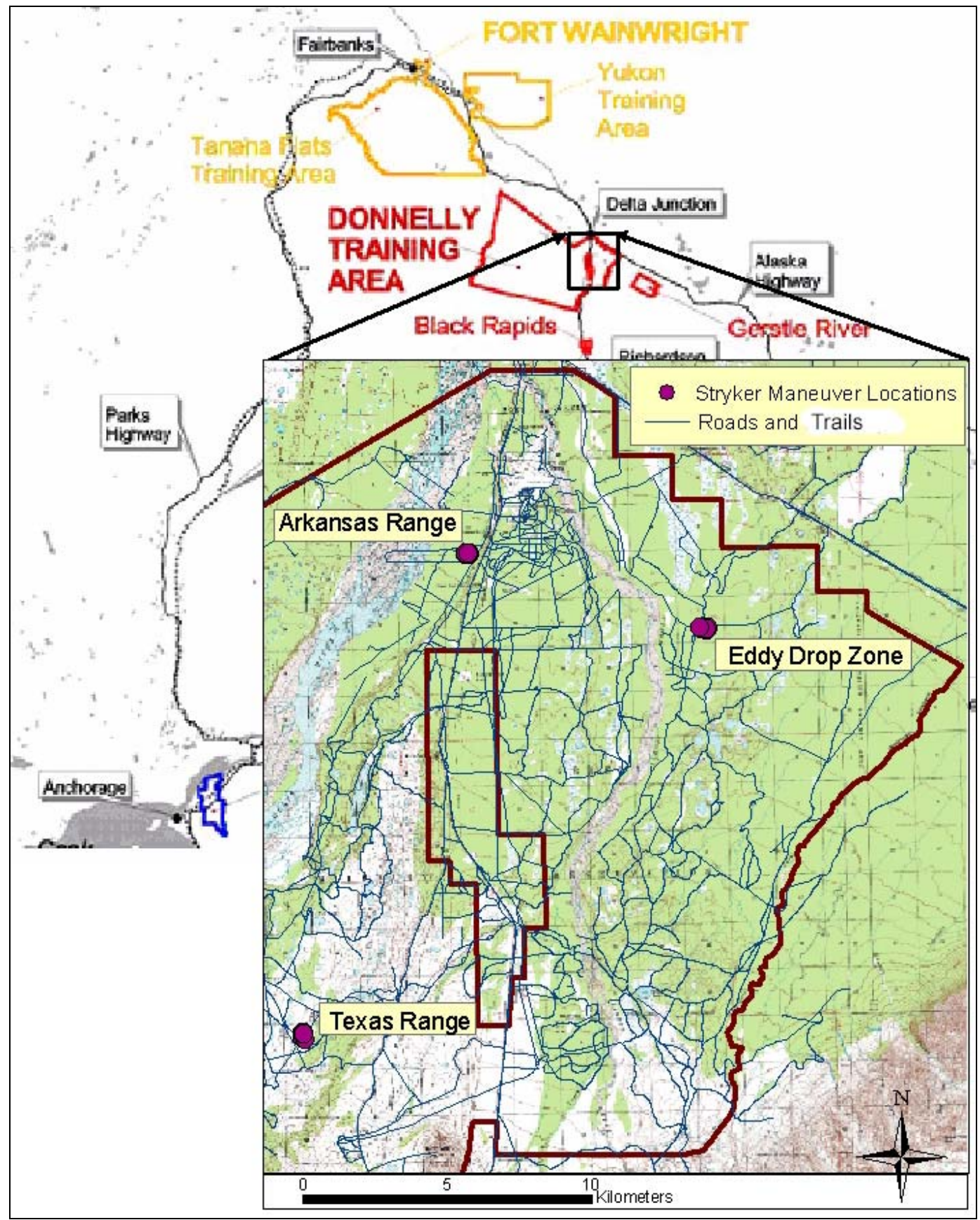

Figure 1. Locations of Stryker maneuver tests at Donnelly Training Area. 


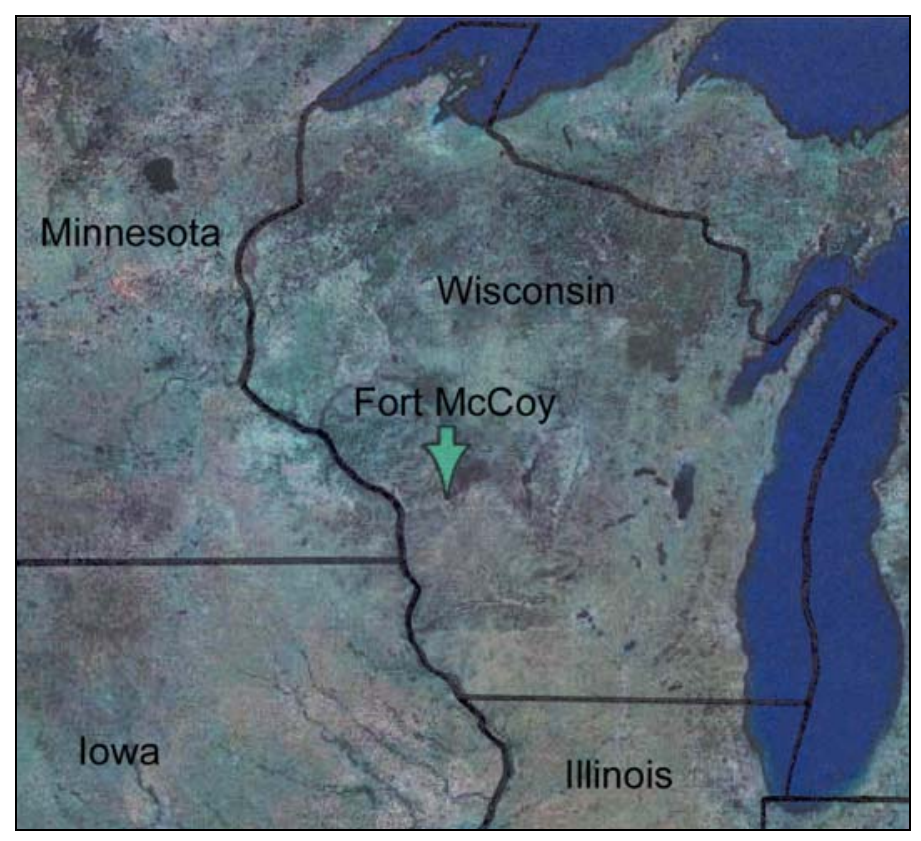

Figure 2. Location of wooded trail at Fort McCoy, Wisconsin.

Rut depth is the distance measured between the bottom of the tire track that has been caused by vehicle traffic and the adjacent undisturbed soil surface. A semi-empirical equation to predict rut depth has been developed for off-road vehicles in soft and unfrozen soils (Willoughby and Turnage 1990, Sullivan and Anderson 2000). This equation is a function of soil strength and vehicle parameters. Actual rut depth measurements from each site are compared to the estimated rut depth predicted by the semi-empirical equation.

A method to calculate the volume of soil being displaced and/or the volume change due to ground compression along the tracks is also developed based on the rut depth data. Correlations are established on the amount of rutting between a single pass and multiple passes. Likewise, disturbance relationships are developed on straight path and turning sections.

A guideline was used to quantify the amount of disturbance to the soil and vegetation in terms of percent, which included vegetation damage, removal of vegetation, exposure of soil, and soil compaction. The cumulative impact width is based on the disturbed width and the impact severity. Cumulative impact width and turning radius relationships have been developed for various military vehicles from various training lands for summertime conditions. Cumulative impact width and turning radius relationships for the Stryker vehicle were developed and compared with other military vehicles. 


\subsection{Objectives}

The objective of this report is to determine and quantify the impact of military vehicles on seasonal terrain. Data used for this study included disturbance and rutting measurements from the maneuver impact tests in DTA, Alaska, and rut depth data on the control sections of the wooded trail at Fort McCoy, Wisconsin. The disturbance and rutting are quantified as follows:

1) Compare measured rut depth and the results from the semi-empirical rut depth equation.

2) Evaluate disturbance and rutting by comparing single pass and multipass, and straight path versus turning maneuvers, and develop a method to calculate the volume of the soil displaced and compressed along the tracks from the rut depth measurements.

3) Establish a cumulative impact width and turning radius relationship for the Stryker vehicle. Compare cumulative impact width and turning radius relationship for the Stryker vehicle and other conventional military vehicles.

4) Assess disturbance during the winter season (on frozen ground and snow cover), and compare the vehicle impact against the disturbance during spring breakup on the same terrain.

\subsection{Definition of Terms}

Freezing Index or Air Freezing Degree Days: Yearly sum of the differences between $0{ }^{\circ} \mathrm{C}$ and daily mean temperature for the days with means below $0{ }^{\circ} \mathrm{C}$.

Frost Depth: Thickness of the layer of frozen soil with subsurface temperatures below $0{ }^{\circ} \mathrm{C}$.

Permafrost: Area in which temperature of the underlying material (soil) is perennially at or below $0{ }^{\circ} \mathrm{C}$ for at least two consecutive winters.

Thaw Depth: Thickness of the thawed soil layer from the surface to an underlying frozen layer, typically occurring when temperature is above freezing in spring.

Thawing Index $\left(I_{\mathrm{at}}, \mathrm{TI}\right)$ : Yearly sum of the differences between $0{ }^{\circ} \mathrm{C}$ and the daily mean temperature for the days with means above $0{ }^{\circ} \mathrm{C}$.

Rut Depth: Distance measured between the bottom of the tire track that has been caused by vehicle traffic and the adjacent undisturbed ground surface.

Snow Depth: Thickness of the snow cover on the ground. 


\section{LITERATURE REVIEW}

Off-road vehicle traffic induces various impacts on terrain, especially during the thawing season. The impact is a function of vehicle type, the soil (strength, type, drainage, etc.), terrain, and climatic conditions. Several research studies have been undertaken, including vegetation disturbance (compression, breakage, removal, etc.), soil compaction, bulk densities, saturated hydraulic conductivity, and rutting of various vehicles for different purposes and operation. These reports are grouped according to vehicle impact on arctic and subarctic terrain, vehicle impact from military vehicles on training lands, and impact of mechanized vehicles on forest operations.

\subsection{Vehicle Impact on Arctic and Subarctic Terrain}

A compilation of studies conducted on the disturbance and recovery of Alaskan tundra terrain caused by natural (fire, erosion, thaw lakes, frost action, etc.), and human-induced (off-road transportation, construction) activities is documented in Walker et al. (1987). The impacts from off-road transportation corridors, such as bulldozed trails and summer off-road vehicle trails, were addressed. Disturbance from construction of winter snow and ice roads with the main emphasis on the effects on vegetation was also addressed. Cross-tundra vehicle traffic may produce all levels of initial disturbance, ranging from compression of vegetation to displacement and removal of vegetation (Walker et al. 1977, Abele et al. 1978, Lawson 1982, Everett et al. 1985, Walker et al. 1987, Emers et al. 1995). Their studies concluded that the disturbance is based on many factors, including vehicle type, acceleration, turning radius, speed, time of summer, number of passes, slope, and vegetation.

A few studies have been conducted on the long- and short-term effects of offroad vehicle traffic on arctic tundra and subarctic alpine tundra soils (Sparrow et al. 1978, Abele et al. 1984, Slaughter et al. 1990). Soils with high and low ice content can be found in arctic and subarctic alpine terrain. Areas with high-icecontent soils were found to be more vulnerable to vehicle damage than those with low ice content (Hok 1969, Gersper and Challinor 1975). Sparrow et al. (1978) investigated the relationships between the severity of soil disturbance and the parameters of soil drainage class, soil morphology (soil profile), topography, and soil compaction (bulk density) of existing off-road vehicle trails. Their study concluded that poorly drained soils underlain by permafrost are often most heavily damaged, and soil bulk densities were relatively higher on traffic areas than the undisturbed areas. 
Several disturbance rating procedures have been established to rate the impacts of vehicles on permafrost-underlain terrain; some are summarized in Appendix C. A more quantified rating scheme that includes compression, displacement, breakage, and deposition of vegetation was developed by Abele et al. (1978) and is shown in Table C1. Later, Slaughter et al. (1990) developed summary ratings from the results of several off-road vehicle impact studies (Table C2) for typical vehicles listed in Table C3. These off-road vehicles ranged from small all-terrain $(900-600 \mathrm{~kg})$ to heavy wheeled and tracked $(1,500-10,000$ $\mathrm{kg}$ ) vehicles, and are widely used in subsistence harvesting, sport hunting, recreation, and general transportation in Alaska.

\subsection{Impact of Military Vehicles on Training Lands}

Similarly, vegetation disturbance and soil deformation from military vehicle operations can cause environmental damage by decreasing plant development and increasing erosion on training lands, and are of great concern for training land managers. Training lands in Alaska have experienced thermokarst erosion caused by loss of insulating vegetation in permafrost zones. Evaluations and guidelines are being developed and monitored for land sustainability (Jorgenson et al. 2004; Shoop et al. 2004a, b). Analyses were conducted by Shoop et al. $(2004 a, b)$ for U.S. Army Alaska training lands, and criteria were developed in which rut depths less than $6 \mathrm{~cm}$ (2.5 in.) are considered to be minor damage and rut depth greater than $15 \mathrm{~cm}$ (6 in.) is significant. The need to maximize training capacity is important for the Army, but disturbance must be kept to a minimum because of environmental consequences and to minimize the terrain restoration needs.

Several recent research studies have been conducted to determine the effects of military vehicle traffic, both wheeled and tracked, on soil, and the ensuing environmental damage. The results are documented by Braunack (1986a, b); Ayers (1994); Ayers et al. (2000); Halvorson et al. (2001); Haugen (2002); Gatto (2002); and Haugen et al. (2002). These studies, however, were conducted on military training lands in temperate regions with no seasonal or frost effects, except for Halvorson et al. (2001) and Gatto (2002). Braunack (1986a) conducted a test using the M113 (tracked, armored personnel carrier vehicle) on sandy soils in straight and turning paths to determine the effects of soil bulk density, saturated hydraulic conductivity, cone penetrometer resistance, and surface micro-relief (rut depth). In contrast to other studies, results from Braunack (1986a) showed a lower soil cone resistance within the tracks for the single pass and no change for two and six passes both on straight and turn tracks. It was also observed that a larger area was disturbed when the vehicle turned with increased rut width and depth. 
Changes in rut geometry caused by freeze-thaw effects have been investigated by both Gatto (2002) and Halvorson et al. (2001). Gatto (2002) investigated rut depth and soil physical properties changes over several winter seasons caused by soil freezing from ruts generated from an M1, HMMWV, and HEMTT at Ethan Allen Firing Range (EAFR) in northwest Vermont, and showed that slumping of soil occurred in sidewalls of deep ruts in the spring as the soil thawed and loosened the compacted soil in the ruts. Halvorson et al. (2001) measured rut depths ranging from 2 to $15 \mathrm{~cm}$ and $64 \mathrm{~cm}$ wide, generated from an M1 A2 tank during summer at Yakima Training Area (YTA) in central Washington, and found that ruts were smoothed over time as a result of several events of shallow freeze-thaw cycles (cold wet winters).

The type of military maneuvers can also influence the impact on the terrain, whether the vehicles are performing column formation (single and multi-pass paths) or turning maneuvers. Guidelines to measure the disturbance to the soil and vegetation were established using impact severity and its corresponding disturbed width based on work by Ayers et al. (2000), Haugen (2002), and Haugen et al. (2002), as listed in Table 1. They have established cumulative impact width and turning radius relationships for several military vehicles from test data collected at YTA and Australia during summer conditions. These relationships are used for comparison to the test data measured for the Stryker vehicle at the Donnelly Training Area.

An empirical equation to predict rut depth has been developed by Willoughby and Turnage (1990) for off-road vehicles in soft and unfrozen soils. This equation has been incorporated into a vehicle performance prediction model (Richmond et al. 1995) and applied in a model to evaluate vehicle severity factors for estimation of U.S. Army lands' training capacity (Sullivan and Anderson 2000).

\subsection{Impact of Mechanized Forest Operations on Woodlands}

Disturbance caused by machines used in forest operations for wood harvesting and timber extraction has been found to create site impacts, especially on sensitive forests with soft soil. Many researchers have concluded that harvesting in both poorly drained and well-drained soil with a high seasonal water table can result in soil compaction or rutting, and may limit or restrain root growth (Aust et al. 1995, Stone 2002, Nugent et al. 2003). These machines induced ground pressure ranging from $20 \mathrm{kPa}$ to $125 \mathrm{kPa}$ (Table C4). Aust et al. (1995) conducted compaction and rutting studies on coarser surface material (sandy soils) overlying finer subsoil materials (sandy clays and clays). Bulk densities were found to be $20 \%$ higher on the rutted and compacted area than the non-trafficked 
sites. Also, the average saturated hydraulic conductivity rate at which free water is able to drain through the soil structure decreased at least $10 \%$ after rutting and compaction. Similarly, Nugent et al. (2003) conducted a study on peat sites $(95 \%$ water content and 5\% solid content) and found that harvesting and extraction machines compacted the top $40 \mathrm{~cm}$ of the soil (peat) profile after trafficking based on the cone penetrometer resistance data. The average rut depth after one pass of $73.9-\mathrm{kPa}$ ground pressure harvester was $15.3 \mathrm{~cm}$ with cone penetrometer resistance of $494 \mathrm{kPa}$.

Table 1. Guidelines for impact severity based on work by Haugen (2002) and Haugen et al. (2002).

\begin{tabular}{|c|l|}
\hline $\begin{array}{c}\text { \% Impact } \\
\text { severity }\end{array}$ & \multicolumn{1}{c|}{ Guidelines } \\
\hline 0 & No visible disturbance as compared to surrounding vegetation/area. \\
\hline 10 & $\begin{array}{l}\text { Laying down of vegetation; will recover quickly; few, if any, broken stems; no evidence of } \\
\text { vegetative shearing; very difficult to see impact after a few days. }\end{array}$ \\
\hline 20 & $\begin{array}{l}\text { Some broken stalks/plants; no possibility of these stalks/plants straightening or returning } \\
\text { to initial conditions within a few days; visible for a couple of months after impact; visible } \\
\text { soil disturbance, possibly exposing bare soil as a result of vehicle weight. }\end{array}$ \\
\hline 40 & $\begin{array}{l}\text { Obvious depressed soil and vegetation with slight vegetation removal and significant } \\
\text { vegetative damage; crushing, shearing, and slight removal of vegetation likely; piling on } \\
\text { track edge evident due to turning and weight of vehicle; movement of plants/soil toward } \\
\text { the edge of vehicle track without completely shearing plant at roots; some bare soil } \\
\text { exposed. }\end{array}$ \\
\hline 60 & $\begin{array}{l}\text { About one-third of vegetation still present and intact on the track; significant amount of } \\
\text { bare soil exposed; larger piling of vegetation on the edge of the track due to shearing } \\
\text { motion of the vehicle, fully removing species from track; some of the pile has overturned, } \\
\text { exposing some roots to air, suggesting vegetation may not recover. }\end{array}$ \\
\hline 80 & $\begin{array}{l}\text { Few vegetative species still intact on vehicle path; some vegetation has been sheared } \\
\text { down to just above roots, so very little of plant remains above ground, while other } \\
\text { vegetation has been fully sheared, removing roots; piling of vegetation and soil on the } \\
\text { edge of the path; pile is completely overturned, exposing roots, suggesting the majority } \\
\text { of species will not recover. }\end{array}$ \\
\hline 100 & $\begin{array}{l}\text { Complete removal of vegetation and soil; shearing action of vehicle has left vehicle track } \\
\text { bare; sheared vegetation and soil is piled on edge of track. }\end{array}$ \\
\hline
\end{tabular}




\section{METHODS}

The methods used to quantify the disturbance from military vehicles on the terrain include comparison of actual rut depth and results to the semi-empirical rut depth equation; soil displacement correlations between single pass and multipass runs, straight path versus turning maneuvers; cumulative impact width and turning radius relationships; and comparison between the Stryker and other conventional military vehicles.

\subsection{Rut Depth}

\subsubsection{Measurements}

Rut depth is the distance measured between the bottom of the tire track that has been caused by vehicle traffic and the adjacent undisturbed soil surface. Rut depth is typically measured with a profilometer, which is placed in the center of the tracks, and depths. This was the technique used at Fort McCoy and DTA. However, more detailed rut depth data were collected from the maneuver impact tests at DTA using a profilometer made of a metal bar with sliding rods as shown in Figure 3. The rods are spaced every $2 \mathrm{~cm}$ horizontally and each rod is marked at $1-\mathrm{cm}$ intervals vertically. The profilometer was placed in the center of the rut and a photo of the rut depth taken, and its location noted using a GPS unit. The photos were printed and lines were drawn of the natural (undisturbed) ground surface profile (the outside of the ruts) and maximum level of the rut. Rut depth is determined by counting the $1-\mathrm{cm}$ intervals on the rod between the surface and rut lines (Fig. 3).

\subsubsection{Rut depth model}

Soil sinkage or rut depth (z) can be calculated for wheeled and tracked vehicles using semi-empirical equations developed by Willoughby (Willoughby and Turnage unpublished memo 1990), Richmond et al. (1995), and Sullivan and Anderson (2000). Although rut depth and sinkage are not equivalent, the measured difference is small and they were considered equivalent for these calculations. The equations for wheeled and tracked vehicles, respectively, are 


$$
\begin{aligned}
& z_{\text {soil }}=\frac{10 * r_{\mathrm{i}}}{\left[\frac{2 * R C I * r_{\mathrm{i}} * b_{\mathrm{i}}}{W_{\mathrm{i}} *\left(1-\delta_{\mathrm{i}} / h_{\mathrm{i}}\right)^{3 / 2} *\left(s^{1 / 5}\right)}\right]^{5 / 3} * N^{1 / 2} \quad(\text { Wheeled })} \\
& z_{\text {soil }}=\left[0.00443 * L_{\mathrm{i}} * e^{\left(5.887 * W_{\mathrm{i}} / R C I * b_{\mathrm{i}} * L_{\mathrm{i}}\right)}\right] * N^{1 / 2} \quad \text { (Tracked) } \\
& s=\frac{V w-V v}{V w}
\end{aligned}
$$

where $Z_{\text {soil }}=\quad$ sinkage or rut depth, $\mathrm{m}$ (in.)

$\mathrm{RCI}=$ rating cone index $(\mathrm{kPa}, \mathrm{psi})$

$b_{\mathrm{i}} \quad=\quad$ undeflected tire or track width, $\mathrm{m}$ (in.)

$L_{\mathrm{i}} \quad=\quad$ track length, $\mathrm{m}$ (in.)

$r_{\mathrm{i}}=$ tire radius, $\mathrm{m}$ (in.)

$W_{\mathrm{i}} \quad=\quad$ wheel or track load, $\mathrm{N}(\mathrm{lb})$

$h_{\mathrm{i}}=$ unloaded section height, $\mathrm{m}$ (in.)

$\delta_{\mathrm{i}}=\quad$ deflection, $\mathrm{m}$ (in.) for the running gear element $i$

$S \quad=\quad$ wheel slip

$V w=\quad$ velocity of the wheel (mph)

$V v=$ velocity of the vehicle $(\mathrm{mph})$

$\mathrm{N}=$ number of passes.

The variables for tire dimensions listed above are illustrated in Figure 4. Equations 1 and 2 were developed for predicting single-pass and multi-pass rut depths of ground vehicles. Sullivan and Anderson (2000) suggested a value for wheel slip of $20 \%$. A $5 \%$ wheel slip value would not be uncommon for a vehicle traveling on a competent surface, while $50 \%$ slip or more would result from a low-traction surface. In this analysis, equation 1 was used to calculate the expected rut depth using $20 \%$ and 50\% wheel slip for one pass and for 10 and thirteen passes. The predicted rut depth values are compared to the measured rut depth data.

Soil strength was expressed as a Cone Index (CI) or Rating Cone Index (RCI) for the layer of soil from 0 to $15 \mathrm{~cm}$ (0 to $6 \mathrm{in}$.), and also for the layer from 15 to $30 \mathrm{~cm}$ (6 to $12 \mathrm{in}$.) in depth. The soil strength was measured using a $30^{\circ}$ circular stainless steel cone penetrometer, which correlates the soil strength to the shear resistance of the soil. The cone is pushed into the soil at a uniform rate and readings were recorded at $2.54-\mathrm{cm}(1-\mathrm{in}$.) intervals. The CI is calculated from the 
cone penetrometer reading and the cone basal area (ASAE 1999). CI is for sandy soils since these materials do not remold. The RCI accounts for the remolding of more resilient soils and for the effect of multiple passes of vehicles (RCI $=\mathrm{CI} \times$ Remolding Index). Remolding index, however, applies only to fine-grained soils such as silts and clays. Because the soils in this analysis are mainly silty sands (SM and SP-SM), CI values were used in the equations and are expressed in psi or $\mathrm{kPa}$.

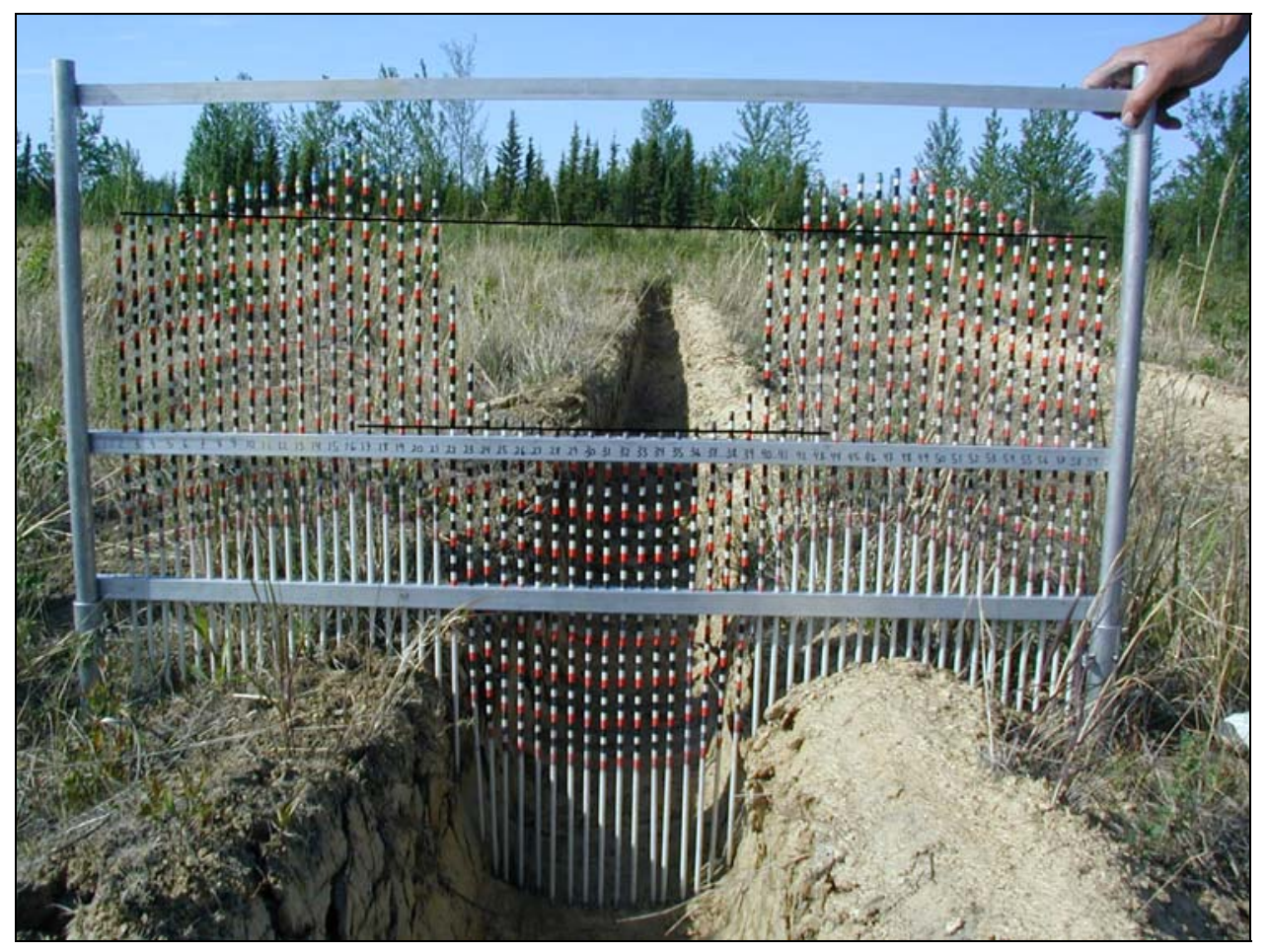

Figure 3. Rut depth measurement and determination using a profilometer.

The maximum estimated rut depth for the vehicle using equations 1 and 2 cannot exceed the vehicle ground clearance height because the vehicle will bottom out at that depth, possibly resulting in immobilization. Therefore, any calculated rut depths greater than the vehicle ground clearance are set equal to the vehicle clearance height. The clearance heights for each vehicle are listed in Table 2 . 


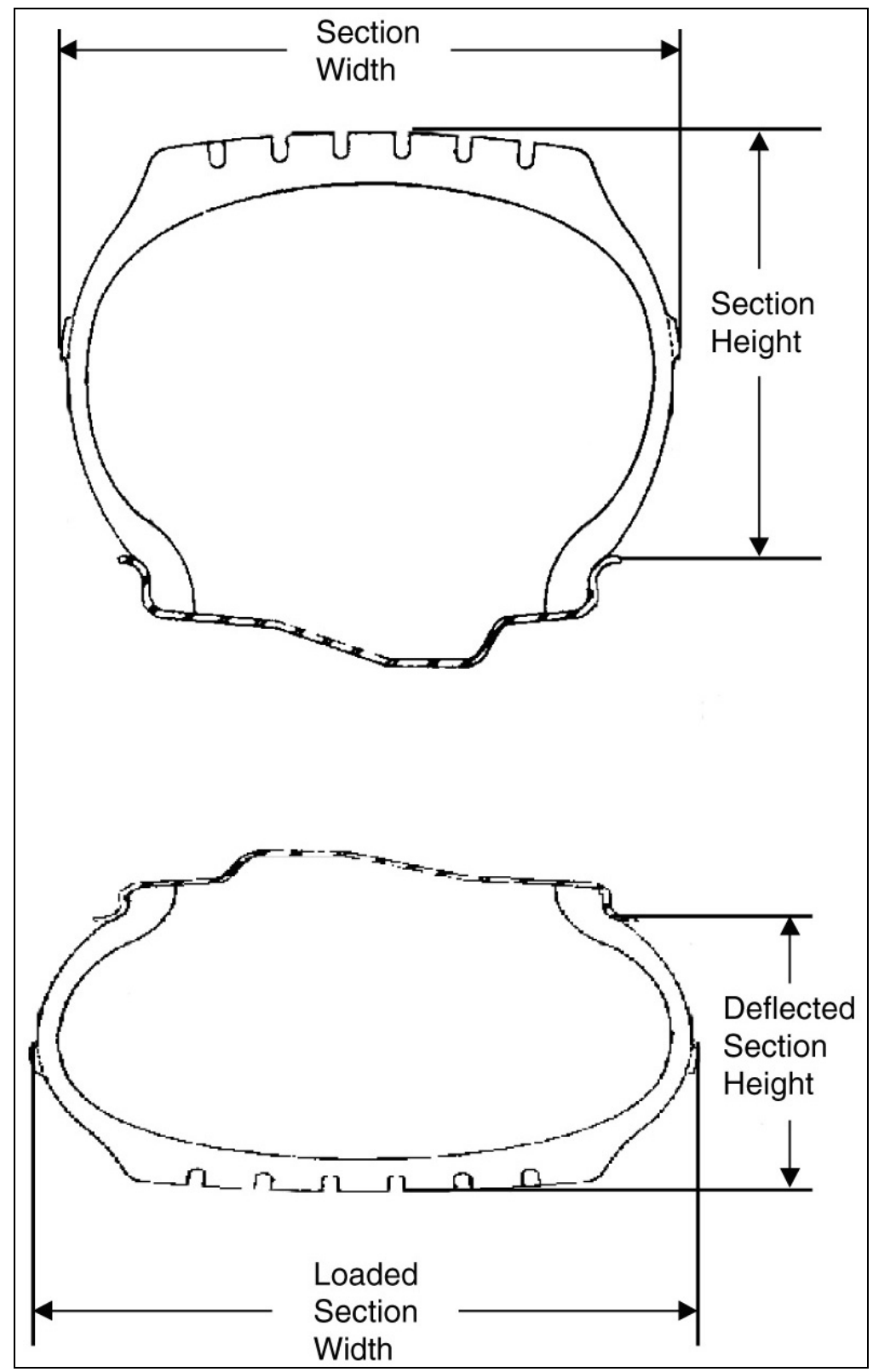

Figure 4. Measurement of tire dimensions. 
Table 2. Comparison of vehicle mobility parameters for the Stryker and other military offroad vehicles.

\begin{tabular}{|c|c|c|c|c|c|c|}
\hline \multirow{2}{*}{$\begin{array}{c}\text { Vehicle } \\
\text { parameters }\end{array}$} & \multicolumn{3}{|c|}{ Wheeled vehicles } & \multicolumn{3}{|c|}{ Tracked vehicles } \\
\hline & Stryker & LAV Gen3 & HEMTT & M113 & M60A3 & M1A1 \\
\hline Width, cm (in.) & $\begin{array}{c}265.4 \\
(104.5)\end{array}$ & $\begin{array}{l}265.4 \\
(104.5)\end{array}$ & $\begin{array}{l}244 \\
(96)\end{array}$ & $\begin{array}{c}268.7 \\
(105.8)\end{array}$ & $\begin{array}{l}363.2 \\
(143)\end{array}$ & $\begin{array}{c}365.2 \\
(143.8)\end{array}$ \\
\hline Length, cm (in.) & $\begin{array}{c}693 \\
(273)\end{array}$ & $\begin{array}{c}692 \\
(272.3)\end{array}$ & $\begin{array}{c}917 \\
(361)\end{array}$ & $\begin{array}{c}488 \\
(192)\end{array}$ & $\begin{array}{l}639.4 \\
(273)\end{array}$ & $\begin{array}{c}792 \\
(311.7)\end{array}$ \\
\hline Weight, kg (lb) & $\begin{array}{c}17,745 \\
(39,120)\end{array}$ & $\begin{array}{c}17,877 \\
(39,412)\end{array}$ & $\begin{array}{c}27,386 \\
(60,375)\end{array}$ & $\begin{array}{c}10,614 \\
(23,400)\end{array}$ & $\begin{array}{c}52,617 \\
(116,000)\end{array}$ & $\begin{array}{c}57,811 \\
(127,451)\end{array}$ \\
\hline $\begin{array}{l}\text { Contact pressure, } \\
\mathrm{kPa}(\mathrm{psi})\end{array}$ & $\begin{array}{c}193 \\
(27.94)\end{array}$ & $\begin{array}{c}182 \\
(26.38)\end{array}$ & $\begin{array}{c}121 \\
(17.56)\end{array}$ & $\begin{array}{c}51 \\
(7.4)\end{array}$ & $\begin{array}{c}76.5 \\
(11.1)\end{array}$ & $\begin{array}{c}90 \\
(13.1)\end{array}$ \\
\hline $\begin{array}{c}\text { Tractive force, } \\
\text { asphalt }\end{array}$ & $\begin{array}{c}125.8 \\
(28,283)\end{array}$ & $\begin{array}{c}126.7 \\
(28,495)\end{array}$ & $\begin{array}{c}194.2 \\
(43,651)\end{array}$ & $\begin{array}{c}75.3 \\
(16,918)\end{array}$ & $\begin{array}{c}373 \\
(83,868)\end{array}$ & $\begin{array}{c}441.1 \\
(99,178)\end{array}$ \\
\hline $\begin{array}{l}\text { Tractive force, ice } \\
\text { kN (lb) }\end{array}$ & $\begin{array}{c}17.4 \\
(3,912)\end{array}$ & $\begin{array}{c}17.5 \\
(3,941)\end{array}$ & $\begin{array}{c}26.8 \\
(6,037)\end{array}$ & $\begin{array}{c}10.4 \\
(2,340)\end{array}$ & $\begin{array}{c}51.6 \\
(11,600)\end{array}$ & $\begin{array}{c}61.0 \\
(13,718)\end{array}$ \\
\hline $\begin{array}{l}\text { Ground } \\
\text { clearance, cm } \\
\text { (in.) }\end{array}$ & $\begin{array}{c}44.3 \\
(17.43)\end{array}$ & $\begin{array}{c}43.1 \\
(16.97)\end{array}$ & $\begin{array}{c}33 \\
(13)\end{array}$ & $\begin{array}{c}40.6 \\
(16.0)\end{array}$ & $\begin{array}{c}45.7 \\
(18.0)\end{array}$ & $\begin{array}{c}43.2 \\
(17.0)\end{array}$ \\
\hline $\begin{array}{l}\text { \% Slope } \\
\text { performance } \\
\text { Frontal/side }\end{array}$ & $\begin{array}{l}60 \\
30\end{array}$ & $\begin{array}{l}60 \\
30\end{array}$ & $\begin{array}{l}60 \\
30\end{array}$ & 60 & 60 & 60 \\
\hline $\begin{array}{l}\text { Cross-country tire } \\
\text { pressure, kPa } \\
\text { (psi) }\end{array}$ & $\begin{array}{c}275.8 \\
(40)\end{array}$ & $\begin{array}{c}172.4 \\
(25)\end{array}$ & $\begin{array}{l}241-276 \\
\text { (35 front, } \\
40 \text { rear) }\end{array}$ & - & - & - \\
\hline $\begin{array}{l}\text { Max cross- } \\
\text { country speed, } \\
\text { kph (mph) }\end{array}$ & $\begin{array}{c}64.36 \\
(40)\end{array}$ & $\begin{array}{l}32.2 \\
(20)\end{array}$ & $\begin{array}{c}64.36 \\
(40)\end{array}$ & $\begin{array}{l}67.6 \\
(42)\end{array}$ & $\begin{array}{l}48.3 \\
(30)\end{array}$ & $\begin{array}{l}72.4 \\
(45)\end{array}$ \\
\hline $\begin{array}{c}\text { General } \\
\text { description }\end{array}$ & $\begin{array}{c}8 \times 8 \\
(4 \text { axles, } \\
8 \text { tires })\end{array}$ & $\begin{array}{c}8 \times 8 \\
(4 \text { axles, } \\
8 \text { tires })\end{array}$ & $\begin{array}{c}8 \times 8 \\
(4 \text { axles, } \\
8 \text { tires })\end{array}$ & $\begin{array}{l}\text { Metal } \\
\text { track pad }\end{array}$ & $\begin{array}{l}\text { Metal } \\
\text { track pad }\end{array}$ & $\begin{array}{c}\text { Metal } \\
\text { track pad }\end{array}$ \\
\hline \multicolumn{7}{|c|}{ Track or Tire Properties } \\
\hline $\begin{array}{l}b_{\mathrm{i}}, \text { Undeflected } \\
\text { width, } \mathrm{cm} \text { (in.) }\end{array}$ & $\begin{array}{c}31 \\
(12.2)\end{array}$ & $\begin{array}{c}31 \\
(12.2)\end{array}$ & $\begin{array}{c}40.6 \\
(16.0)\end{array}$ & $\begin{array}{l}38.1 \\
(15)\end{array}$ & $\begin{array}{l}71.1 \\
(28)\end{array}$ & $\begin{array}{l}63.5 \\
(25)\end{array}$ \\
\hline $\begin{array}{l}L_{\mathrm{i}} \text {, Track length, } \\
\mathrm{cm} \text { (in.) }\end{array}$ & - & - & - & $\begin{array}{l}276.9 \\
(109)\end{array}$ & $\begin{array}{l}434.3 \\
(171)\end{array}$ & $\begin{array}{c}465.1 \\
(183.1)\end{array}$ \\
\hline $\begin{array}{l}r_{\mathrm{i}} \text {, tire radius, } \mathrm{cm} \\
\text { (in.) }\end{array}$ & $\begin{array}{c}56.6 \\
(22.245)\end{array}$ & $\begin{array}{c}56.6 \\
(22.245)\end{array}$ & $\begin{array}{c}66.8 \\
(26.3)\end{array}$ & - & - & - \\
\hline $\begin{array}{l}h_{\mathrm{i}}, \text { Unloaded } \\
\text { section height, } \\
\text { cm (in.) }\end{array}$ & $\begin{array}{c}31.1 \\
(12.24)\end{array}$ & $\begin{array}{c}31.1 \\
(12.24)\end{array}$ & $\begin{array}{c}35.1 \\
(13.8)\end{array}$ & - & - & - \\
\hline $\begin{array}{l}\delta_{\mathrm{i}} \text {, Deflection, } \mathrm{cm} \\
\text { (in.) }\end{array}$ & $\begin{array}{c}5.2 \\
(2.05)\end{array}$ & $\begin{array}{c}5.2 \\
(2.16)\end{array}$ & $\begin{array}{c}8.1 \\
(3.2)\end{array}$ & - & - & - \\
\hline
\end{tabular}




\subsection{Volumetric Soil Displacement}

A method to calculate the volume of deformation (rutting) can be achieved using the rut depth measurements from a profilometer. Using the picture file of rut depth data, the soil displacement or deformation area of the rut can be calculated using image processing software (Image Pro Plus). The area is determined using the correct scale of the profilometer from the rod increments and spacing in centimeters, then tracing the enclosed area of the rut and counting the number of pixels inside it (Fig. 5). Using a conservative assumption that soil being displaced is uniform within $1 \mathrm{~m}$ of track length, the volumetric displacement is computed by multiplying the area of soil displaced by $100 \mathrm{~cm}$ of track length.

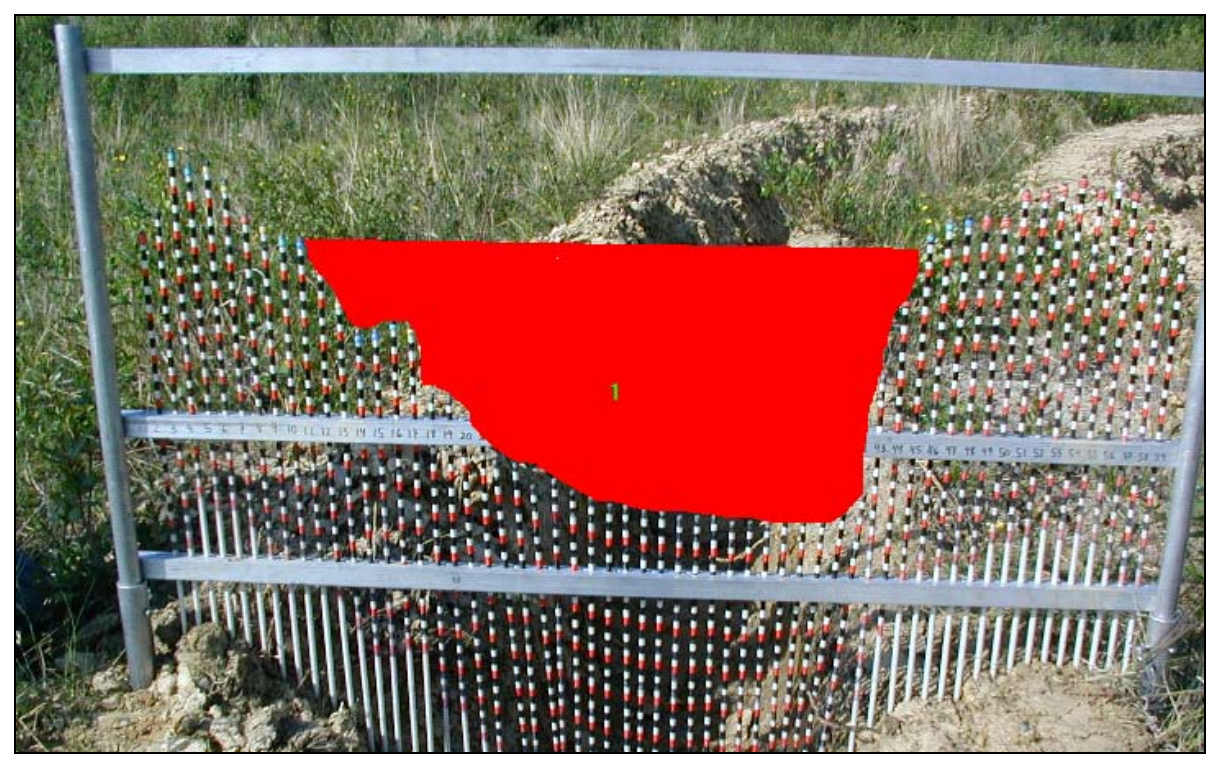

Figure 5. Soil displacement calculation using image processing software to determine the area of a rut.

\subsection{Impact Severity}

The disturbance categories included an imprint, a scrape, and a pile, or a combination of both as illustrated in Figure 6 (Ayers et al. 2000, Haugen 2002, Haugen et al. 2002). An imprint is defined as an occurrence in which soil and vegetation are compressed in the vehicle track. A scrape is an occurrence in which the soil and vegetation have been stripped away from the vehicle track. A pile disturbance happens when soil and vegetation have been displaced from the vehicle track and piled on the side(s). The impact severity was characterized by the amount of vegetation disturbed and removed, and the amount of bare soil 
exposed along the track, using the guidelines in Table 1 based on work by Haugen (2002) and Haugen et al. (2002). Disturbed width was the width over which the impact severity was measured. The cumulative impact width was calculated as the total of the product of the disturbed width and impact severity data for one tire track. The disturbance for the outside tire track was used to determine the cumulative impact width and turning radius relationship.

The turning radius is determined from the coordinates of the vehicle position using data points from five consecutive data points (Ayers et al. 2000). Perpendicular bisects to lines connecting the first to the third, and third to the fifth, data points were calculated from the coordinates of those points. The intersection of those two perpendicular bisects was determined by solving two equations with two unknowns. A turning value of $150 \mathrm{~m}$ is assigned for a straight drive or path (vehicle not turning at all), thus all values for turning radii greater than and equal to 150 are assigned a value of $150 \mathrm{~m}$. The equations and methods to calculate turning radius are given in Appendix D.

Relationships between cumulative impact width and turning radius from other training sites have been developed for various military vehicles by Ayers et al. (2000) and Haugen et al. (2002). Both the M1A1 and Light Armored Vehicle (LAV) cumulative impact width and turning radius relationships were developed from summertime test data in Washington, and the M113 data were from Australia during the summer. These relationships are used for comparison in this analysis since this methodology was developed to quantify disturbance on training lands using military vehicles where the impact to the terrain is related to U.S. Army operation and maneuver exercises.

The Stryker and other conventional military vehicles, such as the M1A1, M113, M60A3, and HEMTT, along with the Stryker predecessor, the LAV III (Light Armored Vehicle Generation III), are compared in Table 2. The disturbance varies between tracked and wheeled vehicles owing to their traction elements (tire or track footprints) and weight. The Stryker is a new Army vehicle and weighs approximately $18,000 \mathrm{~kg}(40,000 \mathrm{lbs})$ when loaded. The eight-wheeldrive Stryker is a combat vehicle, and consists of four axles (one tire per axle per side) with $44.3 \mathrm{~cm}$ (17.43 in.) of ground clearance. For turning maneuvers, the Stryker tends to create a wider track because the second, third, and fourth tires do not follow the first tire track, especially on tighter turns. Other vehicles can create wider tracks when driving on turns than on straight paths. Tracked vehicles have a tendency to skid while turning. For wheeled vehicles, the wheels are turning while the tracked vehicles' pads are dragging on turns. 


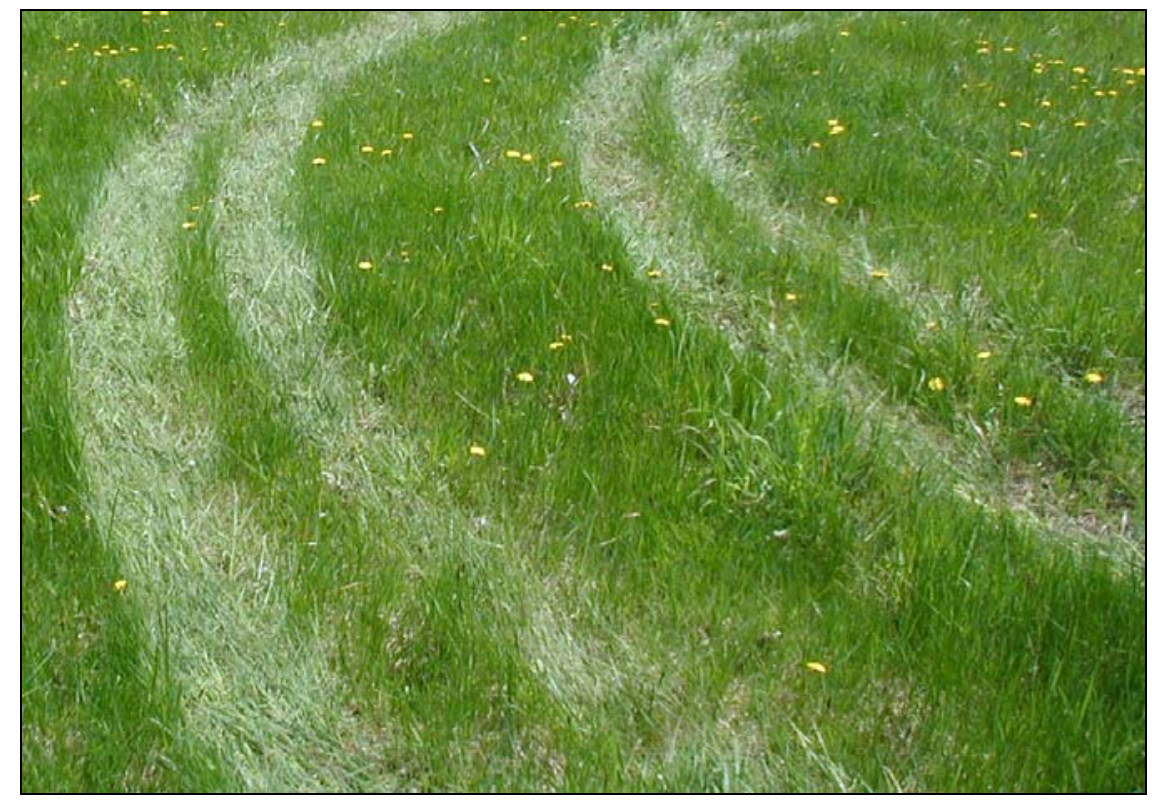

a. Example of imprint disturbance.

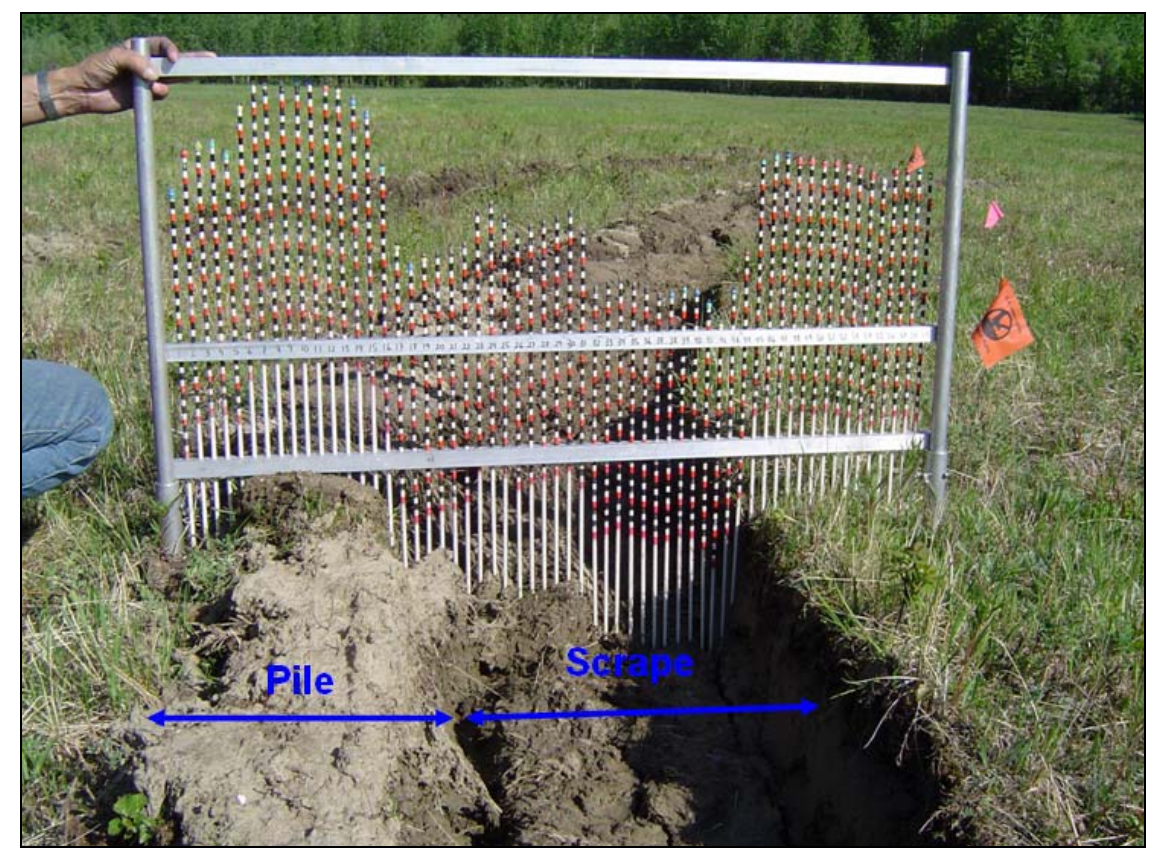

b. Example of a combination of pile and scrape disturbances.

Figure 6. Disturbance categories used to determine impact severity. 


\section{$4 \quad$ TEST SITES}

\subsection{Locations}

\subsubsection{Donnelly Training Area (DTA [formerly Fort Greely]), Alaska}

Rut depth and disturbance measurements were collected from the maneuver impact tests performed during spring breakup at three locations east of the Delta River. These tests were conducted at the Arkansas Range, Eddy Drop Zone, and Texas Range (Fig. 1) in May 2003 using the 20-ton wheeled Stryker vehicle. A preliminary analysis of this test is reported by Affleck et al. (2004a).

The winter test was conducted in March 2003 at the Texas Range using the Stryker vehicle. This test is briefly discussed in Affleck et al. (2004b) and Shoop et al. (2004a, b).

\subsubsection{Fort McCoy, Wisconsin}

Rut depth data used in this report were measured on the control sections of a trail and were collected for a stabilization demonstration study at Fort McCoy for M60A3 (tracked) and HEMTT (wheeled) vehicles in April 1995 as documented in Kestler et al. (1999) (Fig. 2). Stabilization techniques were applied and control sections were selected along the trails before trafficking was conducted. Each stabilization method was evaluated. Rut depths and other soil properties data were collected after trafficking.

\subsection{Climatic Conditions}

\subsubsection{DTA, Alaska}

DTA is subjected to a wide range of weather extremes and seasonal variations. The terrain condition can be described by the soils, vegetation, and locations of discontinuous permafrost. In winter, frozen ground allows vehicle maneuvers in areas that would not otherwise be maneuverable due to weaker ground conditions such as a thawed, active layer above permafrost, bogs, or wet areas. Frozen ground along with sufficient snow cover can minimize the disturbance to soil and vegetation. The terrain is most severely damaged by off-road maneuvering when the ground is saturated during the thawing season or when it is subjected to freeze-thaw cycling in the spring and fall, but especially during the spring-thaw period when an impermeable frozen layer exists beneath the freeze-thaw layer. 
Based on the daily mean temperature data from the National Climatic Data Center (NCDC), the 2002-2003 winter season had 153 days of temperature below $0{ }^{\circ} \mathrm{C}$ and a freezing index of $1589^{\circ} \mathrm{C}$-days (Fig. 7a). The chart of the daily average temperature for the 2002-2003 winter season is shown in Figure 7b. The winter season of 2002-2003 was considerably warmer than the previous winter season of 2001-2002, with a freezing index of $2564{ }^{\circ} \mathrm{C}$-days (Fig. 7a).

Frost penetration calculations using the Stefan and modified Berggren equations for each site are given in Appendix B, based on the air freezing index and annual mean temperature prior to spring breakup. Frost depth results do not account for permafrost depth and conditions, especially at the Texas Range site. Observations of ground temperature measured for Big Delta, Alaska, were reported by Aitken (1964). It was noted in Aitken's report that the average measured seasonal frost penetration of the area from the temperature profile was approximately $4.3 \mathrm{~m}(14 \mathrm{ft})$, and the mean annual snowfall was $93.7 \mathrm{~cm}(36.9$ in.). The mean annual air temperature ranges from 0.8 to $-1.9{ }^{\circ} \mathrm{C}$ based on $1999-$ 2003 temperature data.

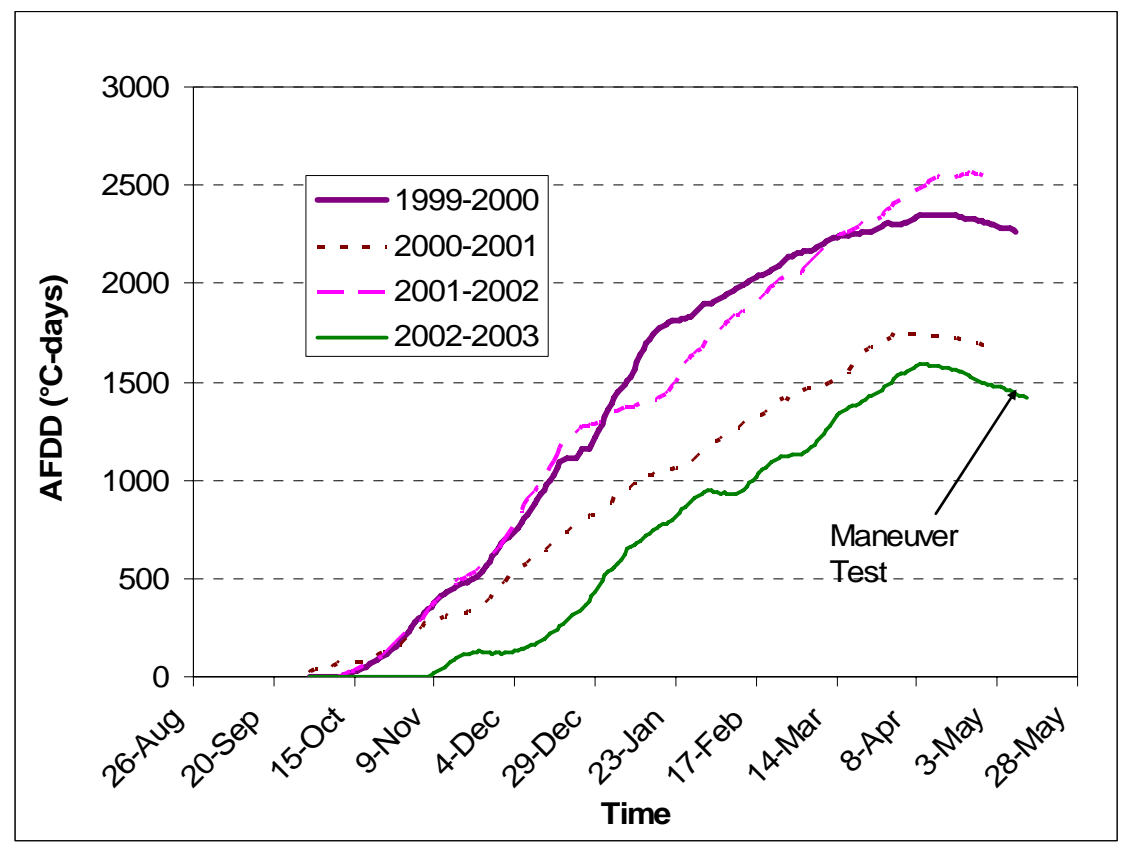

a. Air freezing degree days chart.

Figure 7. Air freezing degree days and daily average temperatures for Delta Junction, Alaska, for four winter seasons. 


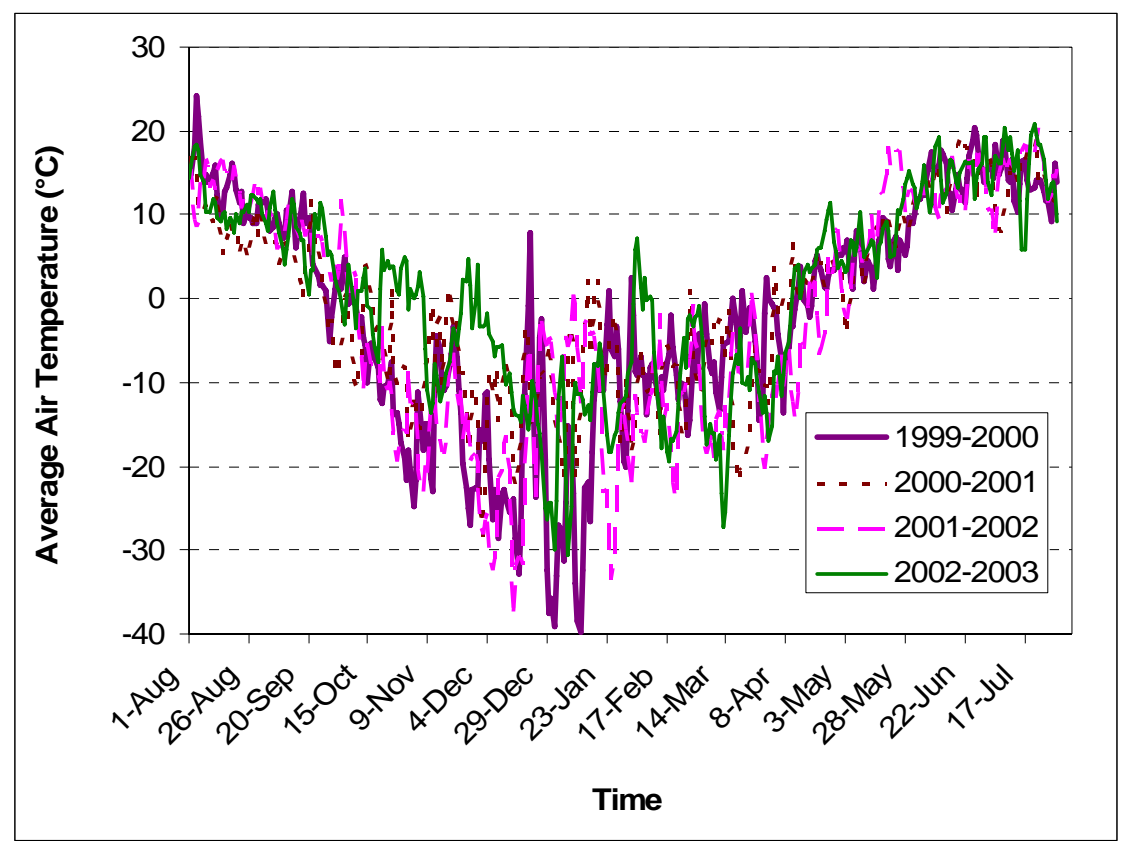

b. Daily average temperatures.

Figure 7 (cont'd). Air freezing degree days and daily average temperatures for Delta Junction, Alaska, for four winter seasons.

\subsubsection{Fort McCoy, Wisconsin}

The average freezing season for the area is 117 days, with a freezing index of $608{ }^{\circ} \mathrm{C}$-days for the winter season of 1994-1995 (Fig. 8). The area's mean annual air temperature is $6.8^{\circ} \mathrm{C}$. The expected frost depth of this site based on modified

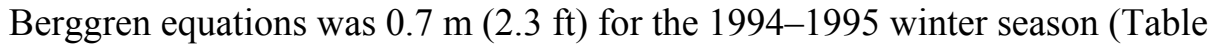
B1). 


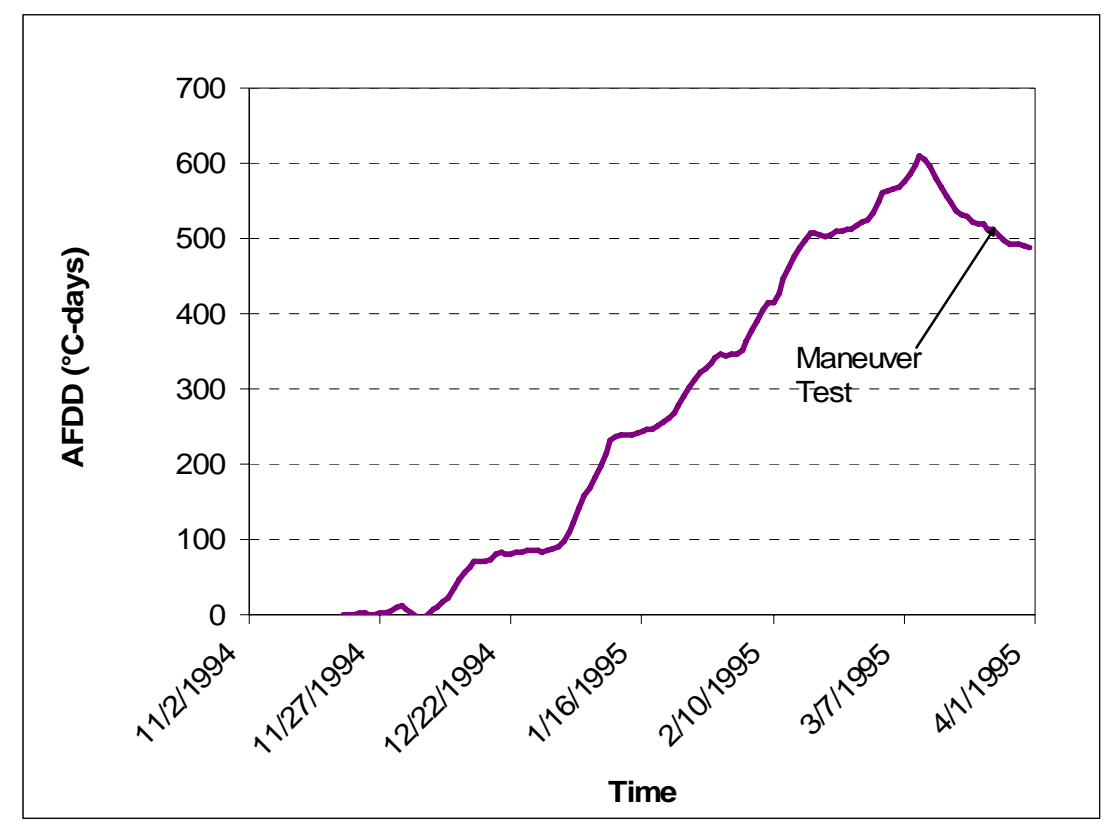

a. Air freezing degree days chart.

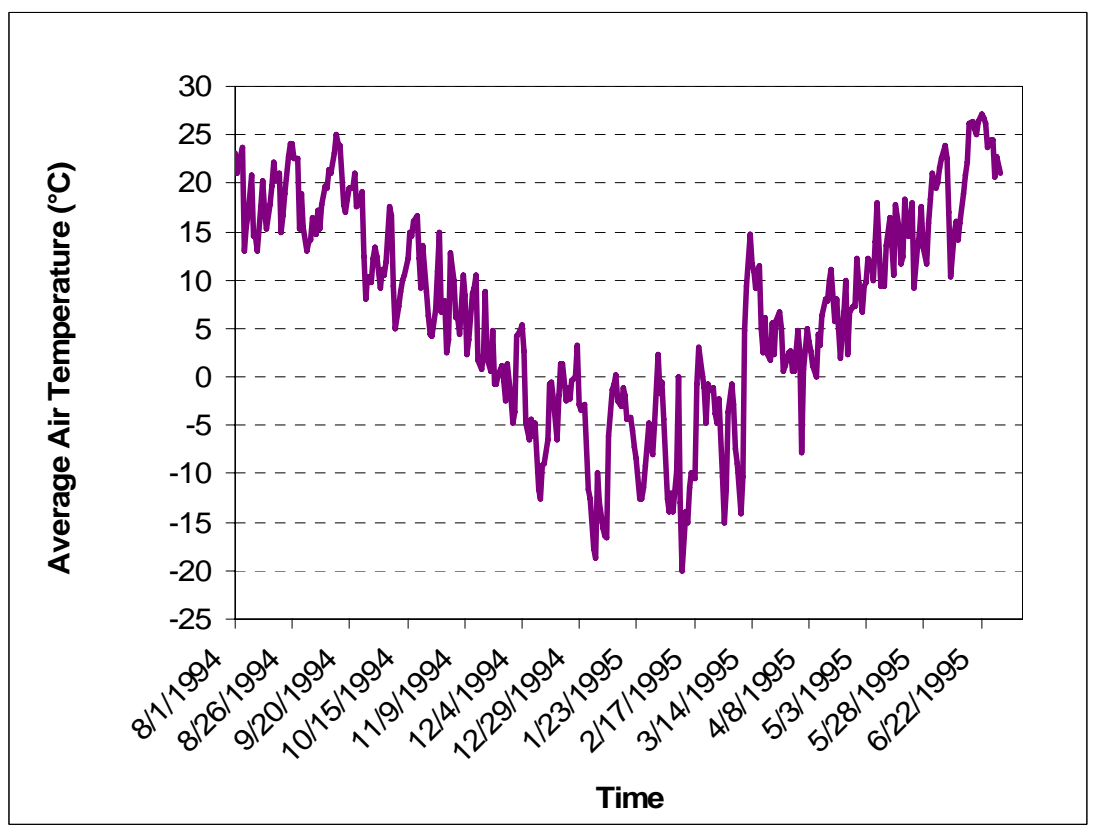

b. Daily average temperatures.

Figure 8. Graph of air freezing degree days and daily average temperature for Sparta, Wisconsin, for the 1994-1995 winter season. 


\subsection{Terrain Description-Soils}

\subsubsection{DTA, Alaska}

Arkansas Range. The terrain is characterized as a fairly flat and nonpermafrost terrain. The soil is outwash deposit, and the gradation curves of the material are classified under USCS as silty sand (SM) (Fig. 9). The silty sand material has a zero plasticity index with decomposed organics on the top $2 \mathrm{~cm}$ of the surface.

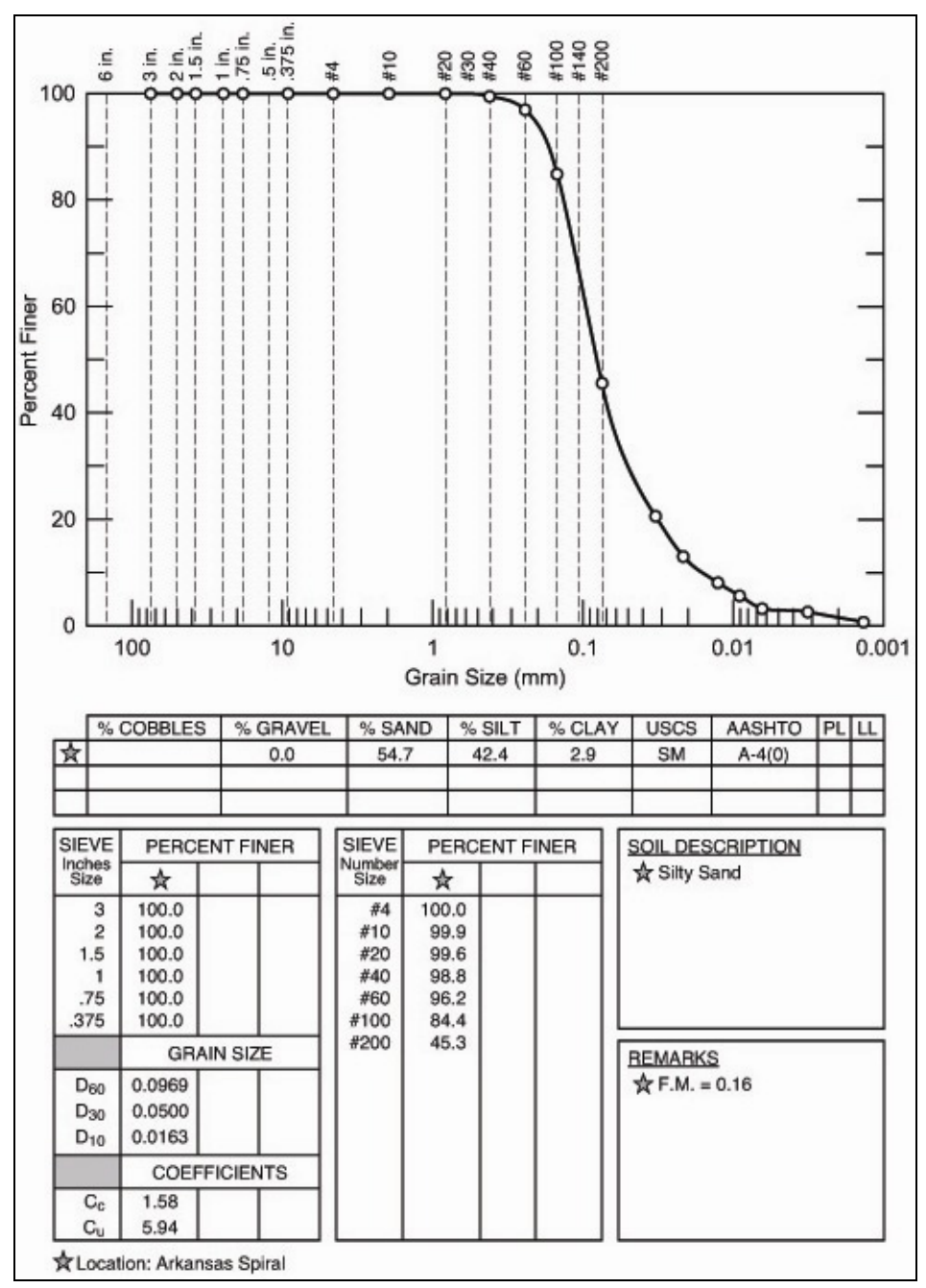

a. Spiral test section.

Figure 9. Grain size distribution of the soil at the spiral and multi-pass test sections at Arkansas Range. 


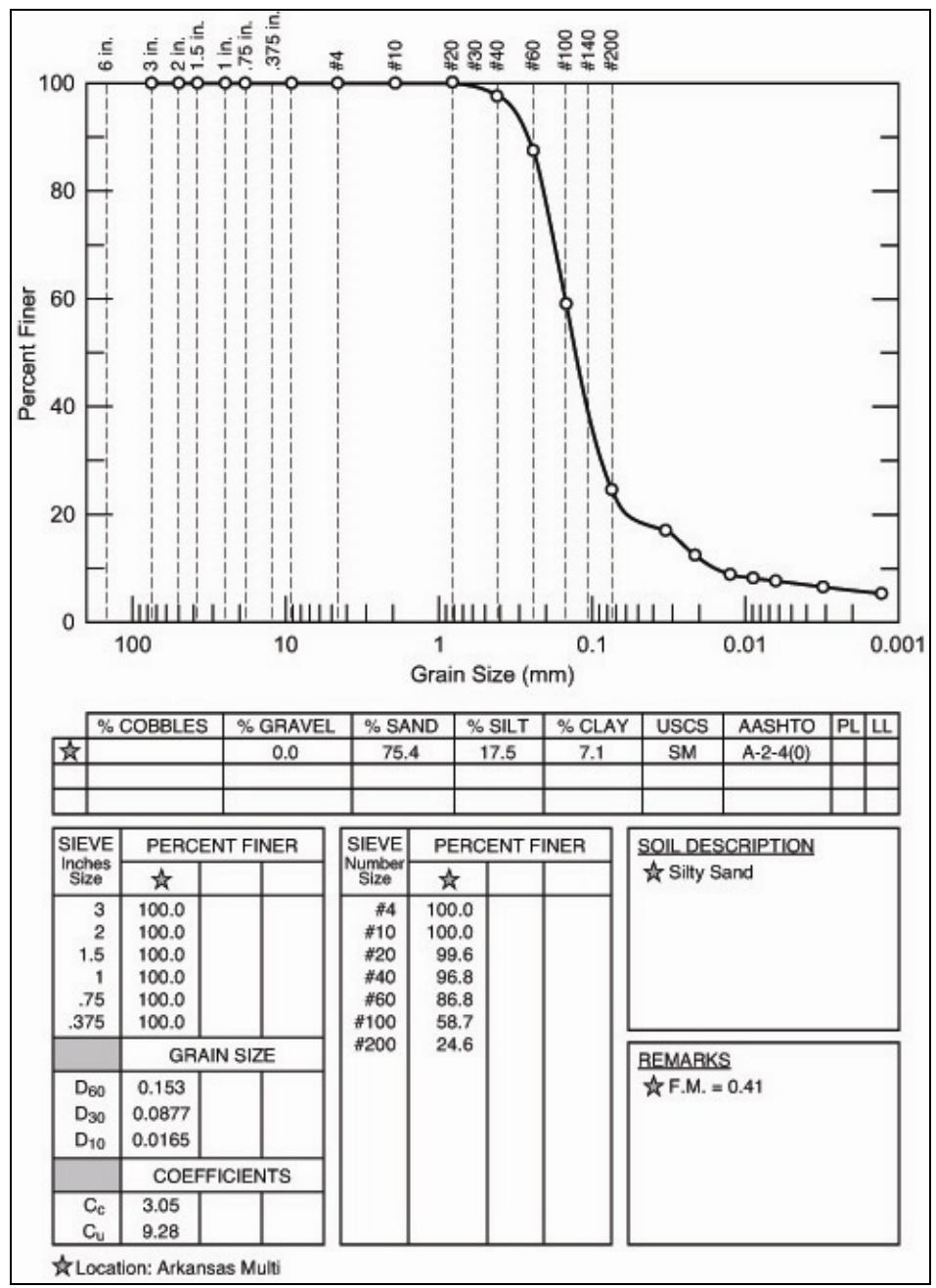

\section{b. Multi-pass test section.}

Figure 9 (cont'd).

The vegetation is composed of grass and short bushes, and was previously mowed in the fall (Fig. 10a). Figure 10b is a map of the GPS tracks, showing the maneuver pattern overlying the ortho-photo. The thirteen-pass test section was located near the tree line, as seen on a map of the maneuver pattern (Fig. 10b). Big roots from the trees were visible on the surface in some areas. The spiral section and the easternmost portion of the multi-pass area were very wet, with surface water ponding; however, the rest of the multi-pass section was fairly dry. 


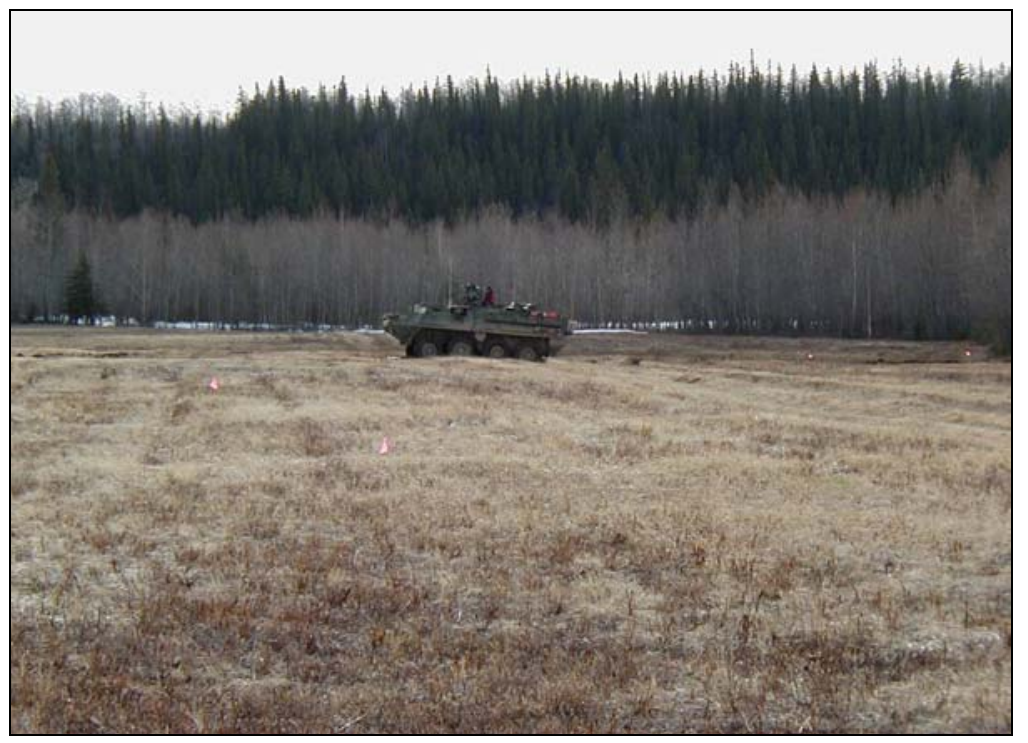

a. Vegetation features.

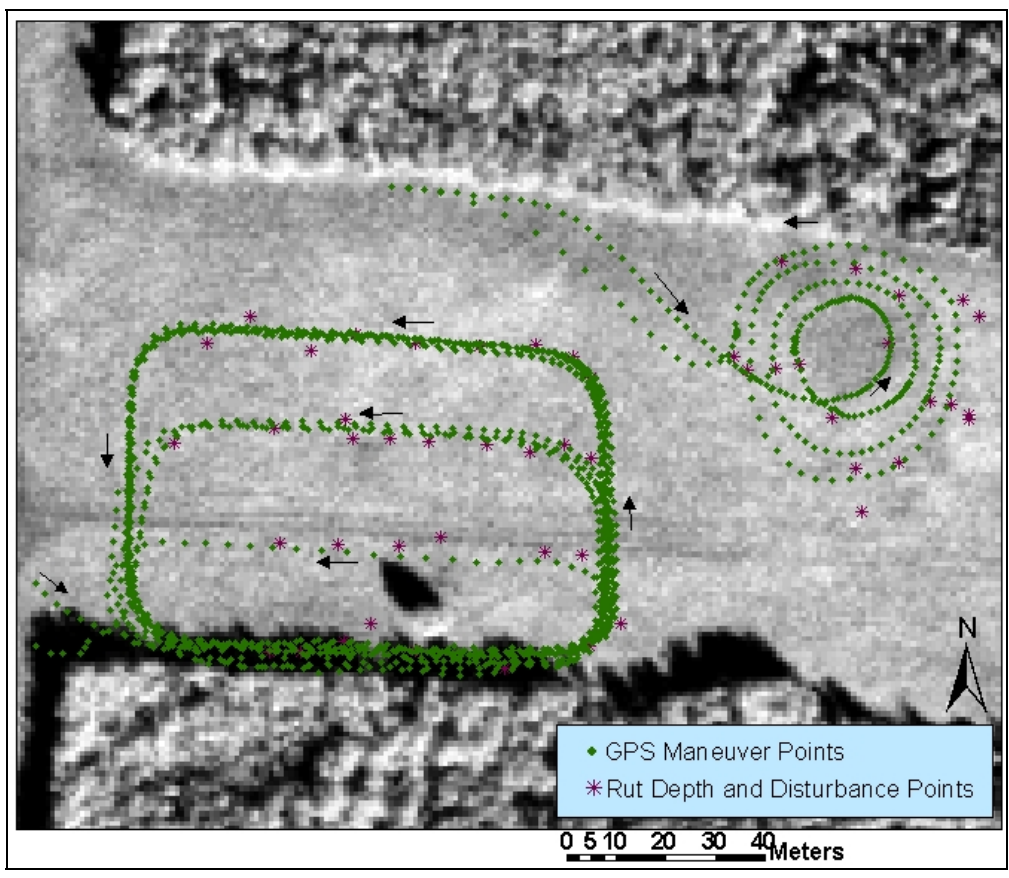

b. Pattern of maneuver impact test.

Figure 10. Photo and map of terrain at Arkansas Range showing vegetation features and pattern of maneuver impact test: spiral section and multi-pass section, with arrows indicating direction of vehicle travel (May 2003). 
Eddy Drop Zone. This site was located on fairly flat, non-permafrost terrain. The soil is glacial outwash deposit and is classified as silty sand (SM) according to USCS. Figure 11 shows the grain size analysis of the soil at the site with zero liquid and plastic limits (non-plastic material). An organic layer ranging from 5 to $10 \mathrm{~cm}$ ( 2 to $5 \mathrm{in}$.) overlays the soil.

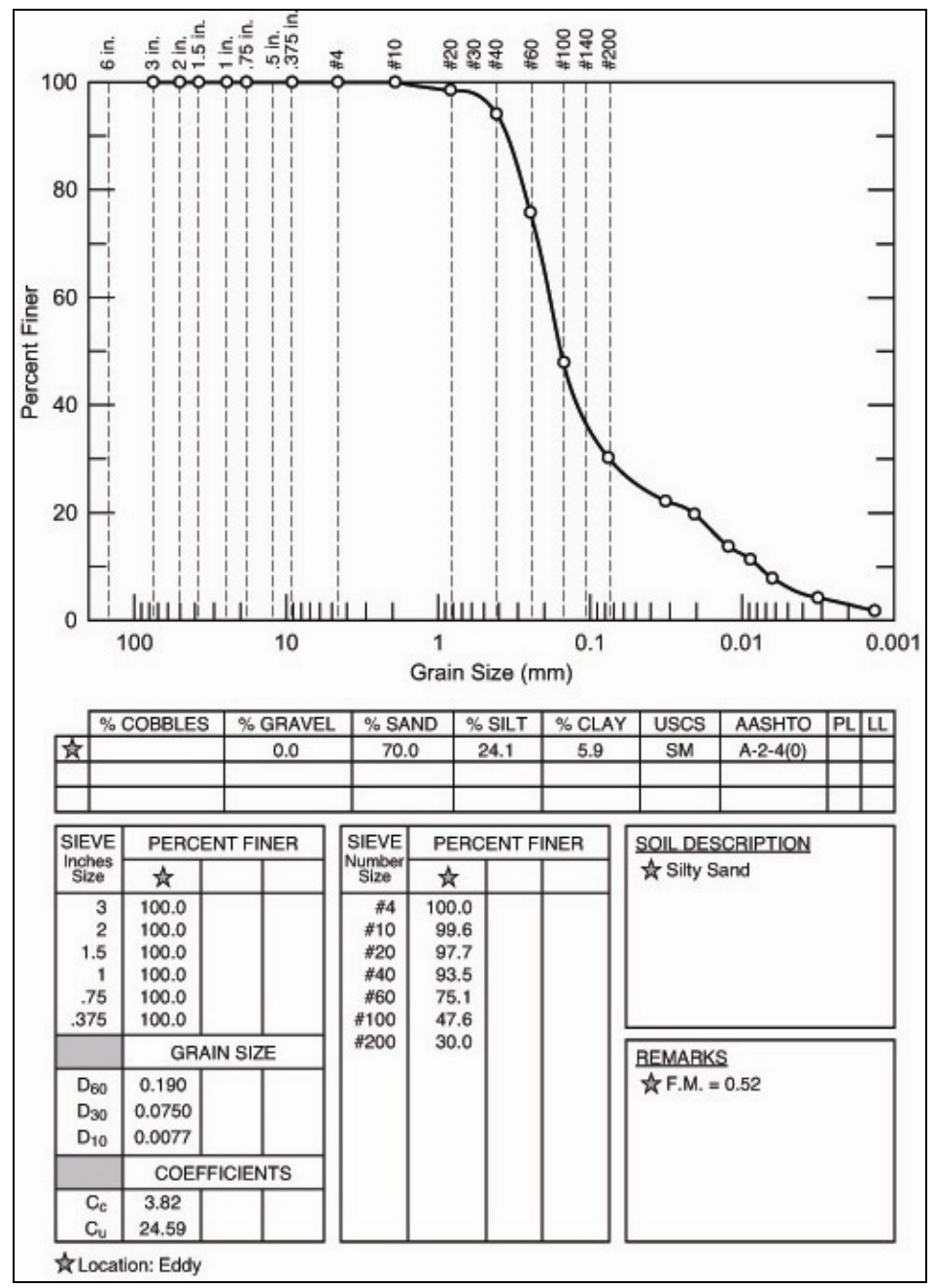

Figure 11. Gradation curve of the soil at Eddy Drop Zone.

The vegetation is composed of sphagnum moss, sedge, tall grass, and thick bushes up to $1 \mathrm{~m}$ (3.5 ft) tall (Fig. 12a). A GIS map with the GPS points tracks maneuver pattern for the multi-pass and spiral test sections is shown over the ortho-photo in Figure 12b. (The vegetation appears as a darker gray on the map.) 


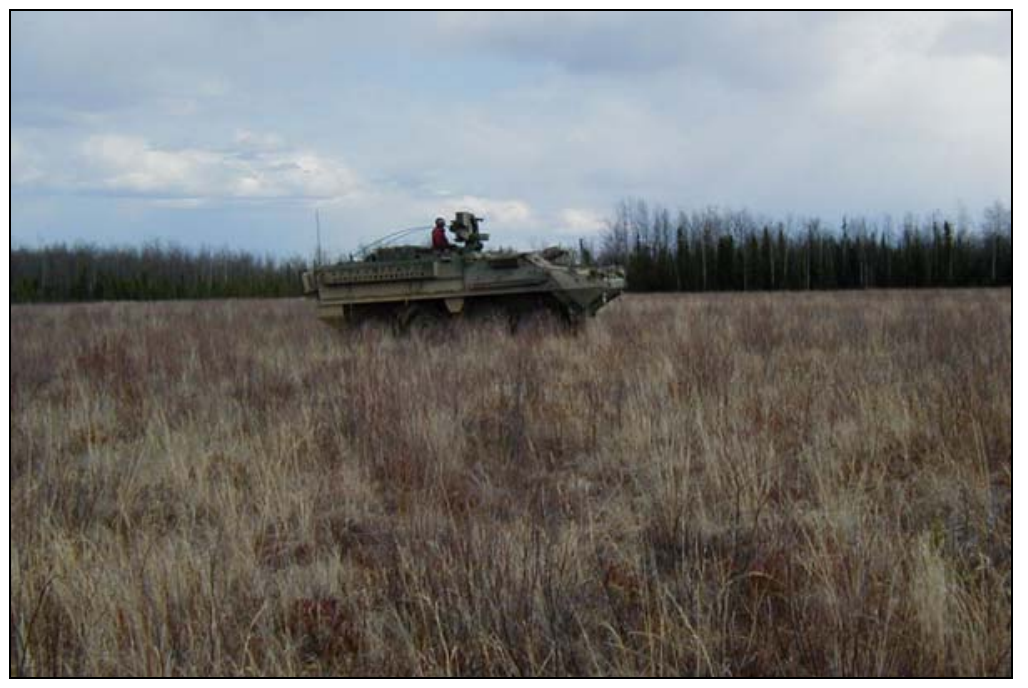

a. Vegetation features.

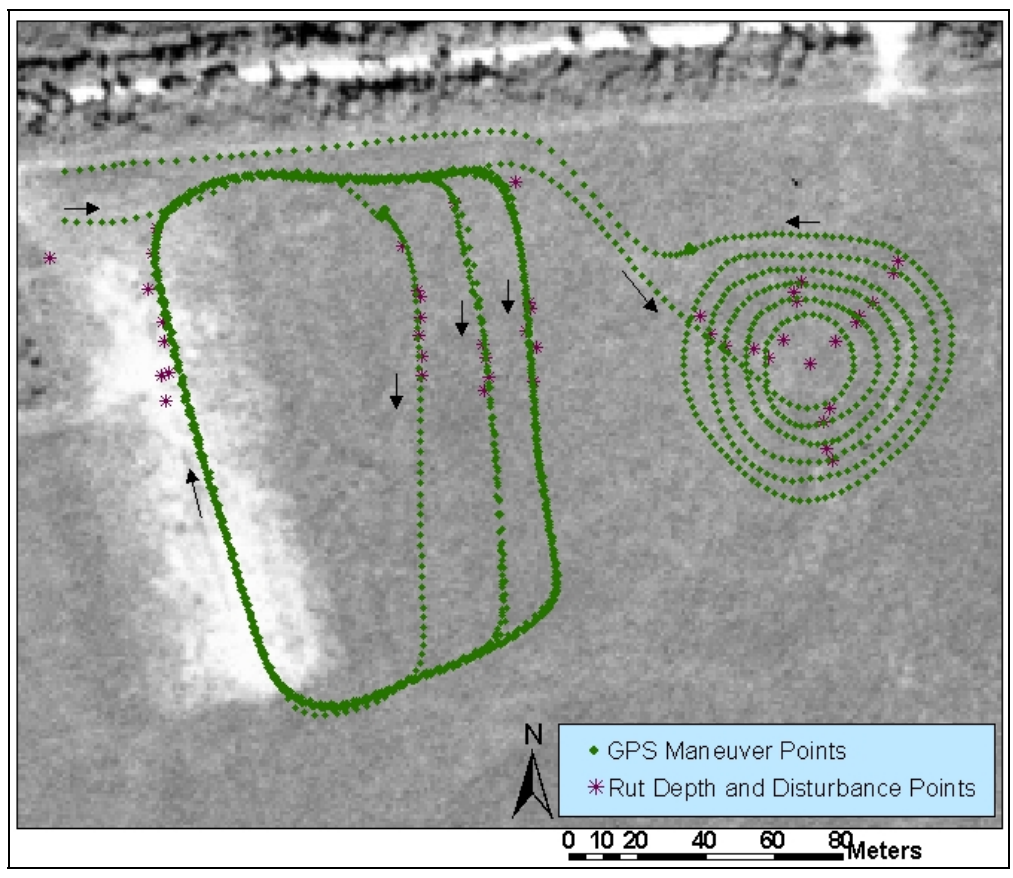

b. Pattern of maneuver impact test.

Figure 12. Photo and map of terrain at Eddy Drop Zone showing vegetation features and pattern of maneuver impact test: the spiral section, and the multi-pass section with arrows showing the direction of vehicle travel (May 2003). 
The test area previously was mowed in $2000,{ }^{*}$ with remnant, noticeable linear undulations of the ground surface. A thick organic layer of varying depths (approximately $20 \mathrm{~cm}$ in some areas) has overlain this dense vegetative area. The lighter area, where the thirteen-pass test was done, was disturbed several years ago. This section was leveled with a grader for helicopter landing and fueling." The disturbed section's vegetation is mostly tall grass with bare ground and minimal organic materials. Thaw depth in the disturbed section was up to 46 $\mathrm{cm}$ with a minimum thaw depth of $11.4 \mathrm{~cm}$ in the dense vegetation area.

Texas Range. This site is an alpine tundra area with an ecological land classification of lowland tussock scrub bog on gently sloping permafrost terrain. The active layer was mostly frozen during the maneuver tests. The soil is described as glacial loess and moraine deposits with very high organics content. The material is characterized as peat as shown in Figure 13.

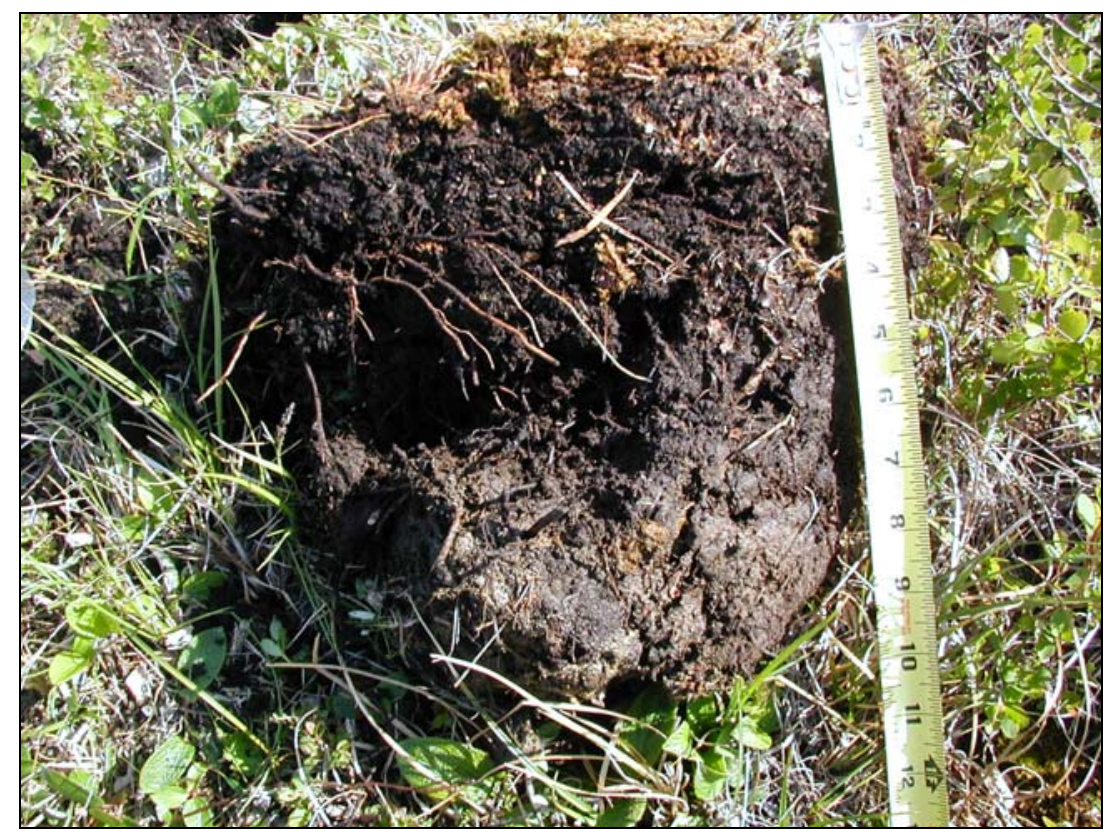

Figure 13. Highly organic material located at the Texas Range maneuver site.

The vegetation is composed of sphagnum moss, sedge, grass, and shrub (Fig. 14a). Only the spiral maneuver test, shown in Figure 14b, was conducted at this site because the Stryker vehicle was available only for a limited time.

\footnotetext{
* Personal communication, E. Clark, U.S. Army Alaska, Integrated Training Area Management Coordinator, 2004.
} 


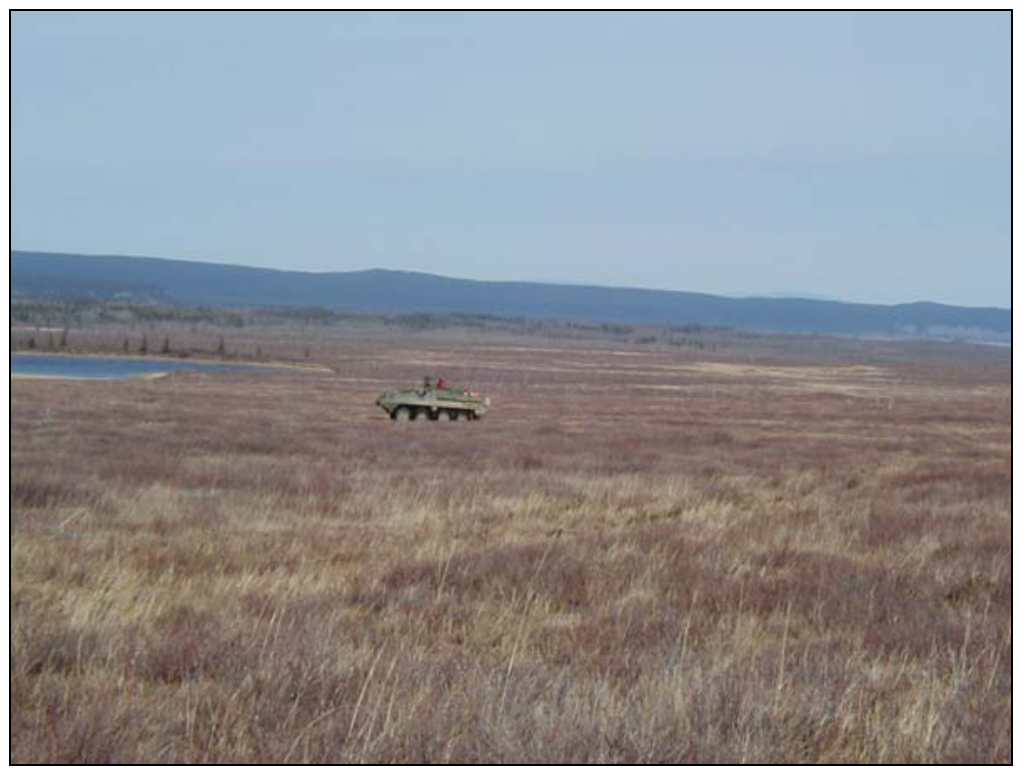

a. Vegetation features.

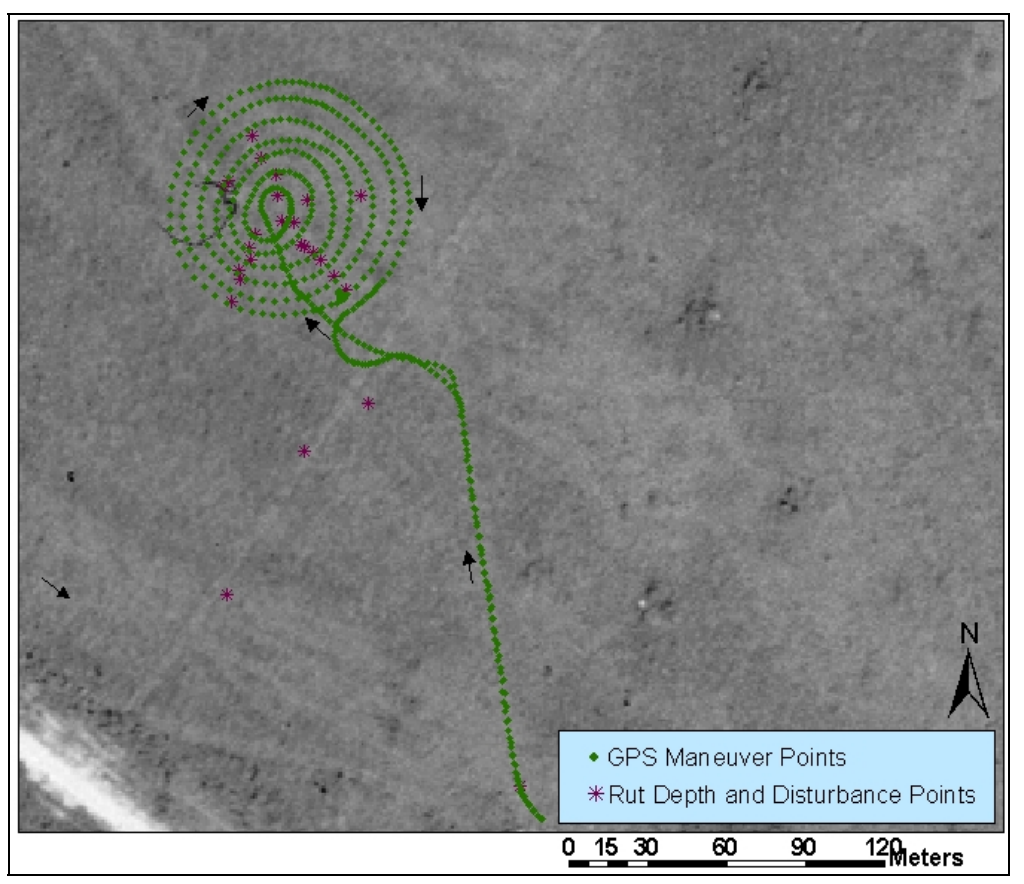

b. Pattern of maneuver impact test.

Figure 14. Photo and map of terrain at Texas Range showing vegetation features and pattern of maneuver impact test showing the spiral section with arrows indicating the direction of vehicle travel (May 2003). 


\subsubsection{Wooded Trail at Fort McCoy, Wisconsin}

The trail consisted of a 0 - to $10-\mathrm{cm}(0-$ to 4 -in.) vegetative/organic mat on top of a sandy soil. The particle size distribution curves of the two control sections are shown in Figure 15. The soils are classified as silty sand (SM) and poorly graded sand with silt (SP-SM) on wet and on dry test sections, respectively. Both of these soils have a zero plasticity index. The frost susceptibility classification of the soil varies from a very low to a very high frost-susceptible range, classified as F2 on Table 2-7 by Andersland and Ladanyi (1994). The terrain is relatively flat with a slope ranging from a 0.6 to $2.8 \%$ grade (Fig. 16). The groundwater table was close to the surface. The average gravimeter water contents on the two control sections used in this report are $15 \%$ and $22 \%$.

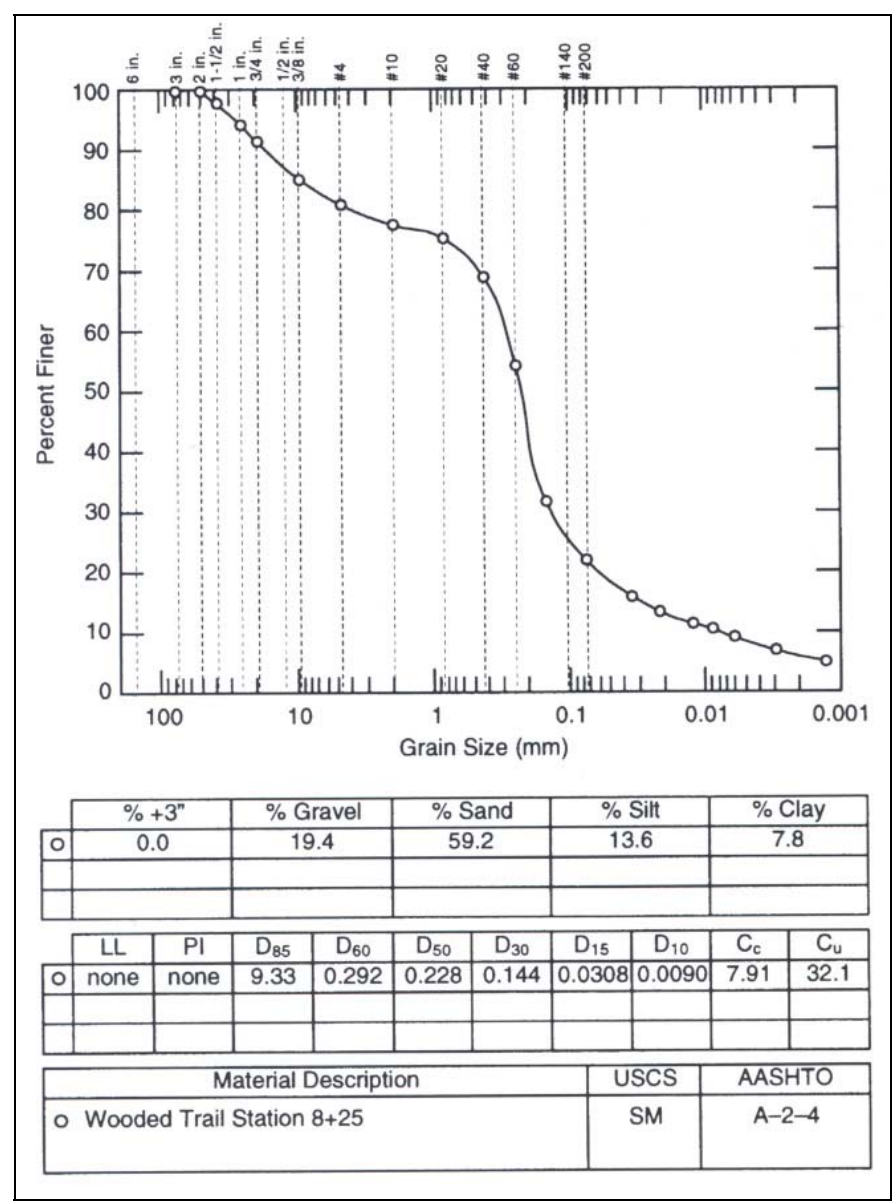

a. Wet section.

Figure 15. Gradation curves for soils on control sections of wooded trail at Fort McCoy. (After Kestler et al. 1999.) 


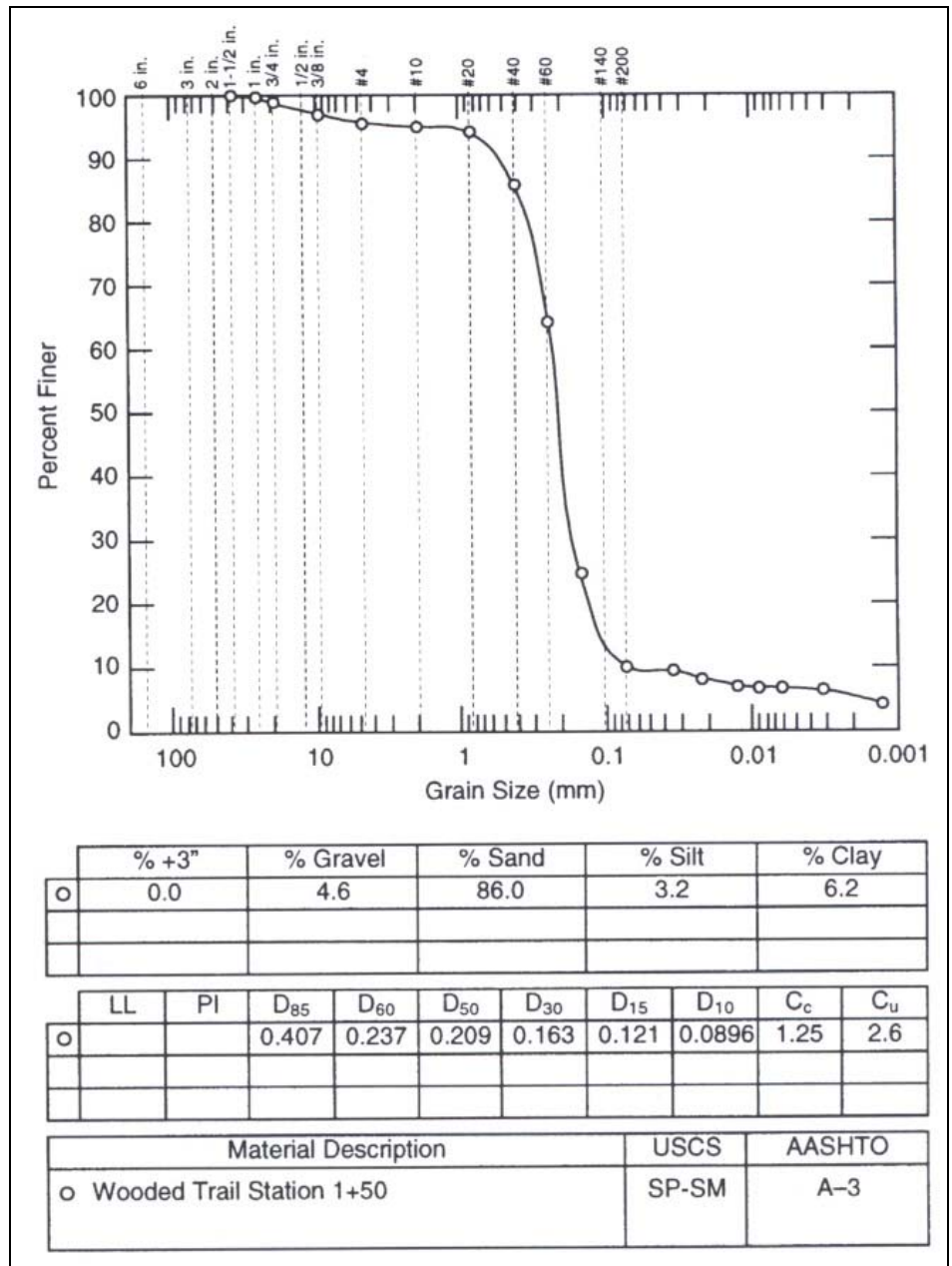

b. Dry section.

Figure 15 (cont'd). Gradation curves for soils on control sections of wooded trail at Fort McCoy. (After Kestler et al. 1999.) 


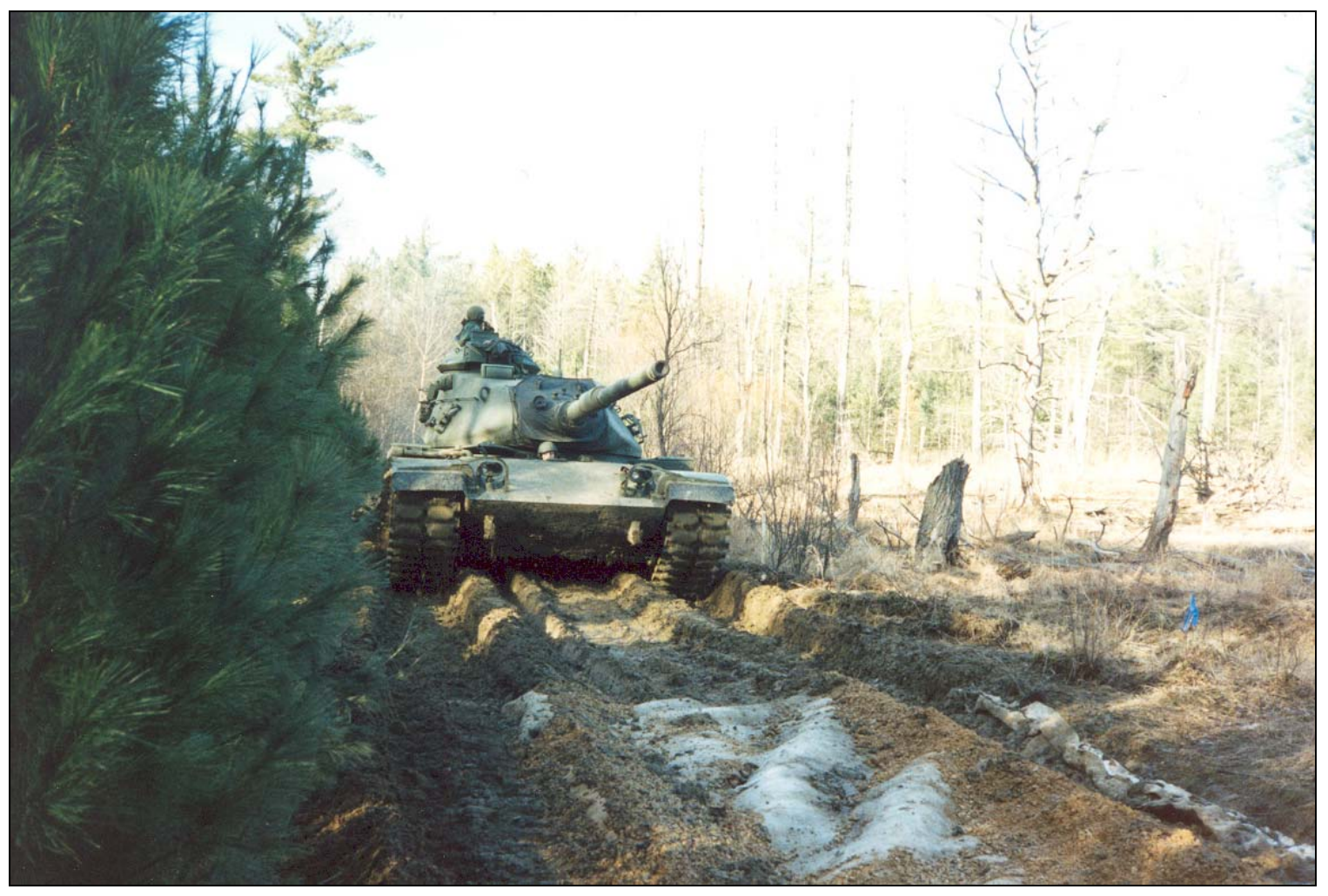

Figure 16. Control section of the wooded trail at Fort McCoy trafficked by an M60A3 in April 1995. 


\section{DATA COLLECTION}

\subsection{Spring Field Measurements}

\subsubsection{DTA, Alaska}

A 20-ton Stryker vehicle (Infantry Carrier Vehicle) was used to perform maneuver impact tests in May 2003 at the Arkansas Range, Eddy Drop Zone, and Texas Range during spring breakup. It was operated using on-road tire pressures of $550 \mathrm{kPa}(80 \mathrm{psi})$ on all eight tires. Tests consisted of spiral and multi-pass tests as shown in Figures 10b, 12b, and 14b. For the spiral test, the vehicle performed turning maneuvers by traversing from a small radius to larger radii, the idea being that the disturbance is significantly different when the vehicle is turning rather than when moving straight ahead. The multi-pass tests were composed of lanes with one, four, eight, and thirteen passes, and were intended to simulate the disturbance from multiple vehicles traveling in column formation.

A Global Positioning System (GPS) unit was mounted on the Stryker vehicle to track its position. Similar GPS units have been used by Ayers et al. (2000). The GPS unit recorded the position data of the test at one-second intervals. The GPS data were used to determine vehicle speed and turning radius.

The velocity of the vehicle is a function of the location changes over time and was derived from GPS coordinates (Ayers et al. 2000, Haugen et al. 2002). Because the vehicle position is recorded at one-second intervals, vehicle speed at a point was calculated by determining the distance to the previous point; this yields the speed in meters per second. Details to calculate the vehicle speed are described in Appendix D.

The turning radius on both the spiral and multi-pass sections was determined by using the data points from five consecutive positions (Ayers et al. 2000). Perpendicular bisects to lines connecting the first to the third, and third to the fifth data points were calculated from the coordinates of those points. The intersection of those two perpendicular bisects was determined by solving two simultaneous equations. Turning radii greater than and equal to $150 \mathrm{~m}$ are assigned a value of $150 \mathrm{~m}$, and are considered as a straight path. Equations used to determine the vehicle turning radius are described in Appendix D.

State-of-the-ground measurements, including gravimeter water content, soil strength, and thaw depth, were conducted during the test. Soil samples were taken in the middle of the tracks after the maneuver impact tests to determine the gravimetric water content. The amount of terrain disturbance was measured 
at many locations along the spiral and multi-pass maneuver paths, and was characterized by rut depth, width, and percent and type of disturbance to soil and vegetation.

The soil strength was measured in the middle of the tracks using a $30^{\circ}$ circular stainless steel cone penetrometer, with 12.83-mm (0.505-in.) diameter and $0.13-\mathrm{mm}^{2}\left(0.2-\right.$ in. $\left.^{2}\right)$ cone base area. The cone is pushed into the soil at a uniform rate and readings are recorded at $2.54-\mathrm{cm}(1-\mathrm{in}$.) intervals. Typically, for vehicle mobility, Cone Index (CI) is expressed by averaging the CI for layers of soil from 0 to $15 \mathrm{~cm}$ (0 to 6 in.) in depth and from 15 to $30 \mathrm{~cm}$ (6 to $12 \mathrm{in}$.) in depth. However, for strongly layered soil such as thawing soil, the CI value used is the average of thawed layer values.

Rut depth measurements were conducted one month after the maneuver impact tests to minimize additional disturbance from foot traffic, because most of the ground was very soft during testing. The effects of soil settlement, potential erosion due to water flow, and slumping of soil into the ruts as a result of freeze-thaw could possibly have happened during the time between testing and measuring, but were assumed to be small relative to the total depth and thus were not considered.

Rut depth measurements along the spiral and multi-pass areas were conducted at three sites in June using a profilometer, which consisted of rods that slide on a metal bar. The rods were spaced every $2 \mathrm{~cm}$ horizontally and each rod was marked at $1-\mathrm{cm}$ intervals vertically. As noted earlier, the profilometer was placed at the center of the rut and a photo of the rut depth taken and its location recorded using a handheld GPS unit. The photos were printed and lines were drawn of the natural (undisturbed) ground surface profile (the outside of the ruts) and maximum level of the rut. Rut depth is determined by counting the $1-\mathrm{cm}$ intervals on the rod between the surface and rut lines as shown in Figure 3. The area of the soil displacement or deformation from the rut depth photos is computed using image processing software called Image Pro Plus (Fig. 5). The volumetric displacement per 1-m track length is calculated by multiplying the area of soil displaced by $100 \mathrm{~cm}$ of track length (units used in the analysis are $\left.\mathrm{cm}^{3} / \mathrm{m}\right)$.

The impact severity measurements were taken in August (three months after the maneuver impact tests) based on impact severity and disturbance width categories (Fig. 6) along the tracks using the guidelines listed in Table 1. The cumulative impact width was computed by multiplying the disturbance width and the impact severity (in decimal form) for each track. With the time gap between testing and measuring, the cumulative impact width most likely exhibited reasonable values where the tracks, soil piles, crushed vegetation, and ruts were 
still visible but limited vegetation rebound had occurred. Reasonable values were also likely on tracks with minimal disturbance.

The in-situ dry density and moisture content adjacent to the test sites were taken from drive cylinder samples in June 2003 as additional information. The dry densities were 1633,1356 , and $559 \mathrm{~kg} / \mathrm{m}^{3}$ with moisture contents of 30,39 , and $157 \%$ for the Arkansas Range, Eddy DZ, and Texas Range, respectively (Table A1). As expected, these moisture contents were drier relative to those samples taken during the tests since samples were collected in the beginning of summer and the ground was able to drain.

\subsubsection{Fort McCoy, Wisconsin}

The wooded trail consisted of a saturated, thawing soil layer over frozen ground. The trail was trafficked with both the M60A3 and HEMTT to evaluate several stabilization methods. The M60A3 has contact pressure of $76.5 \mathrm{kPa}$. The HEMTT has four axles, two tires per axle, and was operated using both on- and off-road tire pressures. The on-road tire inflations used for the HEMTT were 413 $\mathrm{kPa}(60 \mathrm{psi})$ on the four front tires and $689 \mathrm{kPa}(100 \mathrm{psi})$ on the four rear tires. The off-road tire inflations used during the test were $138 \mathrm{kPa}(20 \mathrm{psi})$ on the four front tires and $689 \mathrm{kPa}(100 \mathrm{psi})$ on the four rear tires.

Rut depth was measured using a profilometer and rod after 1, 10, 25, and 50 passes. The ground condition of two control sections was measured. Measure-

ments included the thaw depth, moisture content, soil strength, and densities. The average in-situ dry density and moisture content were $1800 \mathrm{~kg} / \mathrm{m}^{3}$ and $15.64 \%$, respectively. The two control sections are grouped into wet and dry areas. The wet section contained an average moisture content of $22 \%$, while the dry section had a $15 \%$ moisture content.

\subsection{Winter Test}

A disturbance test was conducted using the Stryker vehicle in March 2003 as shown in Figure 17. Both multi-pass and spiral tests were performed. The test was located on the southwest area of the spiral section in May at the Texas Range shown in Figure 14. Snow depth during the test was very shallow, approximately $10 \mathrm{~cm}$ (4 in.). Snow density was not recorded. The site had no snow cover in February and the winter was considerably mild for the area, as noted in Section 4.2.1. The ground was observed to be frozen. As stated in Section 4.3, the terrain at the Texas Range is on permafrost. However, the depth of permafrost was not determined for this test. The active layer is assumed to be frozen all the way to the permafrost. 
The vehicle track was not recorded because the GPS was not functioning. However, rutting was measured in June using a profilometer, and the impact severity was surveyed in August 2003.

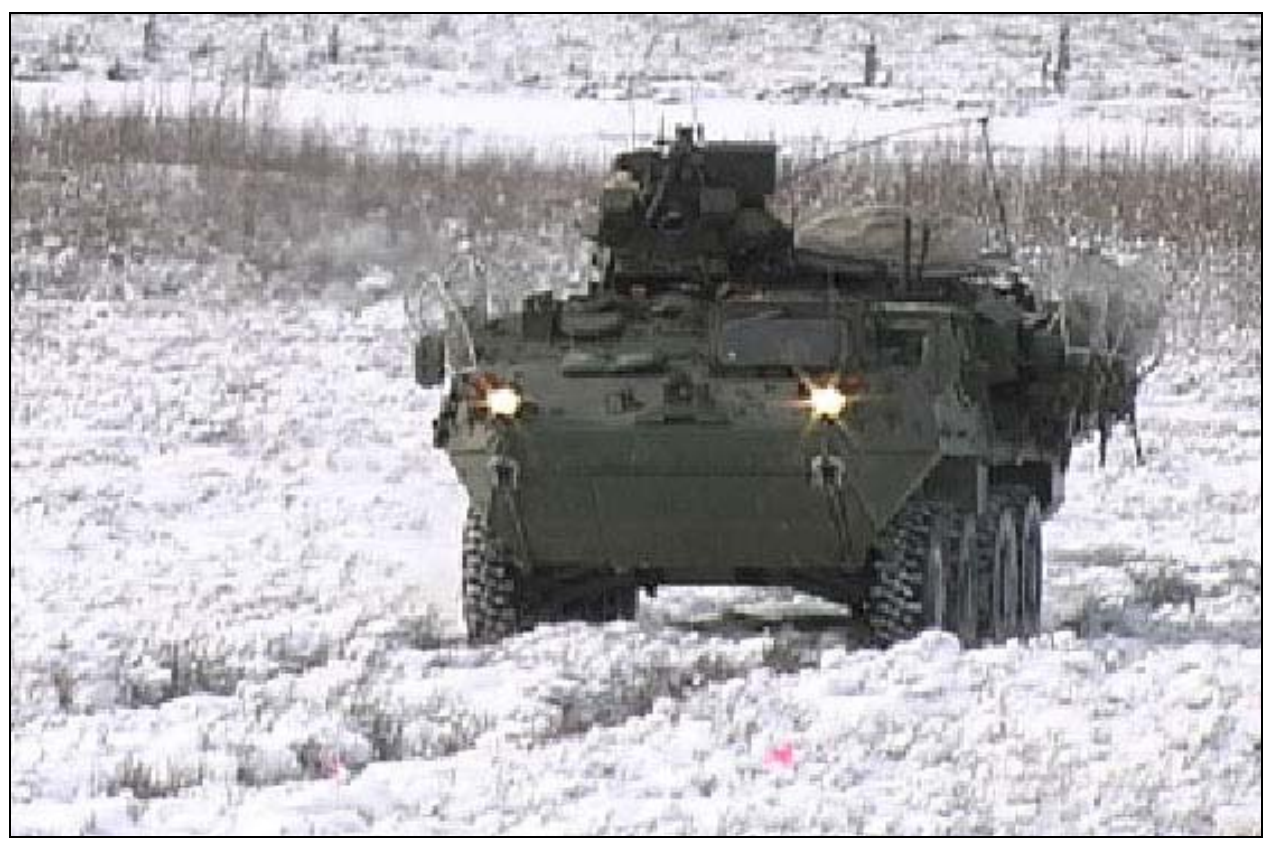

Figure 17. Stryker disturbance test in March 2003 at the Texas Range. 


\section{ANALYSIS AND RESULTS}

Table 3 presents the site description and test conditions during the trafficking to quantify terrain disturbance. As stated earlier, the winter test was conducted only at Texas Range. Data for all of the sites are summarized in Appendix A.

Rut depth was analyzed with respect to soil moisture, thaw depth, soil strength (CI), vehicle speed, turning radius, and number of passes. Results of each test are discussed in detail in Section 6.1. Measured rut depth datasets also were compared with the predictions from the semi-empirical rut depth equations. Volumetric soil displacement was also evaluated.

\begin{tabular}{|c|c|c|c|c|c|c|c|c|}
\hline \multirow{2}{*}{\multicolumn{2}{|c|}{ Test sites }} & \multicolumn{5}{|c|}{ Alaska } & \multirow{2}{*}{\multicolumn{2}{|c|}{$\begin{array}{l}\text { Fort McCoy, } \\
\text { Wisconsin }\end{array}$}} \\
\hline & & \multicolumn{2}{|c|}{ Arkansas Range } & \multicolumn{2}{|c|}{ Eddy Drop Zone } & $\begin{array}{l}\text { Texas } \\
\text { Range }\end{array}$ & & \\
\hline \multicolumn{2}{|c|}{ Terrain description } & \multicolumn{2}{|c|}{ Flat, non permafrost } & \multicolumn{2}{|c|}{ Flat, non permafrost } & $\begin{array}{l}\text { Gently } \\
\text { sloping, } \\
\text { permafrost }\end{array}$ & \multicolumn{2}{|c|}{$\begin{array}{l}\text { Gently sloping, } \\
\text { seasonal frost area }\end{array}$} \\
\hline \multicolumn{2}{|c|}{ Vegetation } & \multicolumn{2}{|c|}{ Grass and short bushes } & $\begin{array}{l}\text { Sphagnum } \\
\text { moss, } \\
\text { sedge, tall } \\
\text { grass, and } \\
\text { thick } \\
\text { bushes }\end{array}$ & $\begin{array}{l}\text { Tall grass } \\
\text { with bare } \\
\text { ground }\end{array}$ & $\begin{array}{l}\text { Sphagnum } \\
\text { moss, } \\
\text { sedge, } \\
\text { and shrub }\end{array}$ & \multicolumn{2}{|c|}{$\begin{array}{l}\text { Wooded trail } \\
\text { with grass } \\
\text { and organic mat }\end{array}$} \\
\hline \multicolumn{2}{|c|}{ Soil type } & \multicolumn{2}{|c|}{ Silty sand (SM) } & \multicolumn{2}{|c|}{$\begin{array}{l}\text { Silty sand (SM) with thick } \\
\text { organic layer in dense } \\
\text { vegetative area }\end{array}$} & $\begin{array}{l}\text { Peat, } \\
\text { organics }\end{array}$ & $\begin{array}{l}\text { Silty sand } \\
\text { (SM) }\end{array}$ & $\begin{array}{c}\text { Poorly } \\
\text { graded } \\
\text { sand with } \\
\text { silt } \\
\text { (SP-SM) }\end{array}$ \\
\hline \multicolumn{2}{|c|}{ Vehicle used } & \multicolumn{2}{|c|}{ Stryker } & \multicolumn{2}{|c|}{ Stryker } & Stryker & \multicolumn{2}{|c|}{ M60A3, HEMTT } \\
\hline \multicolumn{2}{|c|}{ Test sections } & Wet & Dry & $\begin{array}{c}\text { Dense } \\
\text { vegetation }\end{array}$ & $\begin{array}{c}\text { Sparse } \\
\text { vegetation }\end{array}$ & & Wet & Dry \\
\hline \multirow[b]{2}{*}{$\begin{array}{c}\text { Spring } \\
\text { thaw } \\
\text { conditions }\end{array}$} & $\begin{array}{l}\text { Avg. } \\
\text { water } \\
\text { content } \\
(\%)\end{array}$ & 49.3 & 33.9 & 94.5 & 36.2 & 315.7 & 21.8 & 15.3 \\
\hline & $\begin{array}{l}\text { Avg. thaw } \\
\text { depth } \\
\text { (cm) }\end{array}$ & 28.8 & 23.4 & 14.5 & 44.5 & 7.6 & 16.0 & 31.2 \\
\hline $\begin{array}{l}\text { Winter } \\
\text { conditions }\end{array}$ & $\begin{array}{l}\text { Snow } \\
\text { depth } \\
(\mathrm{cm})\end{array}$ & - & - & - & - & 10.0 & - & - \\
\hline
\end{tabular}




\subsection{Rut Depth Measurements}

Overall vehicle speed during the maneuver tests ranged from 1 to $5 \mathrm{~m} / \mathrm{s}(2.2$ to $11.2 \mathrm{mph}$ ) (Fig. 18). This was considered low speed, as the vehicle is designed for moving cross-country at $18 \mathrm{~m} / \mathrm{s}(40 \mathrm{mph})$. Generally, the results showed that the vehicle speed variation in these ranges did not influence the disturbance on the terrain (Fig. 18).

The spiral section at the Arkansas Range was considerably wet. In particular, the easternmost portion of the multi-pass section had visible water ponding. The wet section displayed higher rut depth than the drier section at Arkansas Range, as shown in Figure 18a. However, two-thirds of the multi-pass section was fairly dry. Moisture content ranged from $26 \%$ in the dry portion of the multi-pass section to $58.5 \%$ in the spiral section. Thaw depth in the spiral section was approximately $30.5-33.0 \mathrm{~cm}(12-13 \mathrm{in}$.). In the multi-pass section, ruts were deeper in the easternmost portion, the very wet part, where the average rut depth was $24 \mathrm{~cm}$ (Fig. 19a). As expected, in the dryer parts of the multi-pass section, the ruts were as shallow as $1 \mathrm{~cm}$, as shown in the summary table (Table A1).

The rut depth measurement averages of right and left wheel paths on the previously disturbed section with sparse vegetation at Eddy Drop Zone, which hosted the thirteen-pass lane, ranged from 19 to $36.5 \mathrm{~cm}$ (7.5 to $14 \mathrm{in}$.) where the maximum thaw depth of the area was $45.7 \mathrm{~cm}$ (18 in.) as summarized in Table A2. The speed was significantly lower in the spiral and one-pass section than in the thirteen-pass section at Eddy Drop Zone (Fig. 18b). However, rutting in the spiral and single pass lanes did not exceed $14 \mathrm{~cm}$ (5.5 in.) where thaw depth was shallower (up to $20 \mathrm{~cm}$ ) (Fig. 19b). Moisture content ranged from 30.5 to $42 \%$ on the disturbed section where the thirteen-pass test was located, while the rest of the test section at this site had a moisture content of up to $133.4 \%$. Also, the dense vegetation in this area certainly helped minimize the rutting.

The speeds along the spiral section at Texas Range were variable (Fig. 18c). This test section had very shallow thaw depths, ranging from 7.6 to $10 \mathrm{~cm}(3-4$ in.); thus, the rutting disturbance to vegetation was minimal in comparison (Fig. 18c). The disturbance was mostly exhibited as imprints from the tire track, where the vegetation was compressed to the ground with minimal shear or vegetation removal and bare ground. The soil samples that were taken at this site contained ice lenses, and the moisture content was up to $356.7 \%$. 


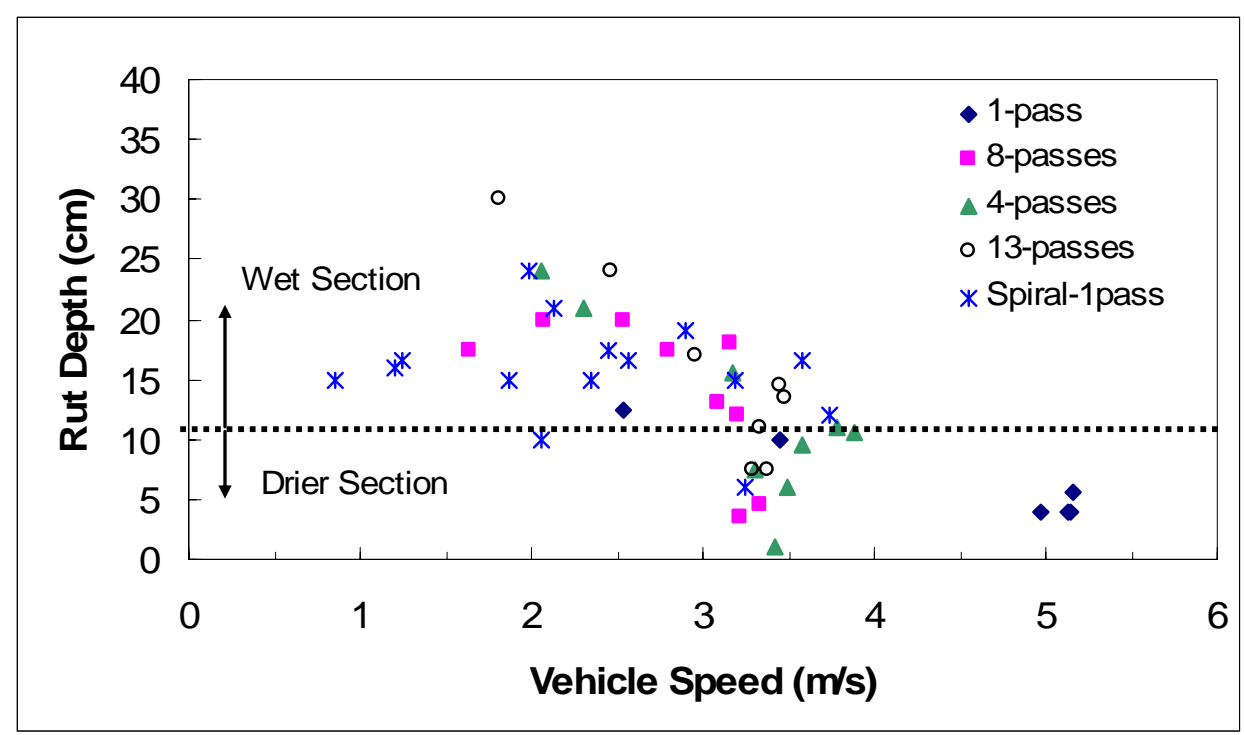

a. Arkansas Range.

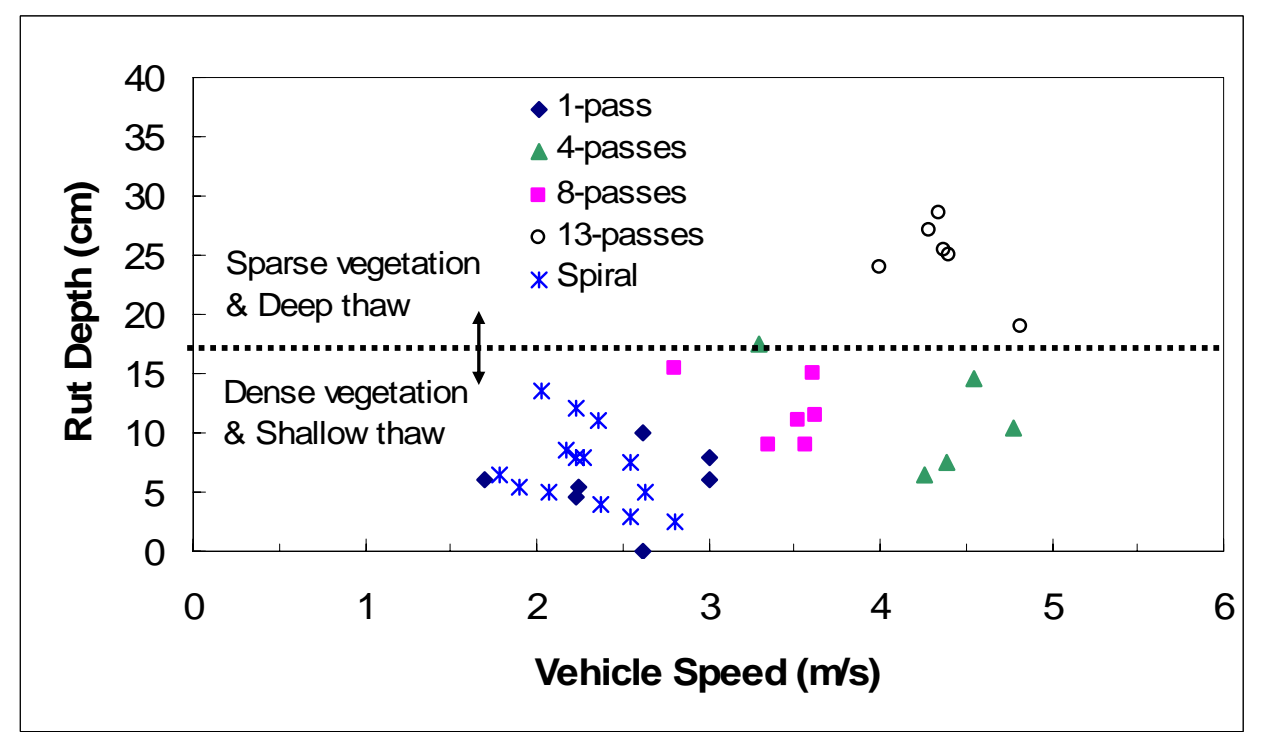

b. Eddy Drop Zone.

Figure 18. Stryker vehicle average speed from a GPS unit at locations where rut depth data were measured at Arkansas Range, Eddy Drop Zone, and Texas Range. 


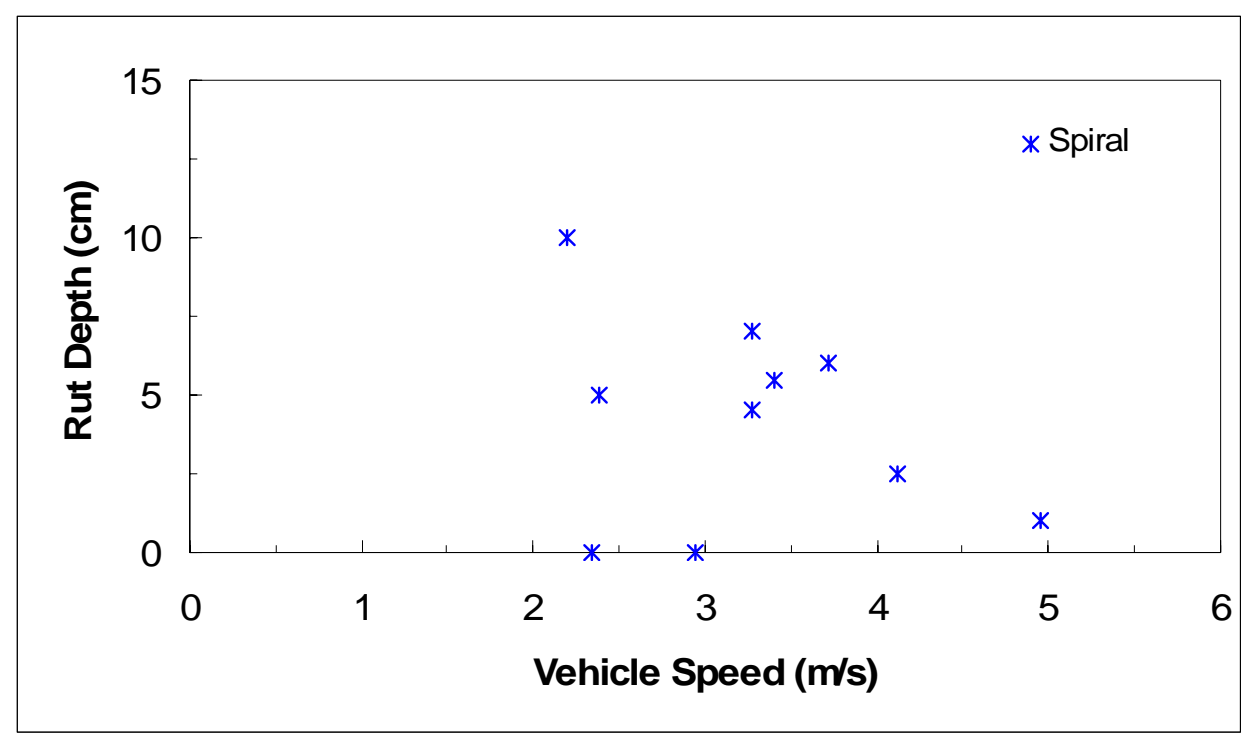

c. Texas Range.

Figure 18 (cont'd).

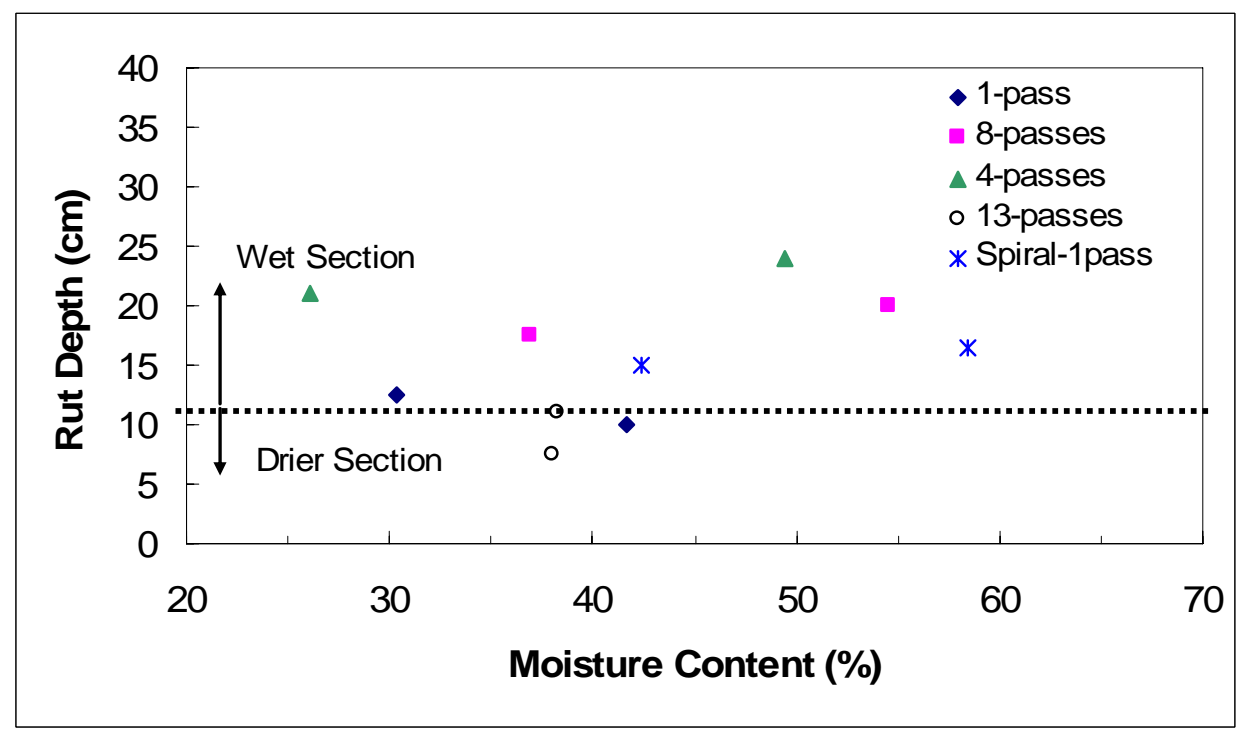

a. Arkansas Range.

Figure 19. Gravimeter water content versus rut depth at Arkansas Range and Eddy Drop Zone. 


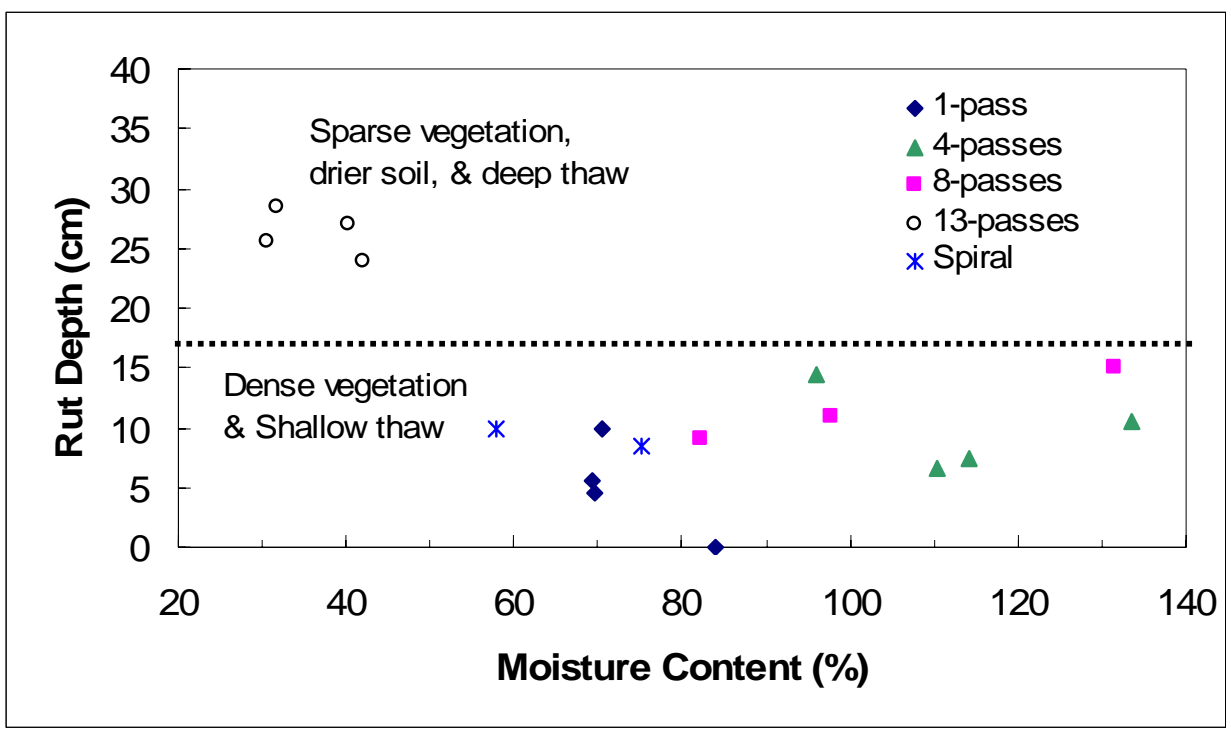

\section{b. Eddy Drop Zone.}

Figure 19 (cont'd). Gravimeter water content versus rut depth at Arkansas Range and Eddy Drop Zone.

The measured rut depths on spiral sections, single pass, and multi-passes at three sites are plotted against the thaw depth, and the result exhibited a linear correlation (Fig. 20). Rut depth is expected to be at least $58 \%$ of the thaw depth and possibly equal to the thaw depth for saturated thawing terrain. However, a couple of data points at the Eddy Drop Zone indicated inconsistency.

The typical rut profile of deep ruts on the straight sections at the Arkansas Range and Eddy Drop Zone comprised a symmetrical deformation showing exposed soil in the center of the tire track, with steep sidewall and capped lip of displaced soil and vegetation raised $10 \mathrm{~cm}$ or more above the adjacent uncompacted soil. Ruts on turns often exhibited one lip (outer side) higher, with a bigger quantity of displaced soil and vegetation next to the adjacent undisturbed soil, than the other lip. The profile of the shallow ruts, such as in the case at the Texas Range and spiral section at the Eddy Drop Zone, with deeper organic layer and dense vegetation, was mainly compression to the thawed layer with a small sidewall and often no distinct lip. Selected photos of rut profiles at each site at DTA are shown in Figures A1-A9. 


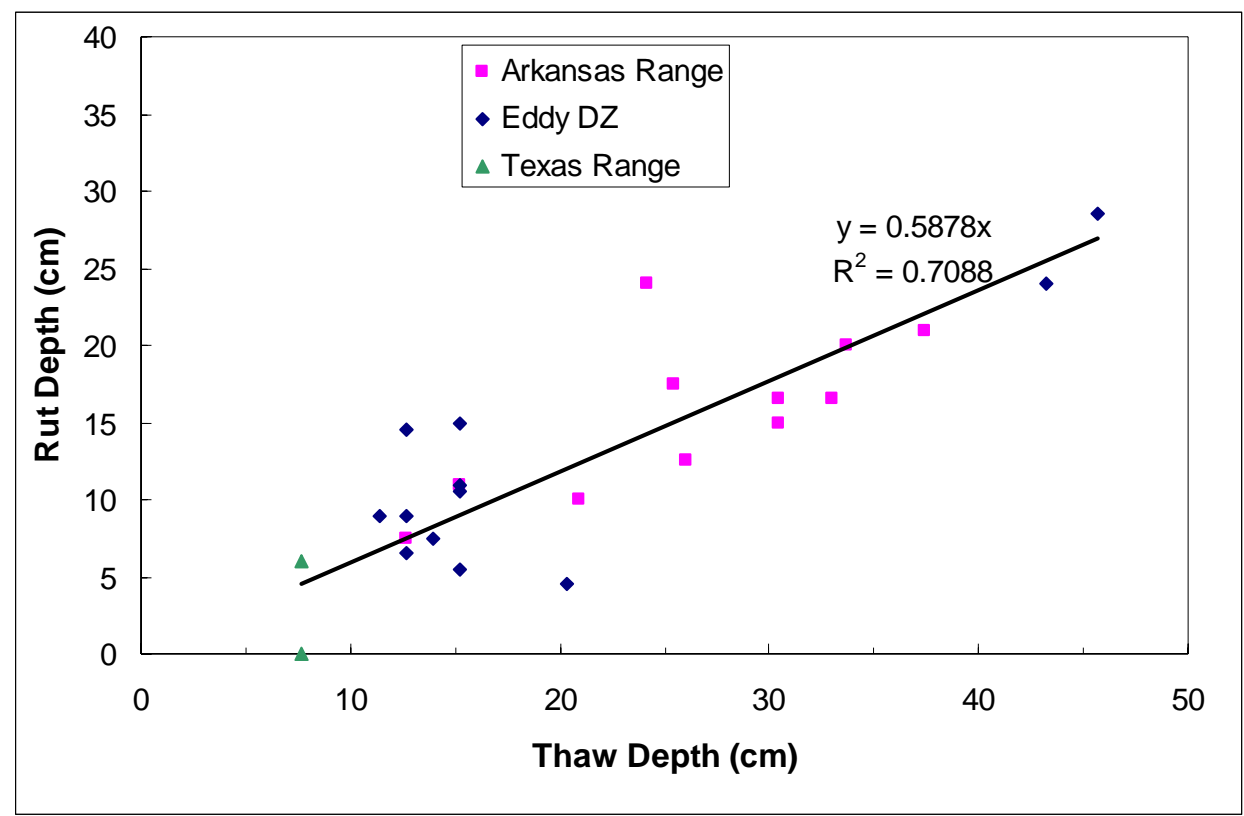

Figure 20. Relationship between average rut depth and thaw depth for all three sites at DTA.

The two control locations along the wooded trail at Fort McCoy are categorized into wet and dry sections. Figure 21 shows relationships between rut depth and number of passes. The results demonstrate a significant increase in rut depth as the number of passes increase. The dry section exhibited relatively shallower rutting than the wet area for both M60A3 and HEMTT.

\subsection{Rut Depth Model Comparison}

The rut depth was calculated using the semi-empirical rut depth equation (eq 1 ) for 20 , and $50 \%$ slip. Slip greater than $50 \%$ can occur during vehicle maneuvering in thawing terrain. The actual rut depth measurements are plotted with the calculated rut depth values (eq 1). The calculations use the measured soil strengths of the thawed layer shown in Figure 22. The actual rut depth measurements show a significant variability, especially for the Arkansas Range. Figure 22 shows that the calculated values significantly underpredict the actual measured rut depths at high CI values. 


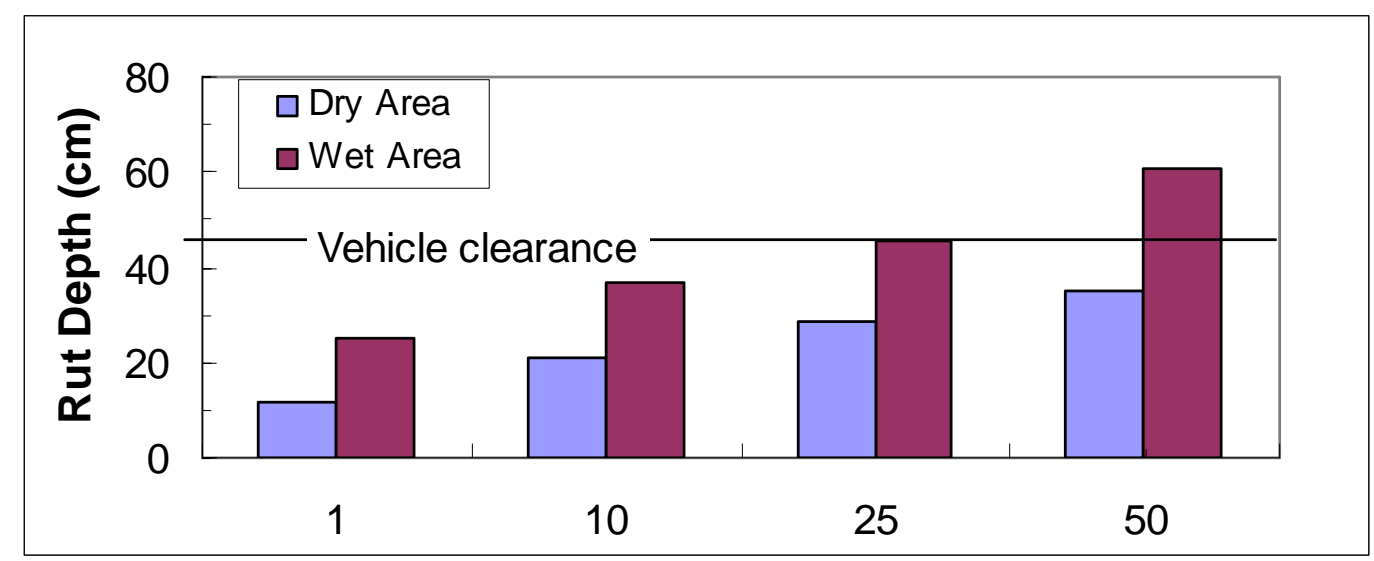

a. Number of passes for M60A3.

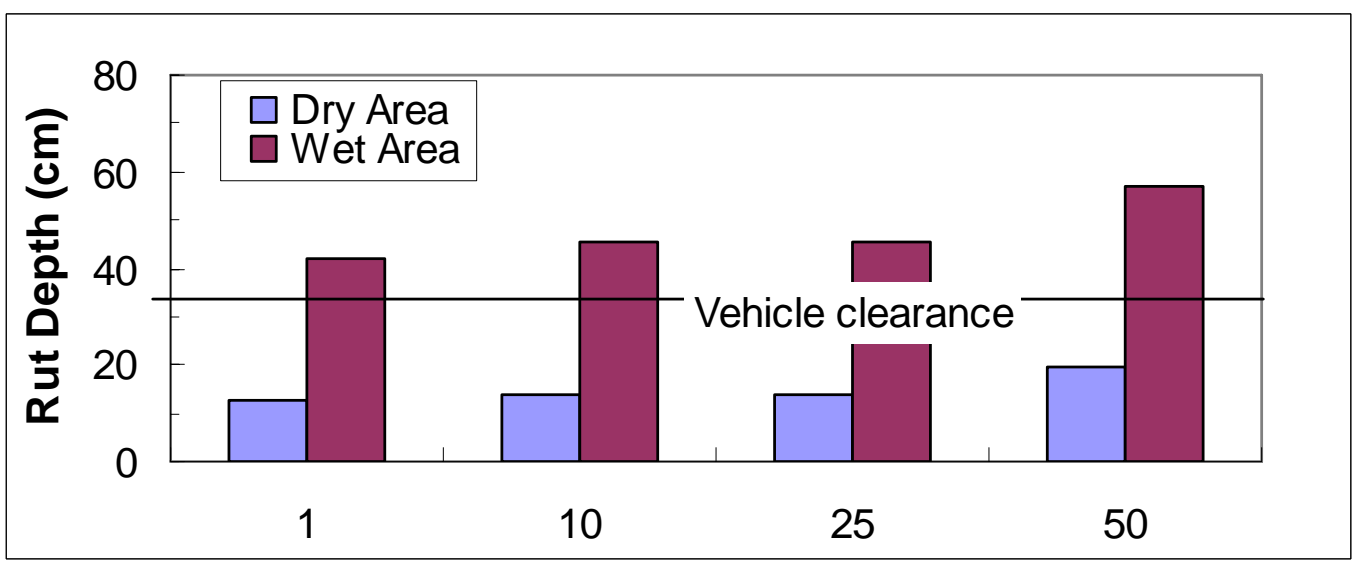

b. Number of passes for HEMTT.

Figure 21. Number of passes and rut depth relationships on the dry and wet sections of the wooded trail. 


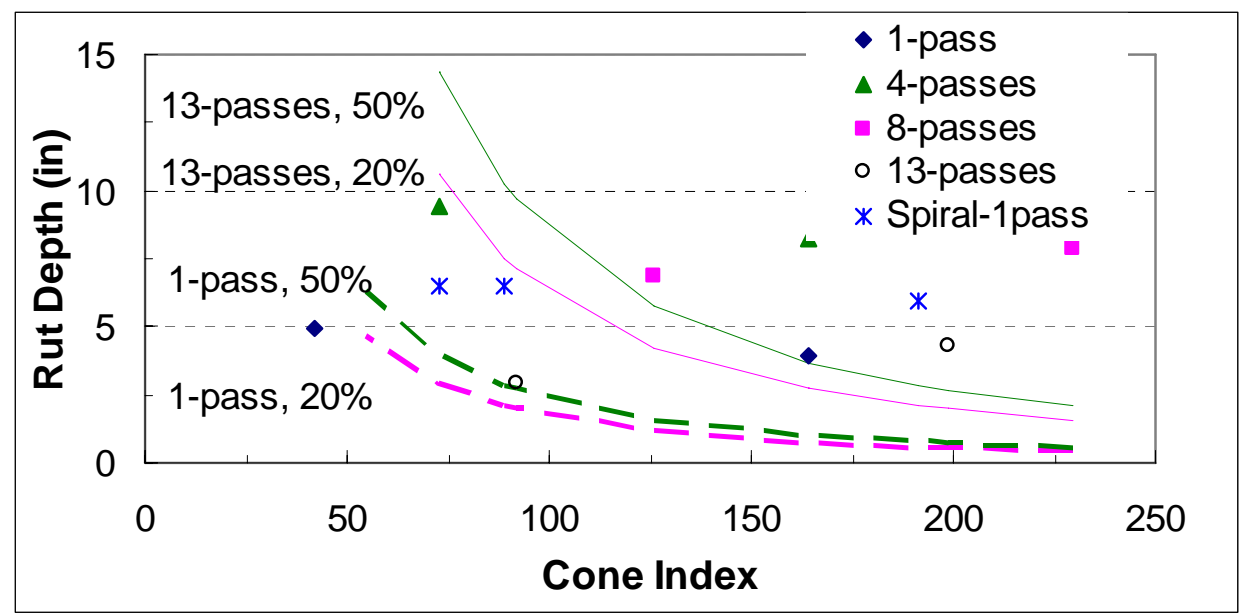

a. Arkansas Range.

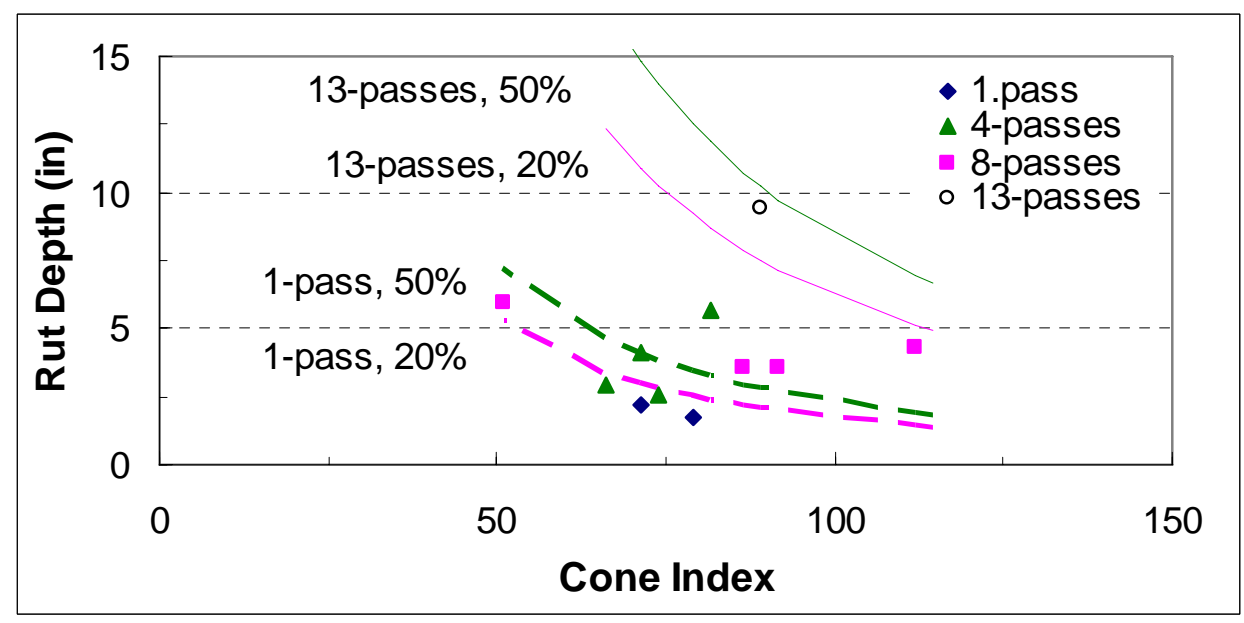

b. Eddy Drop Zone.

Figure 22. Comparison of measured rut depth to predicted rut depth using eq 1 for two values of wheel slip at Arkansas Range and Eddy Drop Zone.

The cone index (CI) was measured on the control sections at Fort McCoy with a value of 25 for 0 - to $15-\mathrm{cm}$ ( 0 to 6 in.) layer. The CI of 75 was measured on the wet section at depth of $15 \mathrm{~cm}$ (6 in.); on the dry section, the CI was measured to have a value of 98 at $16.5 \mathrm{~cm}(6.5 \mathrm{in}$.) from the surface. These CI values were used to calculate the estimated rut depths for the M60A3 and HEMTT vehicles. The comparison between the actual measurements and estimated rut depth are shown in Figure 23. It was observed that the wet section 
became impassable after 15 passes of the HEMTT as a result of rut depths exceeding the vehicle ground clearance (Kestler et al. 1999).

\subsection{Volumetric Soil Displacement}

The volume of the soil being displaced by the vehicle was computed based on the enclosed rut area within $1 \mathrm{~m}$ of the track length. The volumetric soil displacement is an average of the volume of soil displaced for left and right wheel paths. This analysis was calculated only for the Stryker data at DTA because these were the only data with comprehensive photos of rut depth from the profilometer measurements.

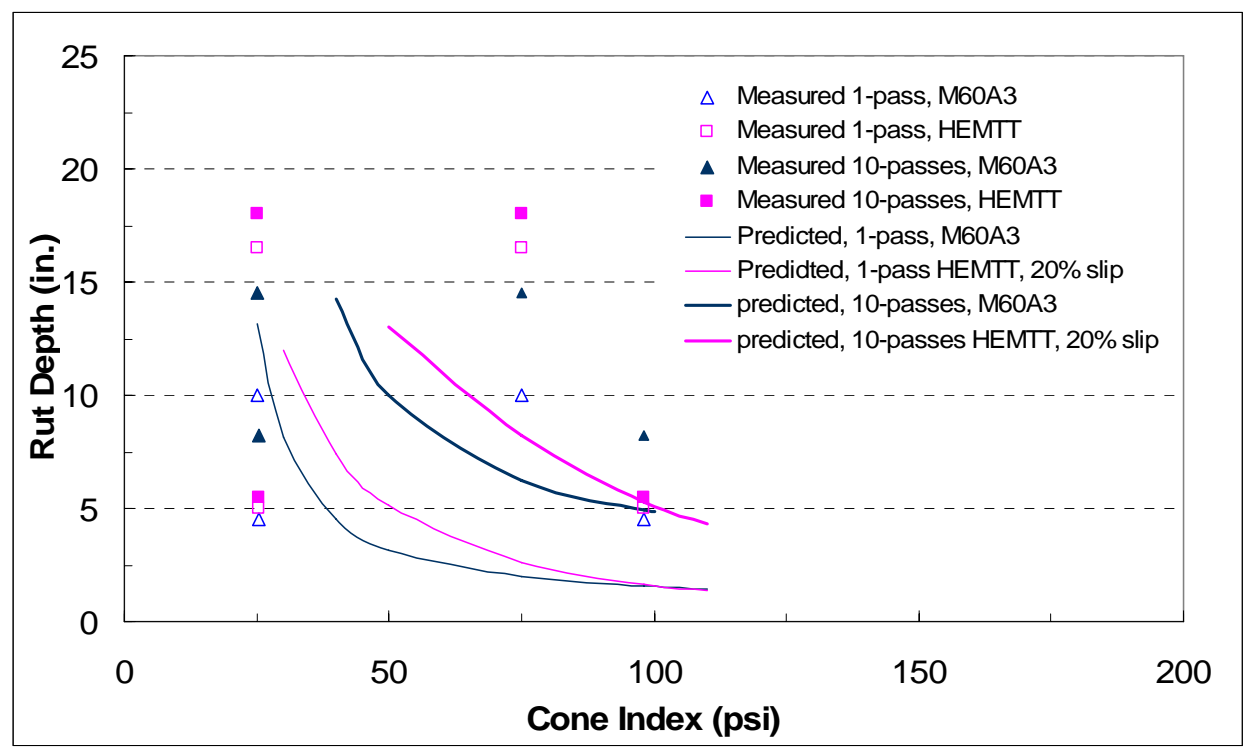

Figure 23. Comparison of measured rut depth to predicted rut depth using eq 1 and 2 on both control sections of the wooded trail.

The soil displacement showed an increase in volume as the number of passes increased, as shown in Figure 24. Note that turning radii of $150 \mathrm{~m}$ are assigned on the straight section of the multi-pass. At Arkansas Range the analysis was conducted only on the wet section since the disturbance was more significant there than on the drier section. The volumetric soil displacement on the one-pass and spiral sections is combined with a gradual increase as the turning radius decreases. The soil displacement for thirteen passes is three times more in volume than on the one-pass section, with a considerable increase as the turning radius decreases (Fig. 24a). Similarly, the volumetric soil displacement for thirteen passes at Eddy Drop Zone is fivefold higher than one pass on the straight 
section of the multi-pass section (Fig. 24b). The increase in soil displacement as the turning radius decreases is due to the wider track that is created, since the second, third, and fourth tires do not follow the first tire track.

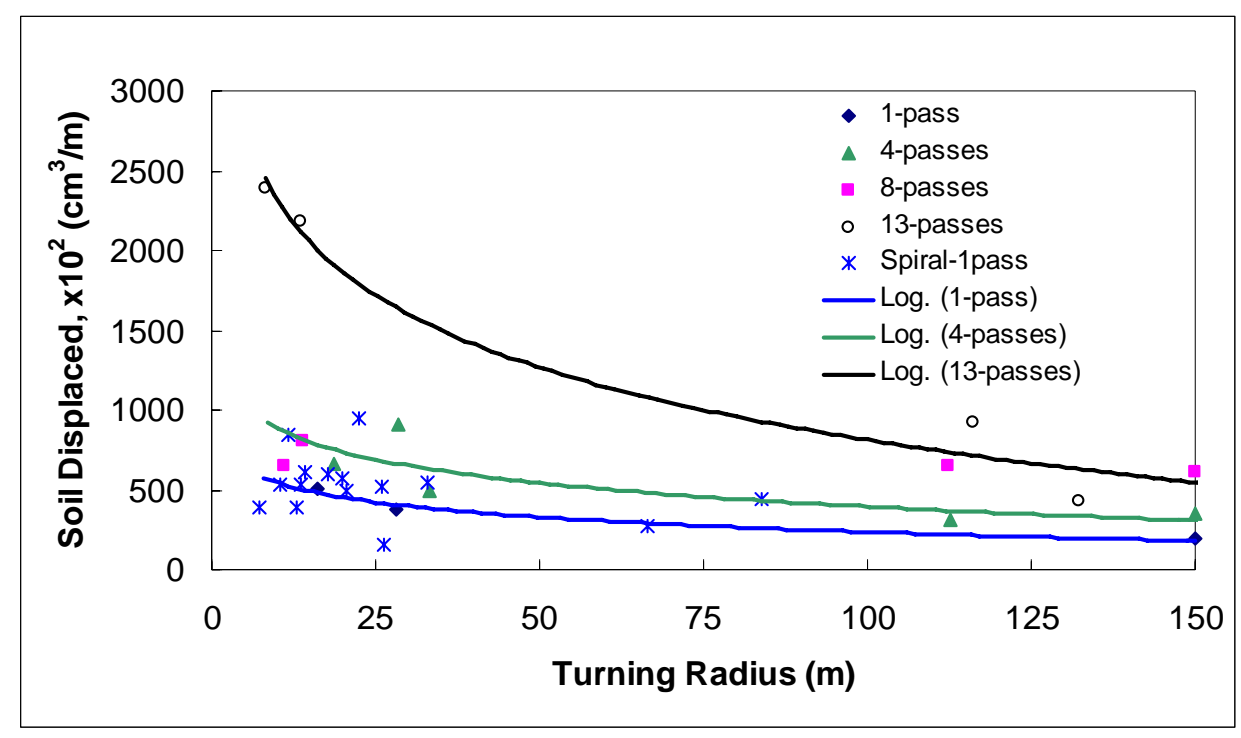

a. Arkansas Range.

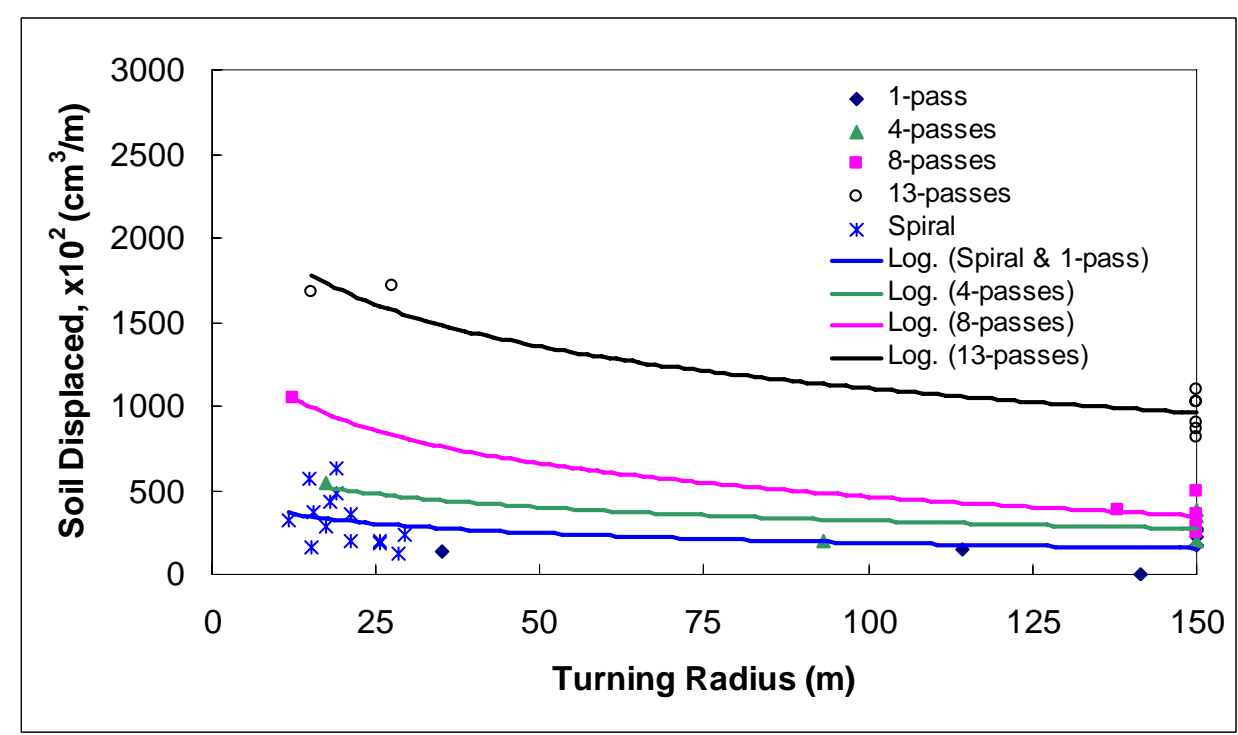

b. Eddy Drop Zone.

Figure 24. Stryker vehicle turning radius versus average volumetric soil displacement for the wet section at Arkansas Range and Eddy Drop Zone. 
Compiling the correlations between the volume of soil displaced and turning radius for Eddy DZ and Arkansas Range sites exhibited a series of relationships (Table 4). These relationships are derived from ranges of soil and vegetation conditions as a function of number of vehicle passes.

\begin{tabular}{|c|c|c|c|c|}
\hline $\begin{array}{c}\text { Maneuver } \\
\text { Tracks }\end{array}$ & Test conditions & Locations & $\begin{array}{c}\text { Correlations, where } \\
y=\text { vol. of soil displaced, } 10^{2}\left(\mathrm{~cm}^{3} / \mathrm{m}\right) \\
x=\text { turning radius }(\mathrm{m})\end{array}$ & $\begin{array}{c}\mathbf{R}^{2} \\
\text { values }\end{array}$ \\
\hline $\begin{array}{l}\text { Spiral and } \\
1 \text { pass }\end{array}$ & Dense vegetation & Eddy DZ & $y=-82.35 \ln x+566.45$ & 0.2436 \\
\hline 1 pass & Wet area & Arkansas & $y=-134.98 \ln x+856.88$ & 0.9690 \\
\hline \multirow[b]{2}{*}{4 passes } & Dense vegetation & Eddy DZ & $y=-115.23 \ln x+849.20$ & 0.5292 \\
\hline & Wet area & Arkansas & $y=-213.88 \ln x+1379.30$ & 0.6133 \\
\hline 8 passes & Dense vegetation & Eddy DZ & $y=-282.30 \ln x+1763.10$ & 0.9217 \\
\hline \multirow[b]{2}{*}{13 passes } & Sparse vegetation & Eddy DZ & $y=-359.21 \ln x+2759.70$ & 0.8943 \\
\hline & Wet area & Arkansas & $y=-654.70 \ln x+3827.90$ & 0.9672 \\
\hline
\end{tabular}

Correlations between soil displacement and rut depth are shown in Figure 25 for all DTA sites. The results showed a significant increase in volumetric soil displacement with increasing rut depth, indicating that the material was increasingly being moved rather than compressed. The deformation is due to plastic flow, which consisted of both compaction and shear of wet, thawed soil.

\subsection{Cumulative Impact Width}

The cumulative impact width was calculated only for the spiral and single pass sections of the multi-pass maneuver tests. Because the cumulative impact width accounts for only one tire track, the disturbance used in this analysis is for the outside tire track only (Fig. 26). Texas Range had significantly less cumulative impact width than Arkansas Range and Eddy Drop Zone (Fig. 26). This was attributable to shallow thaw at Texas Range, while Arkansas Range and Eddy Drop Zone had deeper thaw. The cumulative impact width trend for Texas Range appears to have a linear relationship to the turning radius (Fig. 26). In general, the cumulative impact width showed less on straight sections and higher as the vehicle is turning. This is due to the higher force required for the vehicle to turn, and generating larger shearing effect on to the thawed, soft soil. 


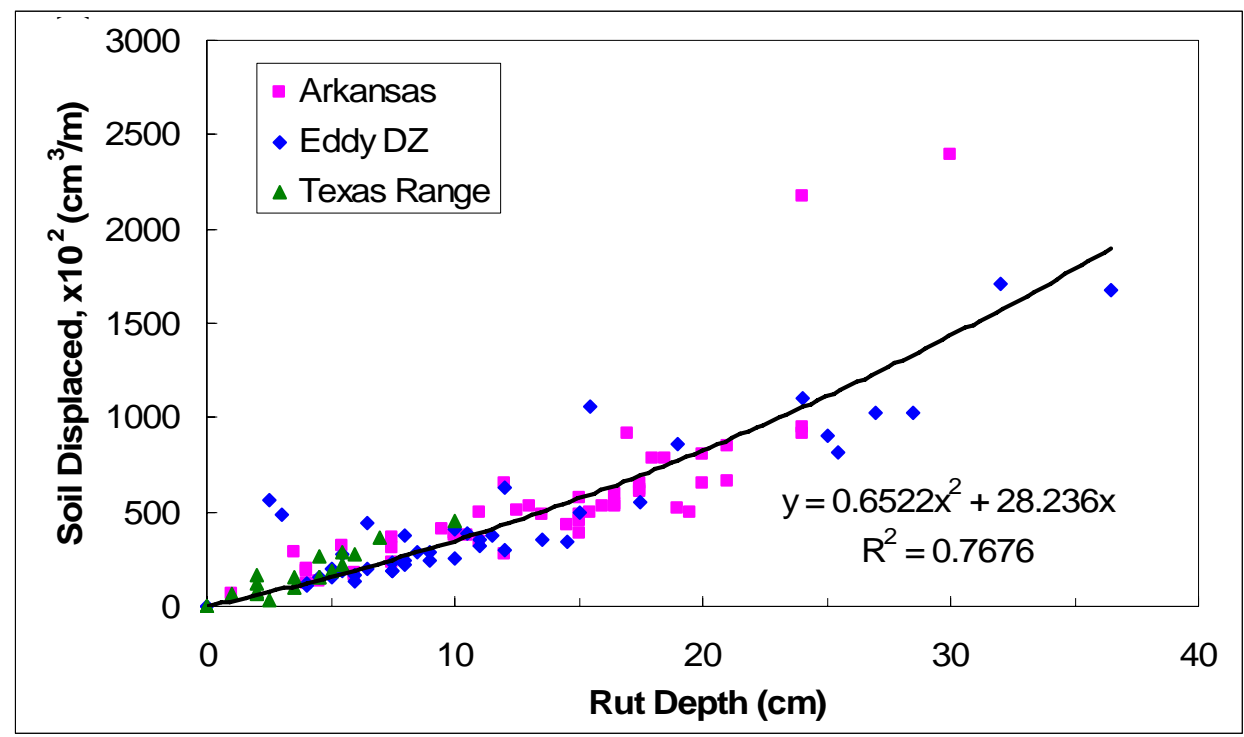

Figure 25. Rut depth versus average volumetric soil displacement at Arkansas Range, Eddy Drop Zone, and Texas Range.

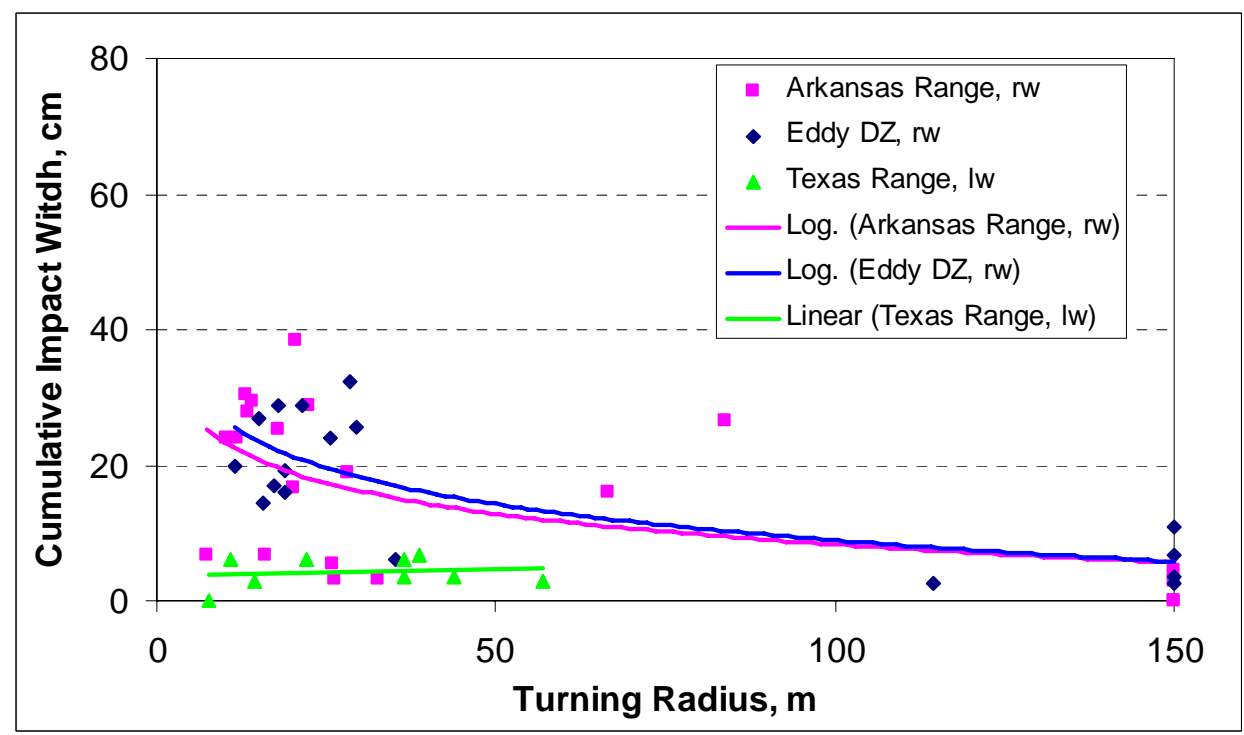

Figure 26. Stryker vehicle turning radius and cumulative impact width relationships for the outside tracks for Alaska sites (single pass and spiral only). Arkansas Range and Eddy Drop Zone are considered deep thaw; Texas Range has a shallow thaw depth. 
Figure 27 plots the comparison between disturbance on the left (inside track) and right (outside track) wheel paths as a function of turning radius at Arkansas Range. Results show that the inside track has a higher cumulative impact width than the outside track, especially as turns get tighter and with an increasing number of passes. This is because the vehicle's inside track generates a tighter turn than the outside track, thus creating a wider track and higher disturbance. The eight-pass for the outside track, however, shows a higher cumulative impact width than the thirteen-pass straight test as shown in Figure 27b. This was possibly due to the tire tracks of each pass not being in position on top of each other (tracks not laying on top of each pass).

Similarly, the cumulative impact width at the Eddy Drop Zone for the inner track (right wheel path) displays a higher cumulative impact width than the outer track, especially as the turns get tighter and as the number of passes increases (Fig. 28). The higher cumulative impact width when the vehicle is turning is due to the higher force required for the vehicle to turn. The straight section shows relatively similar cumulative impact widths on both right and left wheel tracks, as would be expected.

The single-pass cumulative impact width and turning radius relationships for other vehicles, such as the LAV, M113, and M1A1, that were derived from various training sites during summer conditions on unfrozen terrain, are used for comparison. Using the relationship from the Arkansas Range data (for the inside wheel track), the Stryker's cumulative impact width on thawing ground showed not as severe at small turning radius compared to the other military vehicles, as seen in Figure 29. The disturbance to the vegetation and soil is greater for the Stryker vehicle on thawed terrain than for the M113, a tracked vehicle on terrain under normal conditions, at turning radius between $40 \mathrm{~m}$ and $150 \mathrm{~m}$ (straight path). 


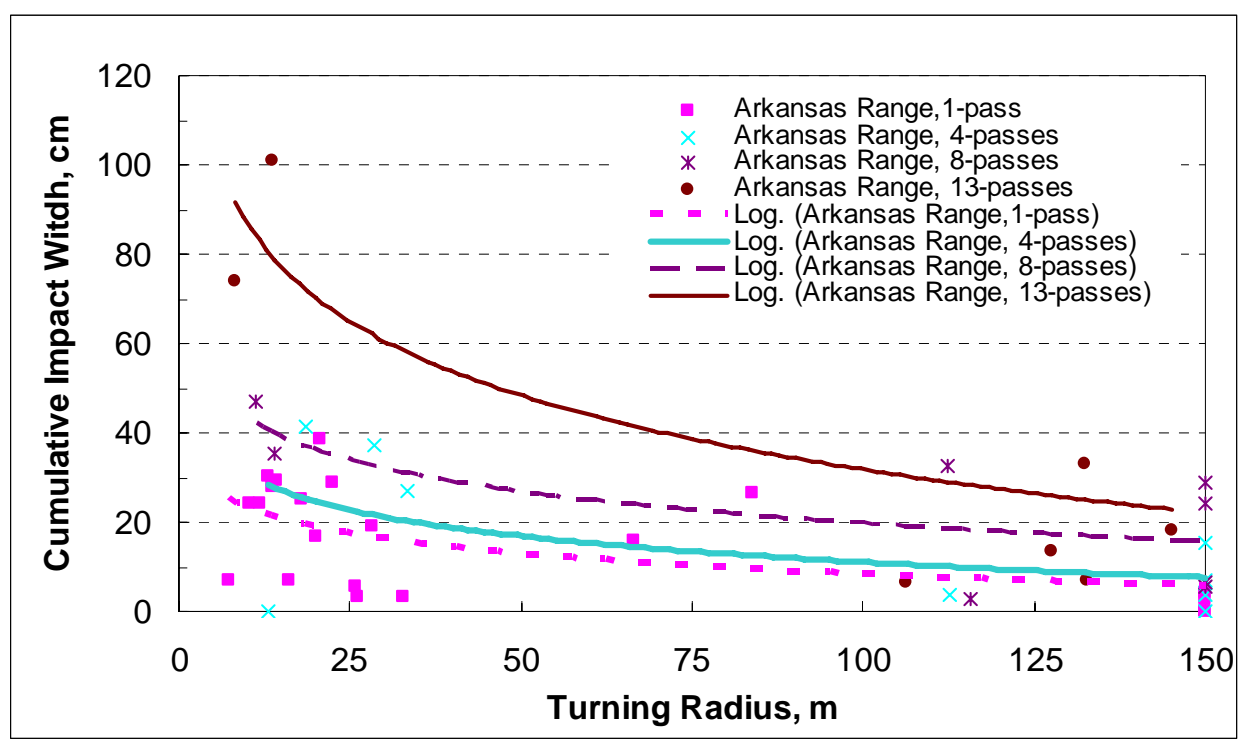

\section{a. Inside track.}

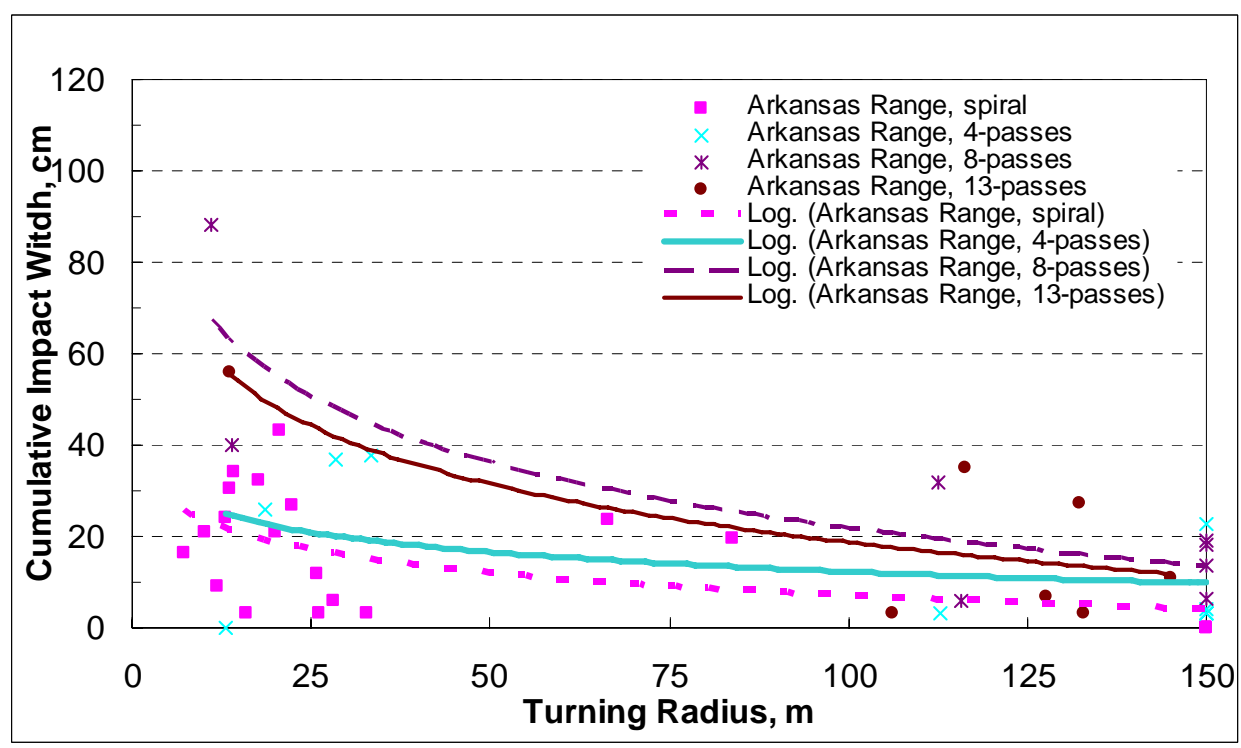

b. Outside track.

Figure 27. Turning radius and cumulative impact width of single and multipass tests at Arkansas Range. 


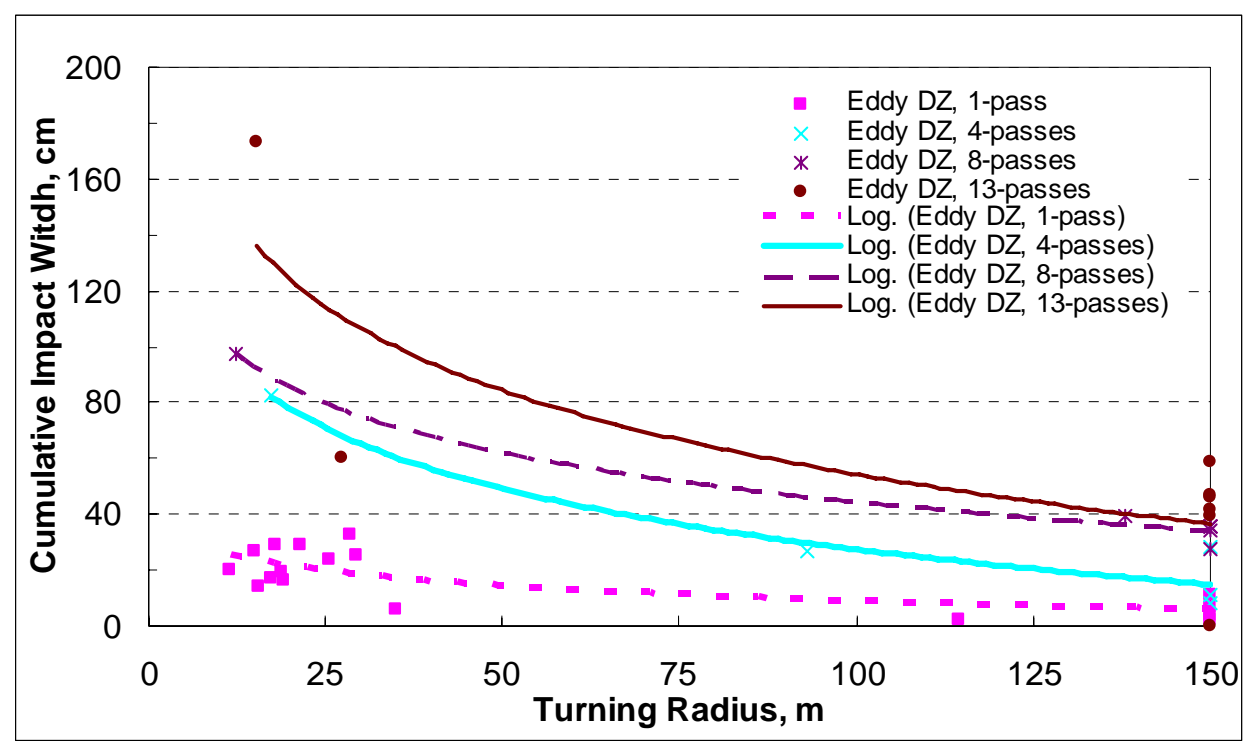

a. Inside track.

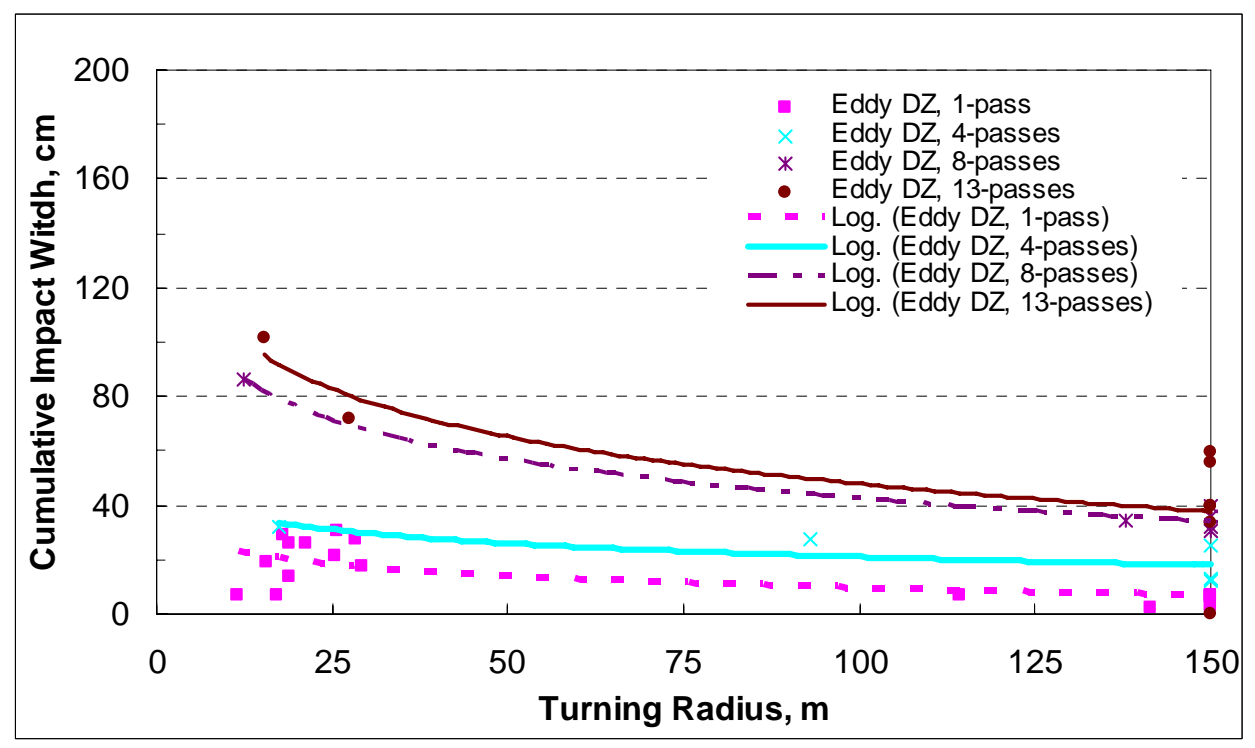

b. Outside track.

Figure 28. Right and left wheel plots of turning radius versus cumulative impact width for single and multi-pass runs at Eddy Drop Zone. 


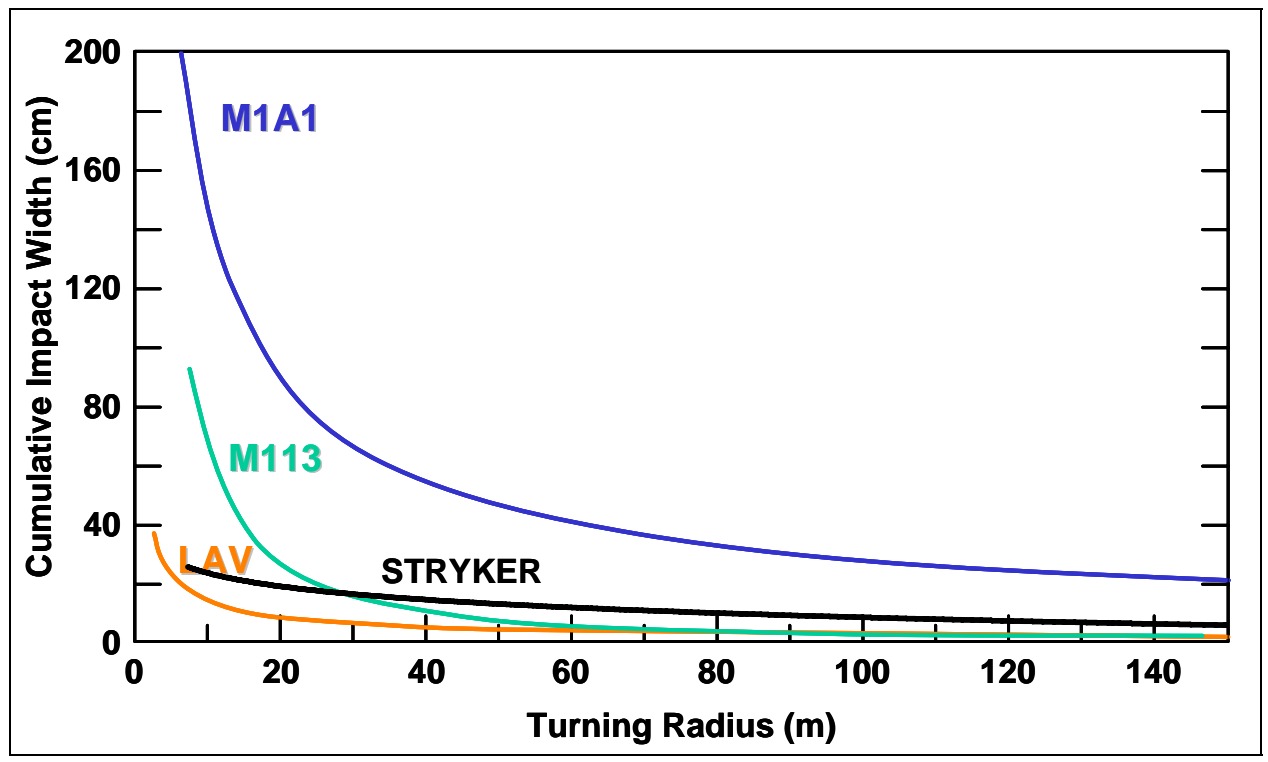

Figure 29. Comparison of cumulative impact width versus turning radius for various military vehicles for single pass. LAV, M113, and M1A1 data were collected from other military lands during the summer season (Ayers et al. 2000, Haugen 2002, Haugen et al. 2002).

\subsection{Disturbance on Winter Terrain}

There were no measurable ruts at both the multi-pass and spiral section during the winter disturbance test. Figure 30 is a rut profile at the thirteen-pass section of the multi-pass section. The impact severity of $10 \%$ resulted from the survey showing the track imprint with vegetation roots still intact, laying down of vegetation, and few broken branches. 


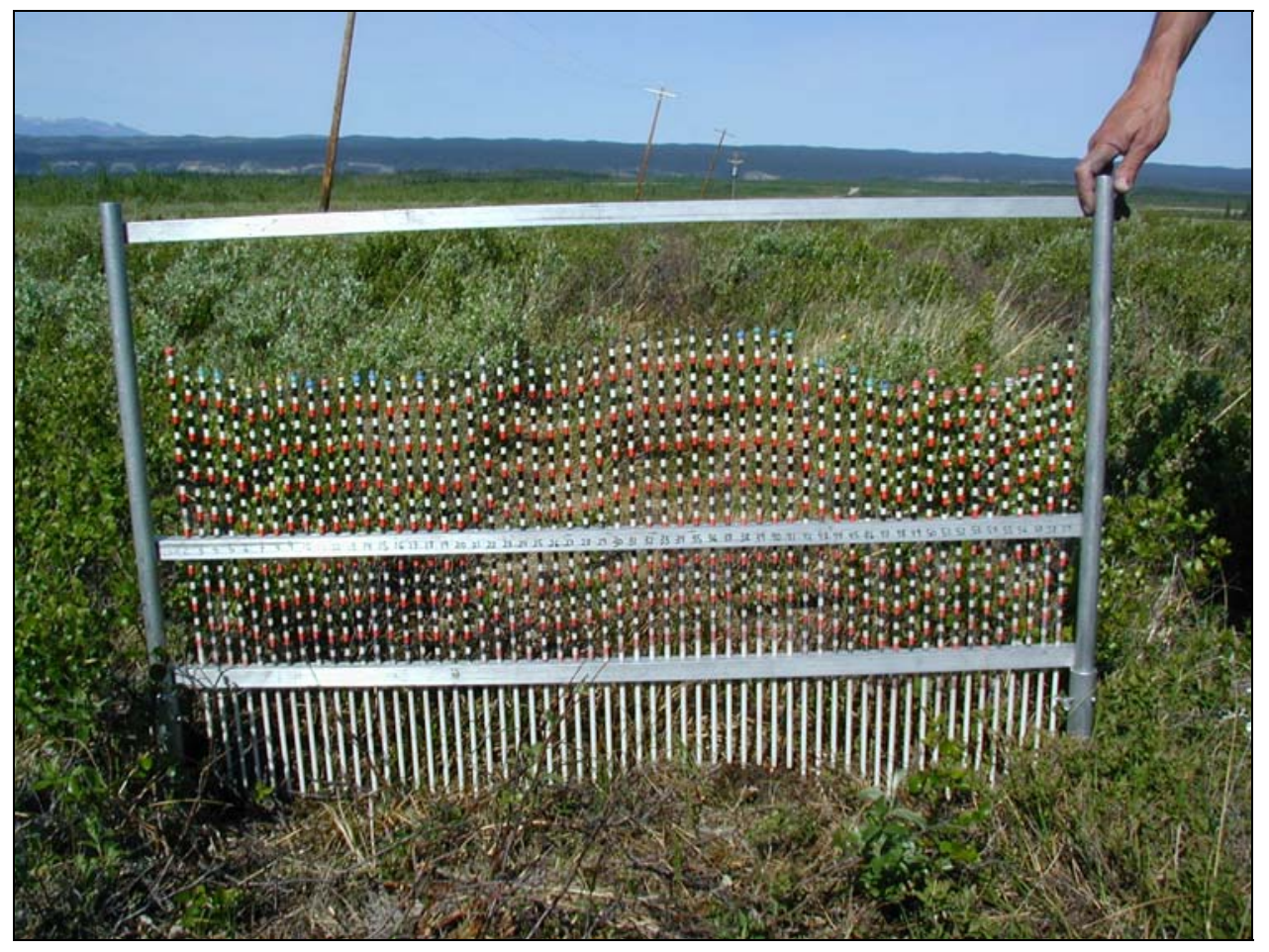

Figure 30. Minor vegetation disturbance and no measurable rut depth resulted from the winter disturbance test. 


\section{$7 \quad$ DISCUSSION}

In general, the ruts that resulted from the Stryker test depended on how deep the thaw was in the area. In some areas, rut depth was the same as thaw depth, while in other areas, rut depth was less than thaw depth. Rut depth was limited when thaw depth was shallow, as seen at Texas Range. Rut depth was deeper in wet areas, such as wet sections of the spiral and multi-pass at Arkansas Range, and wet control section on the wooded trail at Fort McCoy. Rut depths also were severe in areas with sparse vegetation at Eddy Drop Zone. The dense vegetative area at Eddy Drop Zone showed relatively less rutting than the sparse vegetation that was previous disturbed, indicating the additional flotation provided by the vegetation.

Rut depth increased as the number of vehicle passes increased, as observed at Arkansas Range, Eddy Drop Zone, and control sections at Fort McCoy. As rut depth increased, the volumetric soil displacement also increased, resulting in a polynomial relationship from the Stryker ruts at DTA. The volumetric soil displacement increased considerably as the number of passes increased on straight paths and was significantly higher on tighter turns. As the turning radius decreased, a gradual increase was observed in the volumetric soil displacement on the one-pass and spiral sections. A more drastic increase in the volumetric soil displacement with increasing number of vehicle passes was observed as the turning radius decreased. The results also show that the disturbance was more severe on turns than on straight sections.

No correlation was found between moisture content and rut depth. Similarly, there was no correlation found between rut depth and speed. The Stryker's speed was considered to be low.

CI values from the $12.83-\mathrm{mm}-(0.505$-in.-) diameter cone are found to be noticeably variable, and are quite high for the thawed layer. The variability could be attributed to nonhomogenous soil and vegetation conditions. Rut depth estimation of semi-empirical equations showed underpredicting of the measured rut depth at high CI values. The CI values used in the equations were measured from the thawed layer. These equations, however, were developed on soft soil with no layering effects such as frost depth, and no vegetative cover.

The disturbance to the terrain was minimal (tire imprint with vegetation still intact) when the ground was totally frozen, such as the case for Texas Range. Severe disturbances occurred in locations during thaw, including deep ruts, piles, and clumps of dirt piled on the side of the ruts. 
For the most part, the Stryker vehicle showed a vehicle impact profile similar to the other military vehicles. The disturbance to the vegetation and soil for the Stryker vehicle on thawed soil is within the range or even higher than the M113, although the vehicle impact relationships for the M1A1, M113, and LAV were derived from tests on terrain with no influence of freezing and thawing conditions. However, the Stryker vehicle impact is minimal for shallow thaw and within the trend of LAV, the Stryker predecessor. The terrain disturbance from the off-road vehicle operations varies from site to site depending on the ground conditions.

Minimal vegetation disturbance and no rutting were observed in winter when the ground was frozen, even with limited snow cover. This area could have severe rutting and vegetation disturbance if the test is conducted during spring thaw and would have detrimental consequences to the permafrost. 


\section{CONCLUSION}

Rutting and disturbance from off-road vehicles can be quantified using rut depth, impact severity, and volumetric soil displacement. It is important to note that rut depth is not equal to impact severity. Rut depth is a measure of the terrain deformation by the vehicle tire, while the impact severity is the physical disturbance, which is related to vegetation damage and underlying soil exposure caused by the vehicle traffic.

It is essential to understand that findings from the studies during the spring thaw season are for the worst-case scenario when terrain is trafficked using large and heavy military vehicles. The following findings can be concluded from this study:

a. Rut depth and cumulative impact width are minimal when thaw depth is shallow. Off-road vehicles can traverse when thaw depth is less than $6 \mathrm{~cm}$ with minimal disturbance and limited ecological consequences. The underlying frozen layer helps minimize the disturbance and helps support the vehicle load.

b. The deformation of the loose, weak, thawing layer is largely plastic, consisting of both compaction and shear, which corresponds to severe rutting on saturated soils and with deeper thaw. Vehicles should not be allowed to traverse on the terrain during these conditions. It may be necessary to monitor terrain conditions before conducting any off-road vehicle traffic.

c. Rut depth, volumetric soil displacement, and cumulative impact width are relatively moderate on areas with dense vegetation (short bushes) and when thaw depth is shallow. During wet soil conditions, vehicular traffic should avoid areas that were previously disturbed, because the vegetation is damaged and may not provide adequate support.

d. It is expected that rut depth and volumetric soil displacement increase with increasing number of vehicle passes. Because the soil bearing capacity is insufficient when spring thaw occurs as a result of its saturated condition, repetitive loading should be avoided.

e. Disturbance in terms of volumetric soil displacement and cumulative impact width are significantly higher when vehicles are performing turning maneuvers than on a straight path. The 
vehicle requires higher tractive force in order to turn. Vehicle impact to the soil and vegetation was relatively higher on the inside track than on the outside track when the vehicle was turning. Vehicles with more than two axles, such as the Stryker and HEMTT, will create a wider track because the second, third, and fourth tires do not follow the first tire track, especially on tighter turns.

f. Cumulative impact width and turning radius relationship for the Stryker vehicle showed a pattern similar to other military vehicles. The relationship can be used as a baseline for additional measurements for summer or dry conditions.

g. Estimation of rut depth using the semi-empirical equations underpredicted the measured rut depth under thawing and saturated conditions. The semi-empirical rut depth equations can predict a single-pass rut depth under normal soil conditions.

h. The frozen ground occurring in winter allows vehicles to utilize permafrost terrain and wet areas that are not maneuverable in summer. Off-road operations, especially military exercises, can be maximized in winter in order to limit the disturbance to soil and vegetation. 


\section{RECOMMENDATIONS}

Recovery study on the vegetation and healing of soil (ground) due to freezethaw action should be evaluated. This is important for development of planning strategy (timing or rotation) of training lands in order to maximize the capacity but limit the disturbance consequences.

In the literature review, there was no topic being discussed or studied on disturbance and rutting of off-road vehicles due to high speed, including acceleration. One can expect that the disturbance is severe when a vehicle is traversing on soft soil terrain at high speed. Fast acceleration could shear off vegetation and displace large amounts of soil, creating a severe impact on the terrain. Recommendation on these topics in future should include research impact studies.

GIS applications and GPS units to track off-road vehicle disturbance have been used recently on several research studies. These tools are helpful for quantifying the impact of off-road vehicles, and observation on terrain recovery assessment can be easily surveyed. Aerial photos also can be used to observe terrain disturbance from off-road vehicles.

Limited studies have been conducted on the influence of vegetation as an additional bearing strength of the ground (soil) to support the vehicle load, thus minimizing the disturbance. The strength of vegetation layer such as the root systems and vegetation mat can be difficult to quantify. It would be helpful to determine the tensile and compression strengths of various vegetation types and layer thickness. 


\section{REFERENCES}

Abele, G., D.A. Walker, J. Brown, M.C. Brewer, and D.M. Atwood (1978) Effects of low ground pressure vehicle traffic on tundra at Lonely, Alaska. U.S. Army Cold Regions Research and Engineering Laboratory, Hanover, New Hampshire, Special Report 78-16.

Abele, G., J. Brown, and M.C. Brewer (1984) Long-term effects of off-road vehicle traffic on tundra terrain. Journal of Terramechanics, Volume 21, No. 3, p. 283-294.

Affleck, R.T., S. Shoop, K. Simmons, and P. Ayers (2004a) Disturbance from off-road vehicle during spring thaw. In Proceedings, 12th American Society of Civil Engineers, International Winter Construction Symposium and Expo on Cold Regions Engineering, Alberta, Canada, 16-19 May 2004.

Affleck, R.T., S. Shoop, G. Larsen, E. Clark, C. Collins, and J. Reagan (2004b) Stryker terrain impact tests at Donnelly Training Area, Integrated Training Area Management (ITAM), Issue 23, March 2004.

Aitken, G.W. (1964) Ground temperature observations: Big Delta, Alaska. U.S. Army Cold Regions Research and Engineering Laboratory, Hanover, New Hampshire, CRREL Technical Report 104.

Andersland, O.B., and B. Ladanyi (1994) An Introduction to Frozen Ground Engineering. New York: Chapman and Hall.

ASAE Standard S313.3 (1999) Soil cone penetrometer.

Aust, W.M., M.D. Tippett, J.A. Burger, and W.H. McKee (1995) Compaction and rutting during harvesting affect better drained soils more than poorly drained soils on wet pine flats. Southern Journal of Applied Forestry, Volume 19, Number 2, p. 72-77, May 1995.

Ayers, P. (1994) Environmental damage from tracked vehicles operations. Journal of Terramechanics, 14(3): 173-183.

Ayers, P., M. Vance, L. Haugen, and A.B. Anderson (2000) An evaluation of DGPS-based continuously operating vehicle monitoring systems to determine site-specific event severity factors. U.S. Army Engineer Research and Development Center, Construction Engineering Research Laboratory, Champaign, Illinois, ERDC/CERL Technical Report TR-00-43.

Braunack, M. (1986a) Changes in physical properties of two dry soils during tracked vehicle passage. Journal of Terramechanics, 23(3): 141-151. 
Braunack, M. (1986b) The residual effects of tracked vehicles on soil surface properties. Journal of Terramechanics, 23(1): 37-50.

Emers, M., J.C. Jorgenson, and M.K. Raynolds (1995) Response of arctic tundra plant communities to winter vehicle disturbance. Canadian Journal of Botany, 73: 905-917.

Everett, K.R., B.M. Murray, D.F. Murray, A.W. Johnson, A.E. Linkins, and P.J. Webber (1985) Reconnaissance observations of long-term natural vegetation recovery in the Cape Thompson region, Alaska, and additions to the checklist of flora. U.S. Army Cold Regions Research and Engineering Laboratory, Hanover, New Hampshire, CRREL Report 85-11.

Gatto, L.W. (2002) Sediment dynamics in vehicle ruts. In Proceedings of 12th International Soil Conservation Organization (ISCO), Volume 2, p. 393-399.

Gersper, P.L, and J.L. Challinor (1975) Vehicle perturbation effects upon a tundra soil-plant system: I. Effects on morphological and physical environmental properties of the soils. Soil Science Society of America Proceedings, 39, p. 737744.

Halvorson, J.J., D.K. McCool, L.G. King, and L.W. Gatto (2001) Soil compaction and over-winter changes to tracked-vehicle ruts, Yakima Training Center, Washington. Journal of Terramechanics, Volume 38, p. 133-151.

Haugen, L. (2002) Design and testing of a vehicle tracking system for monitoring environmental impact at U.S. Army Training Installations. MS thesis, Colorado State University, Fort Collins, Colorado.

Haugen, L.B., P.D. Ayers, A.B. Anderson, and P.E. Nissen (2002) Using GPS to evaluate movement patterns and impacts during training maneuvers. In Proceedings of the 14th International Society for Terrain-Vehicle Systems (ISTVS), Vicksburg, Mississippi.

Hok, J. (1969) A reconnaissance of tractor trails and related phenomena on the north slope of Alaska. Bureau of Land Management, U.S. Department of Interior, Anchorage, Alaska, p. 66.

Jorgenson, M.T., J.E. Roth, E.R. Pullman, C.T. Schick, B.A. Anderson, S.F. Schlentner, A.G. Palmer, J.H. Boisvert (2004) An ecological land evaluation for Fort Richardson, Alaska: Trafficability, disturbance, and habitat use. Prepared by ABR, Inc., for U.S. Army Alaska, Directorate of Public Works. 
Kestler, M.A., S.A. Shoop, K.S. Henry, J.A. Stark, and R.T. Affleck (1999)

Rapid stabilization of thawing soils for enhanced vehicle mobility: A field demonstration project. U.S. Army Cold Regions Research and Engineering Laboratory, Hanover, New Hampshire, CRREL Report 99-3.

Lawson, D.E. (1982) Long-term modifications of perennially frozen sediment and terrain at East Oumalik, northern Alaska. U.S. Army Cold Regions Research and Engineering Laboratory, Hanover, New Hampshire, CRREL Report 82-36.

Nugent, C., C. Kanali, P.M.O. Owende, M. Nieuwenhuis, and S. Ward (2003) Characteristic site disturbance due to harvesting and extraction machinery traffic on sensitive forest sites with peat soils. Forest Ecology and Management, Volume 180, p. 85-98.

Racine, C.H., and G.M. Ahlstrand (1985) Thaw response of tussock-shrub tundra to experimental all-terrain vehicle disturbance in South-Central Alaska, Arctic, Volume 44, Number 1, p. 31-37.

Richmond, P., S. Shoop, and G. Blaisdell (1995) Cold Regions Mobility Models. U.S. Army Cold Regions Research and Engineering Laboratory, Hanover, New Hampshire, CRREL Report 95-1.

Shoop, S.A. (1993) Effect of soil thaw on off-road vehicle traction. In Proceedings, 6th International Conference on Permafrost, Beijing, China, 5-9 July 1993, Volume 1, p. 559-563.

Shoop, S., R. Affleck, C. Collins, and G. Larsen (2004a) Stryker brigade transformation impact on Alaska training lands. In Proceedings, Sustainable Range Management Conference, New Orleans, Louisiana, January 2004.

Shoop, S., R. Affleck, C. Collins, G. Larsen, and P. Sullivan (2004b) Maneuver analysis methodology to assess vehicle impacts on training lands. American Society of Agronomy Special Symposium on Assessing the Impact of Vehicular Traffic on Natural Areas, Denver, Colorado, November 2003, submitted as a Special Issue of the Journal of Terramechanics.

Slaughter, C.W., C.H. Racine, D.A. Walker, L.A. Johnson, and G. Abele (1990) Use of off-road vehicles and mitigation of effects of Alaska permafrost environments: A review. Environmental Management, Volume 14, p. 63-72.

Sparrow, S.D., F.J. Wooding, and E.H Whiting (1978) Effects of off-road vehicle traffic on soils and vegetation in the Denali Highway Region of Alaska. Journal of Soil and Water Conservation, 33, p. 20-27. 
Stone, D.M. (2002) Logging options to minimize soil disturbance in the Northern Lake States. Northern Journal of Applied Forestry, Volume 19, Number 3, p. 115-121.

Sullivan, P., and A. Anderson (2000) A methodology for estimating Army Training and Testing Area Carrying Capacity (ATTACC) vehicle severity factors and local condition factors. U.S. Army Engineer Research and Development Center, Construction Engineering Research Laboratory, Champaign, Illinois, ERDC/CERL Technical Report TR-00-02.

Walker, D.A., P.J. Webber, K.R. Everett, and J. Brown (1977) The effects of low-pressure wheeled vehicles on plant communities and soils at Prudhoe Bay, Alaska. U.S. Army Cold Regions Research and Engineering Laboratory, Hanover, New Hampshire, Special Report 77-17.

Walker, D.A., D. Cate, J. Brown, and C. Racine (1987) Disturbance and recovery of Arctic Alaskan tundra terrain: A review of recent investigations. U.S. Army Cold Regions Research and Engineering Laboratory, Hanover, New Hampshire, CRREL Report 87-11.

Willoughby, W.E., and G.W. Turnage (1990) Review of a procedure for predicting rut depth. Internal Working Document. 


\section{APPENDIX A: SUMMARY TABLES OF TEST DATA AND EXAMPLE PICTURES OF RUT PROFILE AT DTA}

Table A1. Test data from Arkansas Range Stryker vehicle impact test.

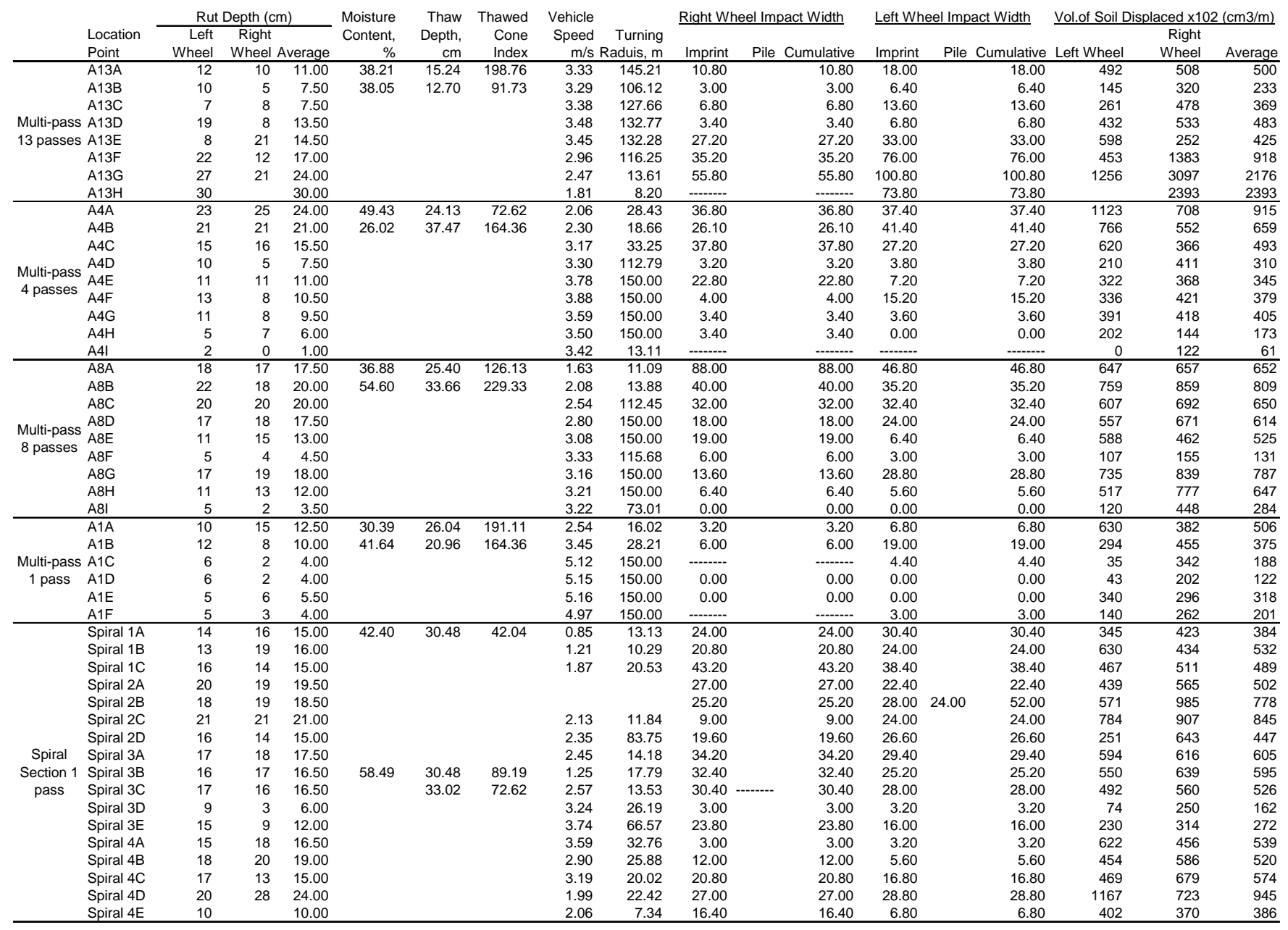


Table A2. Test data from Eddy Drop Zone Stryker vehicle impact test.

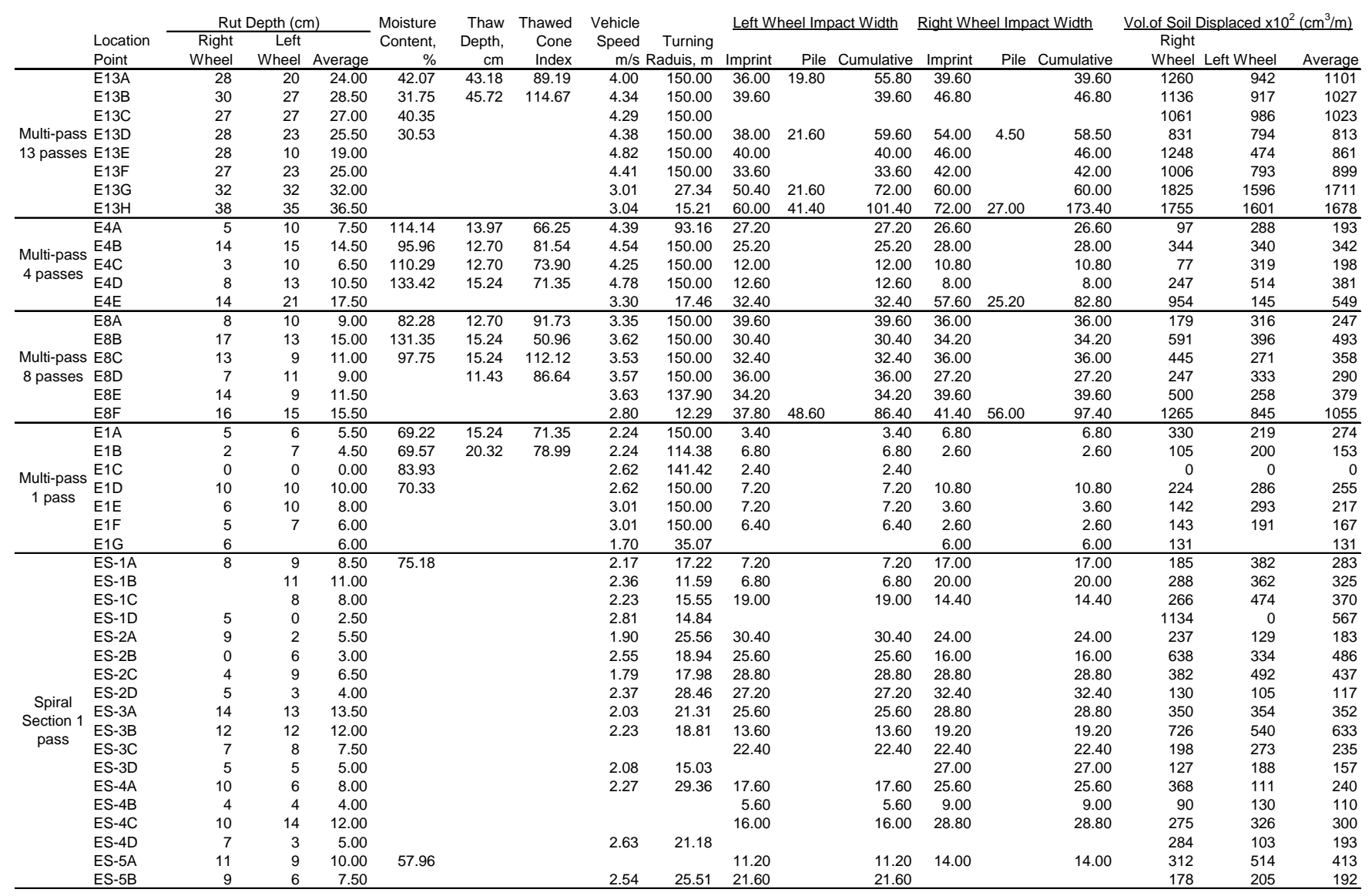


Table A3. Test data from Texas Range Stryker vehicle impact test.

\begin{tabular}{|c|c|c|c|c|c|c|c|c|c|c|c|c|c|c|}
\hline & \multirow[b]{2}{*}{$\begin{array}{l}\text { Location } \\
\text { Point }\end{array}$} & \multicolumn{3}{|c|}{ Rut Depth (cm) } & \multirow{2}{*}{$\begin{array}{r}\text { Moisture } \\
\text { Content } \\
(\%)\end{array}$} & \multirow{2}{*}{$\begin{array}{r}\text { Thaw } \\
\text { Depth } \\
(\mathrm{cm})\end{array}$} & \multirow{2}{*}{$\begin{array}{r}\text { Thawed } \\
\text { Cone } \\
\text { Index }\end{array}$} & \multirow{2}{*}{$\begin{array}{r}\text { Vehicle } \\
\text { Speed } \\
\mathrm{m} / \mathrm{s}\end{array}$} & \multicolumn{3}{|c|}{ Turning Cumulative Impact Width } & \multicolumn{3}{|c|}{ Vol.of Soil Displaced $\times 10^{2}\left(\mathrm{~cm}^{3} / \mathrm{m}\right)$} \\
\hline & & $\begin{array}{r}\text { Right } \\
\text { Wheel }\end{array}$ & $\begin{array}{r}\text { Left } \\
\text { Wheel }\end{array}$ & Average & & & & & $\begin{array}{r}\text { Raduis } \\
(\mathrm{m})\end{array}$ & Left Wheel & Right Wheel & Left Wheel & $\begin{array}{r}\text { Right } \\
\text { Wheel }\end{array}$ & Average \\
\hline & TSS1A & 0 & 0 & 0.00 & 356.75 & 7.62 & 61.16 & 2.34 & 7.82 & 0.00 & 0.00 & 0 & 0 & 0 \\
\hline & TSS1B & 0 & 0 & 0.00 & & & & & & & & 0 & 0 & 0 \\
\hline & TSS1C & 3 & 6 & 4.50 & & & & & & 3.20 & 6.80 & 251 & 48 & 149 \\
\hline & TSS1D & 0 & 0 & 0.00 & & & & & & & 2.20 & 0 & 0 & 0 \\
\hline & TSS2A & 2 & 5 & 3.50 & & & & & & 3.20 & 1.60 & 269 & 34 & 152 \\
\hline & TSS2B & 4 & 0 & 2.00 & & & & & & 2.60 & 6.80 & 0 & 125 & 63 \\
\hline & TSS2C & 10 & 10 & 10.00 & & & & 2.20 & 10.74 & 6.00 & 3.40 & 298 & 613 & 456 \\
\hline & TSS2D & 4 & 6 & 5.00 & & & & 2.38 & 14.40 & 3.00 & 2.40 & 313 & 71 & 192 \\
\hline & TSS3A & 3 & 6 & 4.50 & & & & & & 3.00 & 3.00 & 378 & 156 & 267 \\
\hline Spiral & TSS3B & 4 & 0 & 2.00 & & & & & & 2.60 & 3.80 & 0 & 247 & 124 \\
\hline Section & 1 TSS3C & 11 & 3 & 7.00 & & & & 3.28 & 36.41 & 6.00 & 30.40 & 199 & 529 & 364 \\
\hline pass & TSS3D & 0 & 0 & 0.00 & & & & 2.95 & 21.99 & 6.00 & 5.60 & 0 & 0 & 0 \\
\hline & TSS4A & 6 & 5 & 5.50 & & & & & & 3.80 & 2.80 & 145 & 422 & 284 \\
\hline & TSS4B & 3 & 4 & 3.50 & & & & & & & 3.40 & 108 & 82 & 95 \\
\hline & TSS4C & 4 & 5 & 4.50 & & & & 3.28 & 36.41 & 3.60 & 3.80 & 97 & 212 & 155 \\
\hline & TSS4D & 11 & 0 & 5.50 & & & & 3.40 & 29.09 & & 9.60 & 0 & 451 & 226 \\
\hline & TSS4E & 0 & 4 & 2.00 & & & & & & 3.20 & 0.00 & 334 & 0 & 167 \\
\hline & TSS5A & 12 & 0 & 6.00 & 274.55 & 7.62 & 53.51 & 3.71 & 38.67 & 6.80 & & 0 & 543 & 271 \\
\hline & TSS5B & 4 & 0 & 2.00 & & & & & & & 10.80 & 0 & 157 & 79 \\
\hline & TSS6A & 5 & 0 & 2.50 & & & & 4.12 & 56.79 & 3.00 & 3.40 & 0 & 77 & 38 \\
\hline & TSS6B & 0 & 2 & 1.00 & & & & 4.95 & 43.66 & 3.60 & 5.60 & 121 & 0 & 61 \\
\hline
\end{tabular}


Table A4. Test data from the M60 and HEMTT vehicles, from the control sections along the wooded trail at Fort McCoy, Wisconsin.

\begin{tabular}{|c|c|c|c|c|c|c|c|c|c|c|c|c|c|}
\hline \multirow[b]{2}{*}{ Stations } & \multirow{2}{*}{$\begin{array}{l}\text { Date } \\
\text { measured }\end{array}$} & \multirow[b]{2}{*}{ Vehicle } & \multicolumn{3}{|c|}{$\frac{\text { Left Rut Depth }(\mathrm{cm})}{\text { Number of passes }}$} & \multicolumn{4}{|c|}{$\frac{\text { Right Rut Depth }(\mathrm{cm})}{\text { Number of passes }}$} & \multicolumn{2}{|c|}{ Soil Strength } & \multirow{2}{*}{$\begin{array}{l}\text { Thaw } \\
\text { Depth } \\
\text { (cm) }\end{array}$} & \multirow{2}{*}{$\begin{array}{l}\text { Grav } \\
\text { Water } \\
\text { Content } \\
(\%)\end{array}$} \\
\hline & & & 1 & 10 & 25 & 50 & 1 & 10 & 25 & $50 \mathrm{ClO}-6$ & $\mathrm{Cl}$ & & \\
\hline $1+50$ to $2+50$ & $3 / 24 / 1$ & M60 & $\overline{10}$ & 25 & 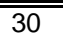 & 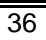 & $\overline{13}$ & $\overline{177}$ & $\overline{27}$ & 3425.33 & 98@6.5 & & 15.27 \\
\hline $7+00$ to $8+25$ & $3 / 24 / 1$ & M60 & 28 & 38 & 46 & 61 & 23 & 36 & 46 & 6125.00 & 75@6 & & 21.83 \\
\hline $1+50$ to $2+50$ & $3 / 26 / 1$ & HEMTT & 10 & 13 & 13 & 23 & 15 & 15 & 15 & 17 & & 31.2 & \\
\hline $7+00$ to $8+20$ & $3 / 26 / 1$ & HEMTT & 46 & 53 & 53 & 53 & 38 & 38 & 38 & 61 & & 16 & \\
\hline
\end{tabular}

A few rut profiles at DTA are shown on the following pages. 


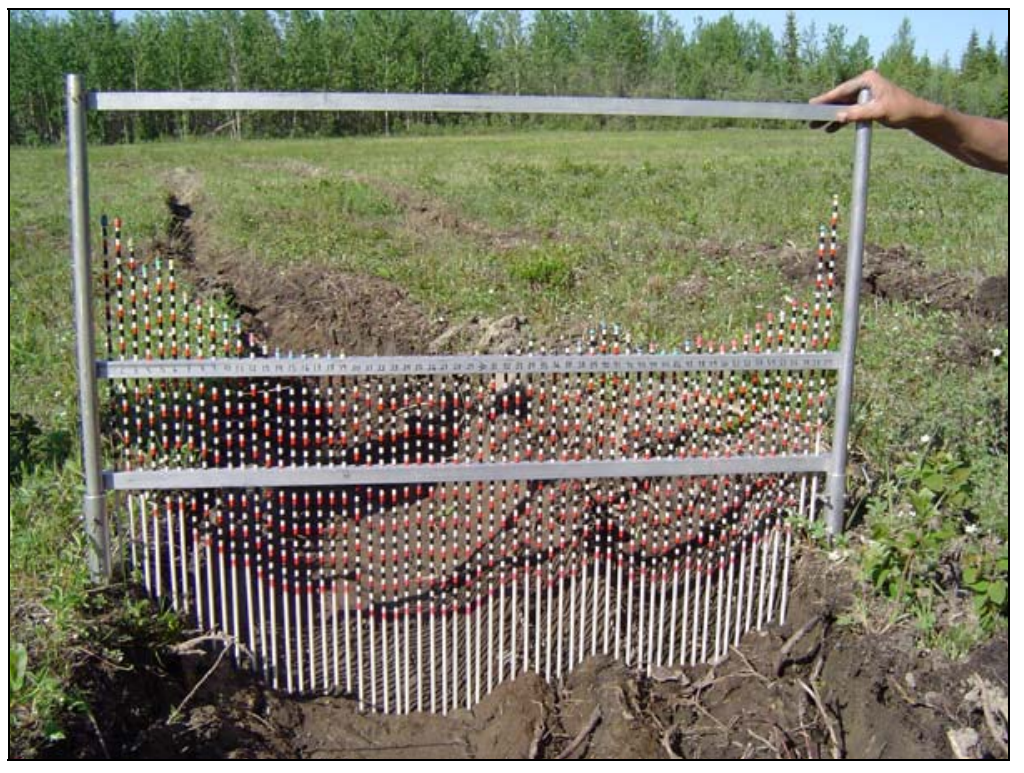

a. Left track.

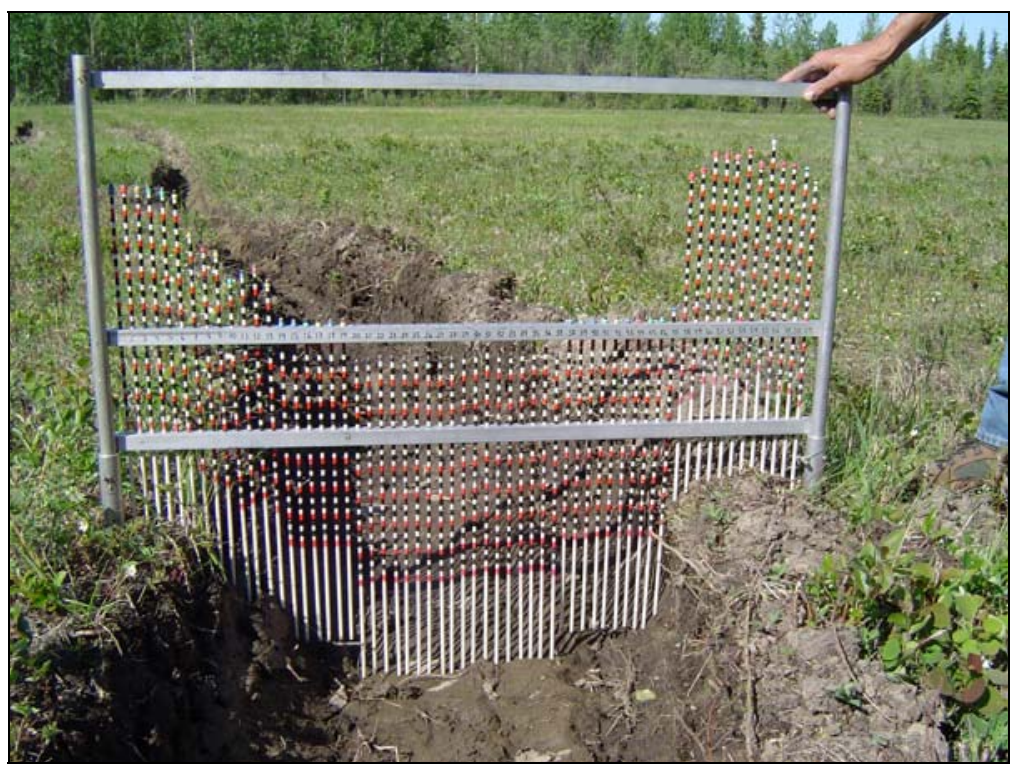

b. Right track.

Figure A1. Rut profiles on point $\mathrm{A} 13 \mathrm{H}$ on turn section of thirteen-pass at the Arkansas Range. 


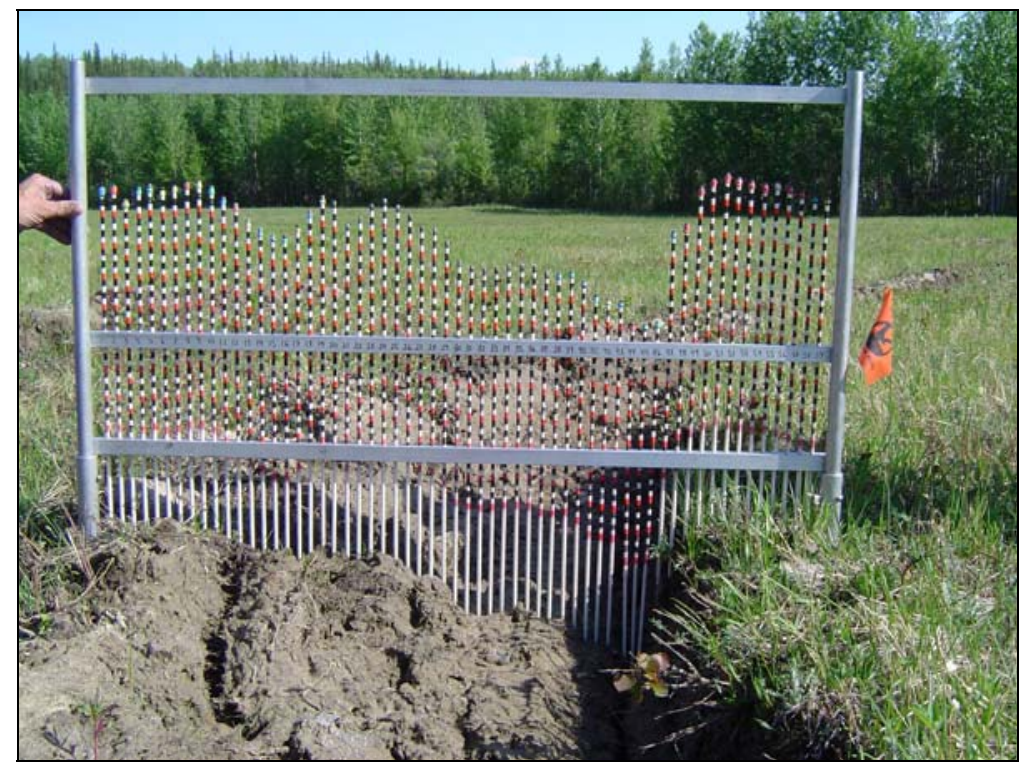

a. Left track.

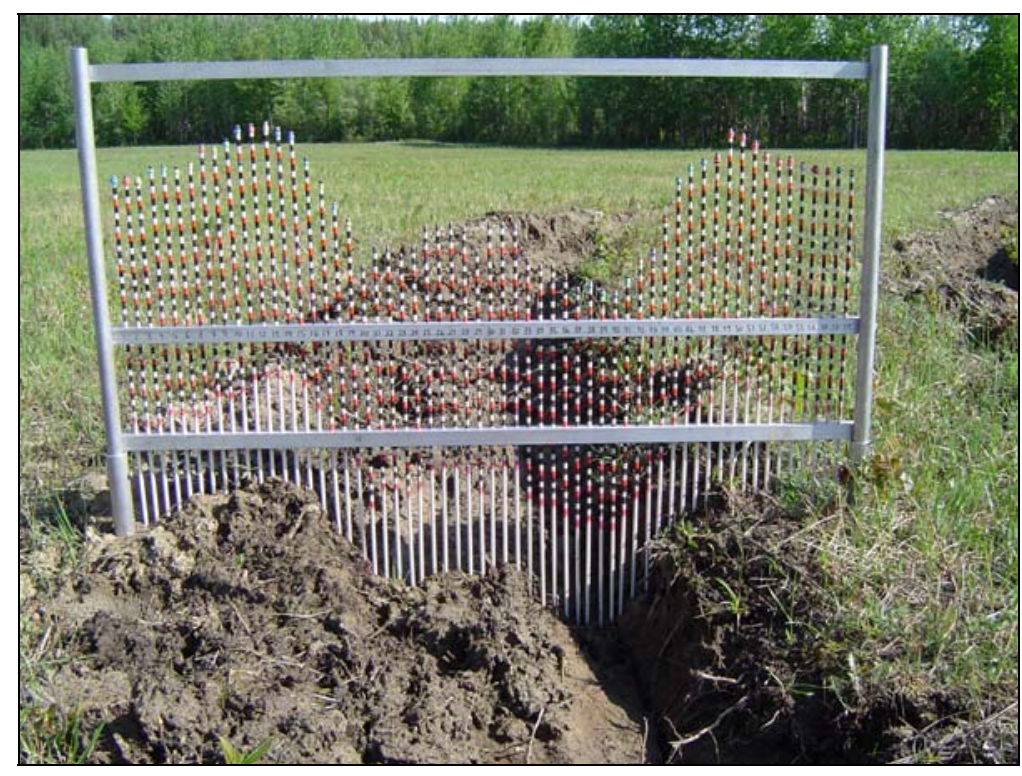

b. Right track.

Figure A2. Rut profiles on point A8A on turn section of eight-pass at the Arkansas Range. 


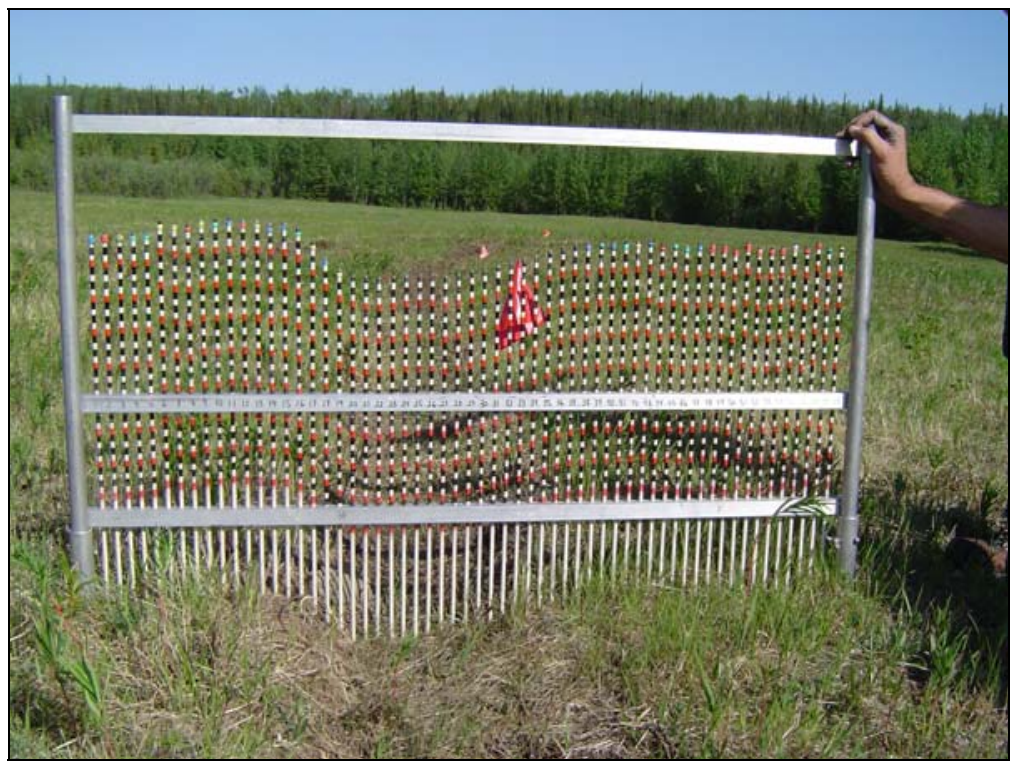

a. Left track.

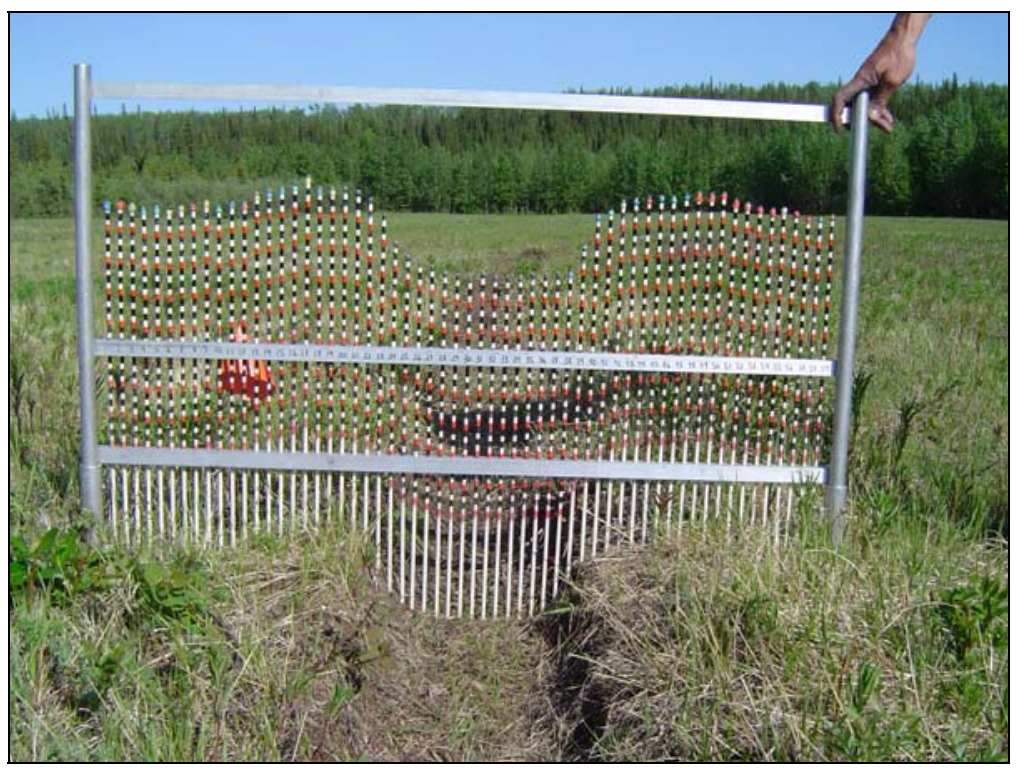

b. Right track.

Figure A3. Rut profiles on point A4D on drier section of four-pass at the Arkansas Range. 


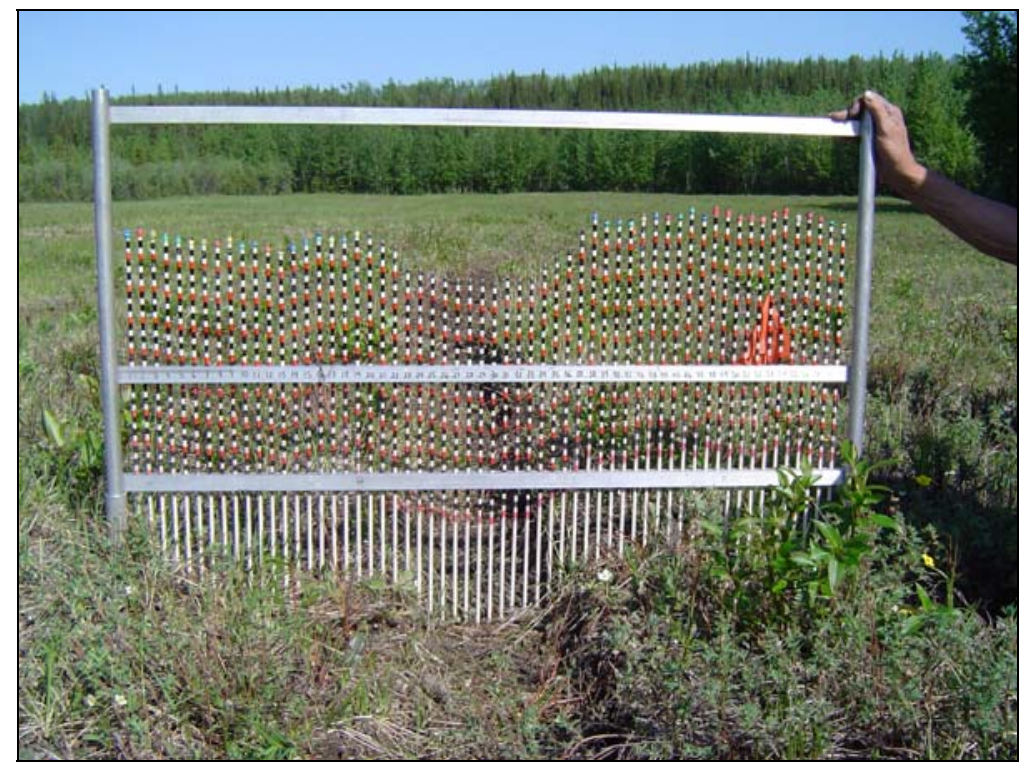

a. Left track.

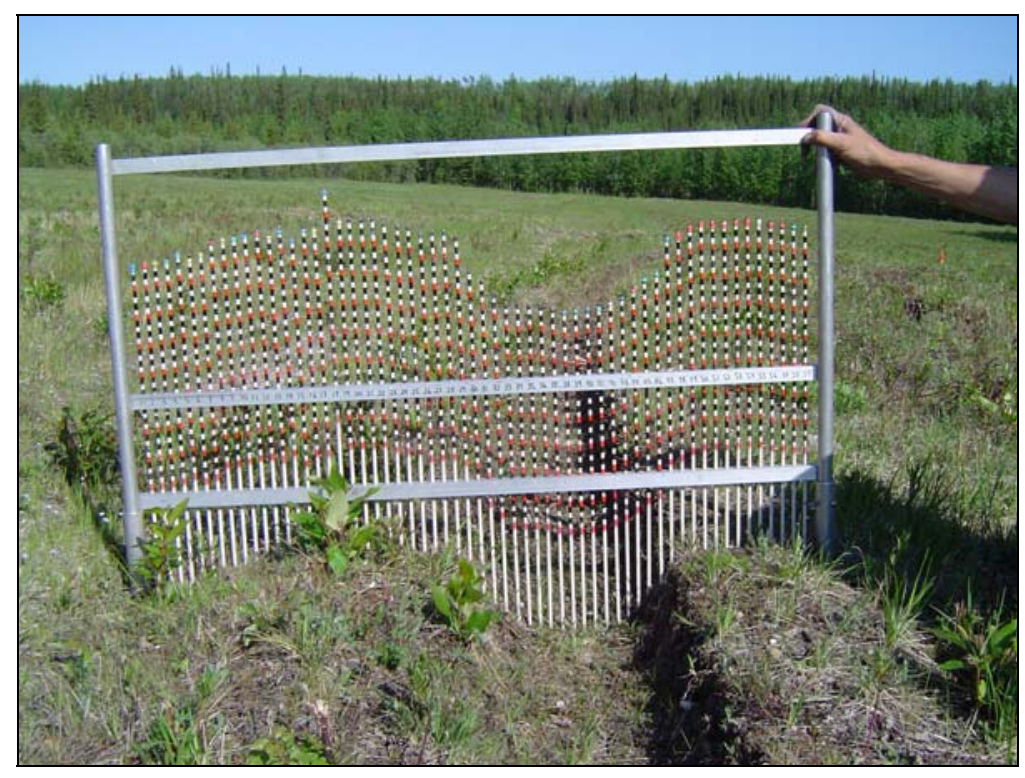

b. Right track.

Figure A4. Rut profiles on point A1B on drier section of one-pass at the Arkansas Range. 


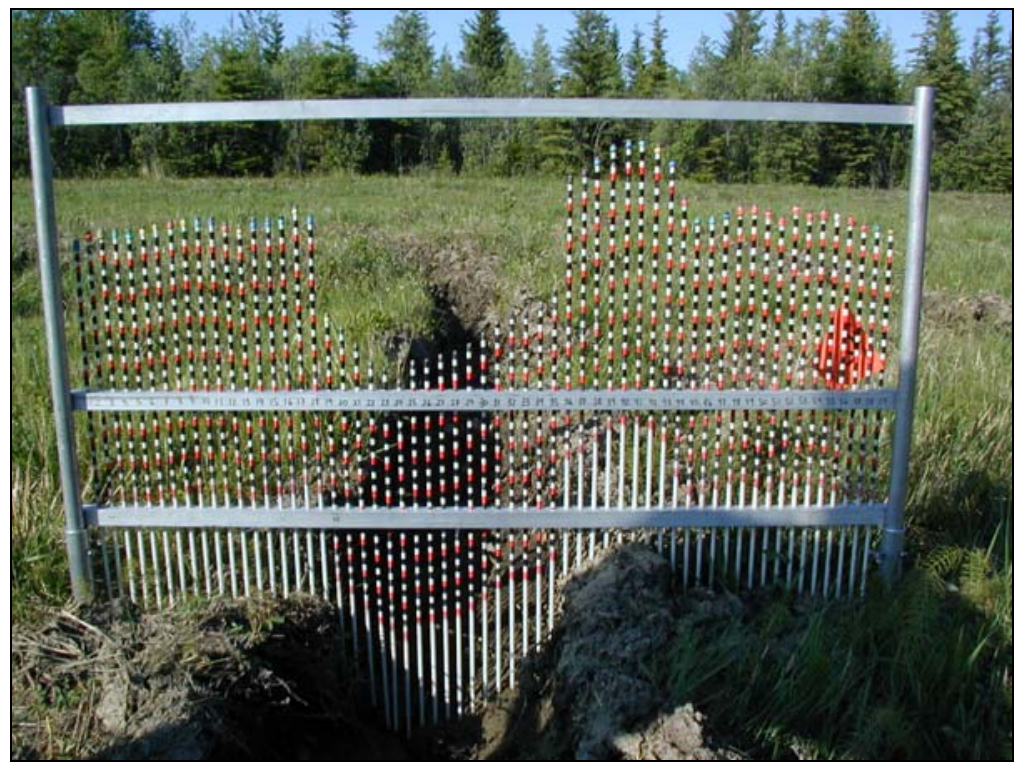

a. Left track.

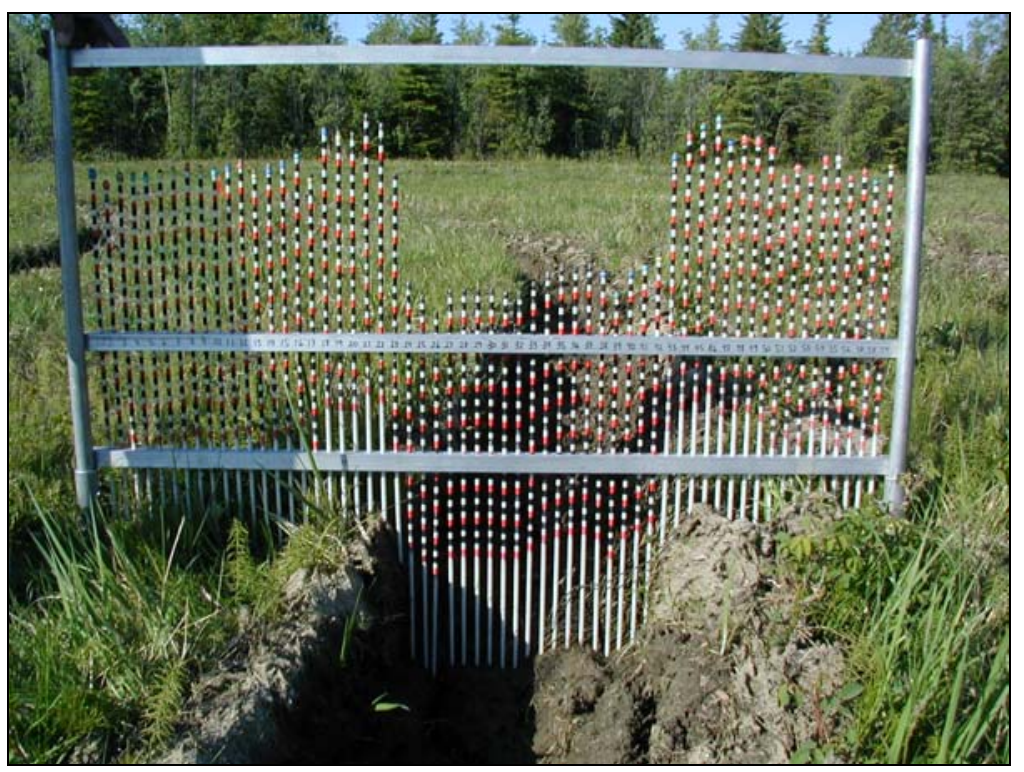

b. Right track.

Figure A5. Rut profiles on point AS2B on spiral section at the Arkansas Range. 


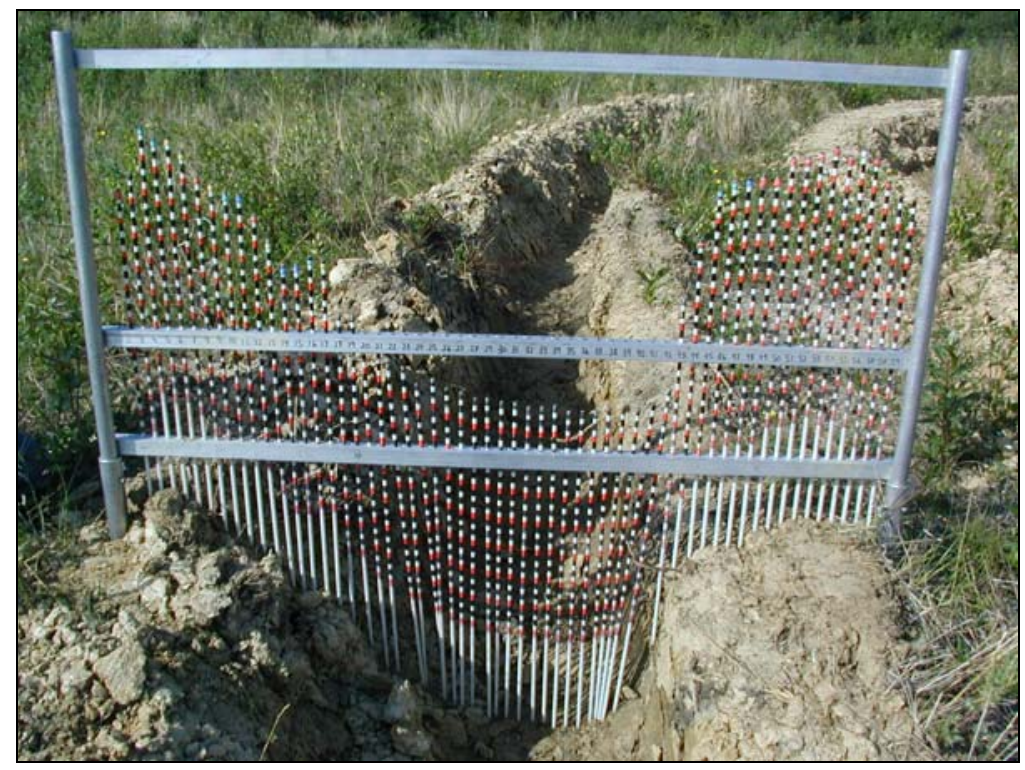

a. Left track.

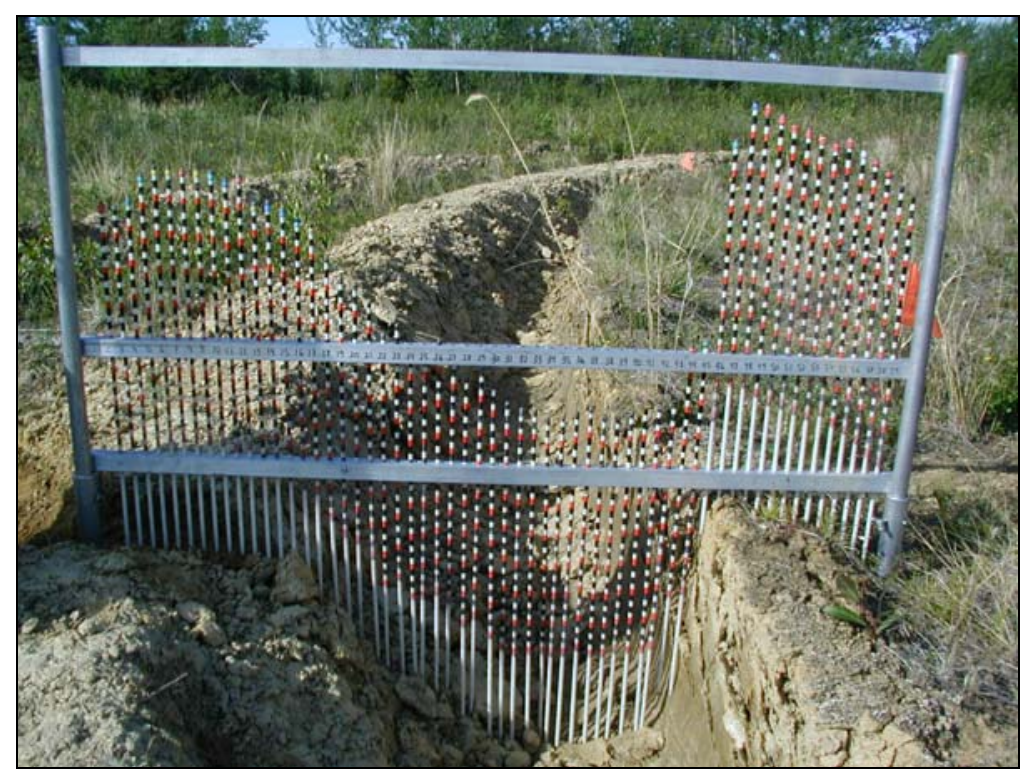

b. Right track.

Figure A6. Rut profiles on point E13G on turn section of thirteen-pass at the Eddy Drop Zone. 


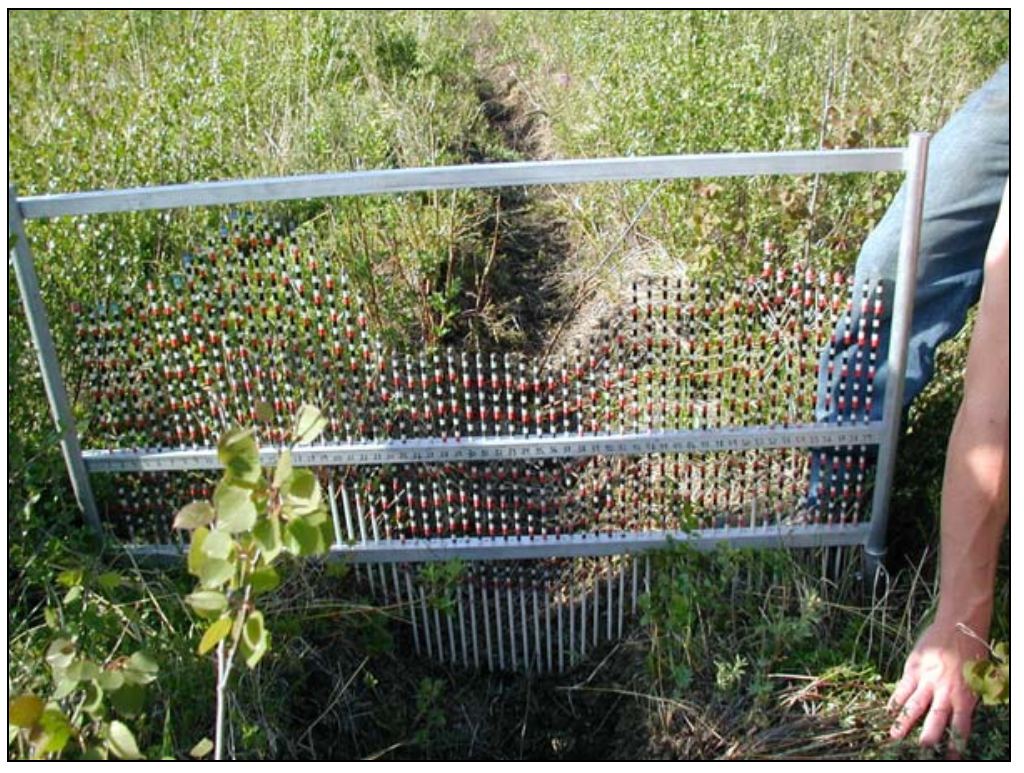

a. Left track.

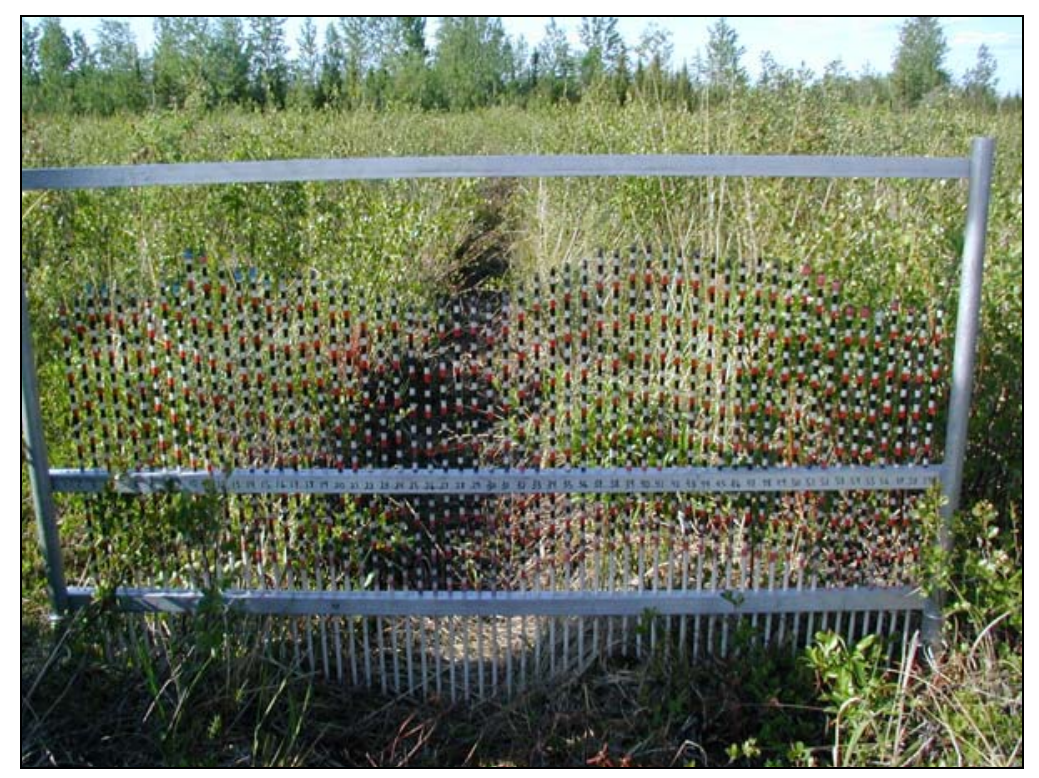

b. Right track.

Figure A7. Rut profiles on point E4C on straight section of four-pass at the Eddy Drop Zone. 


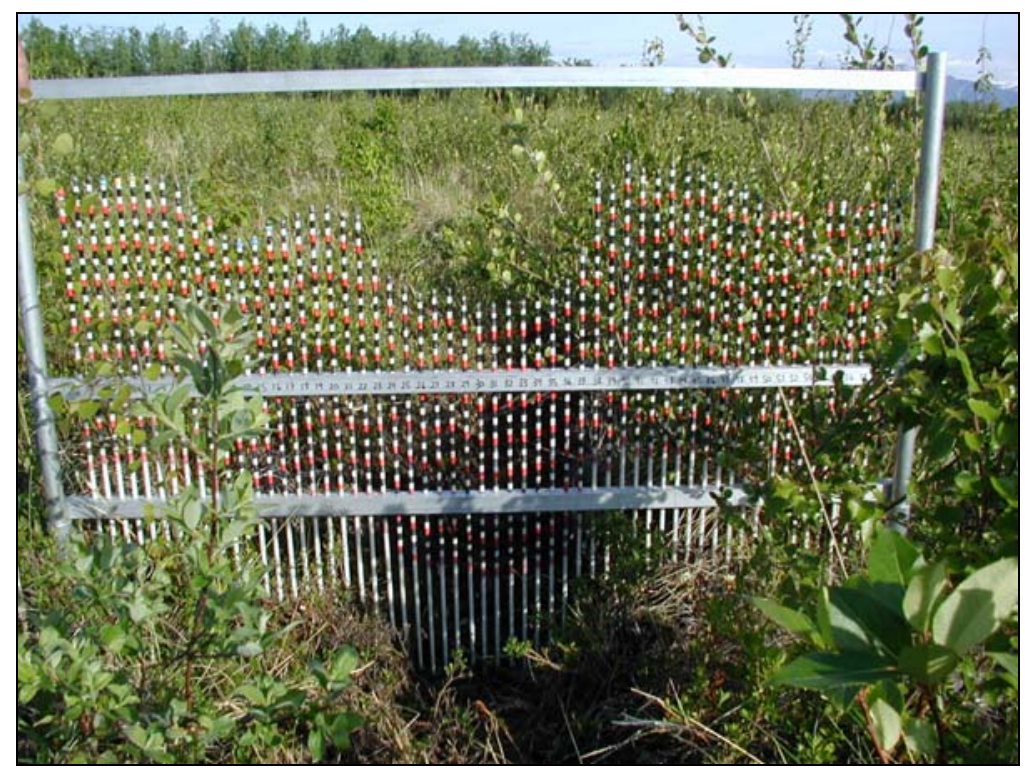

a. Left track.

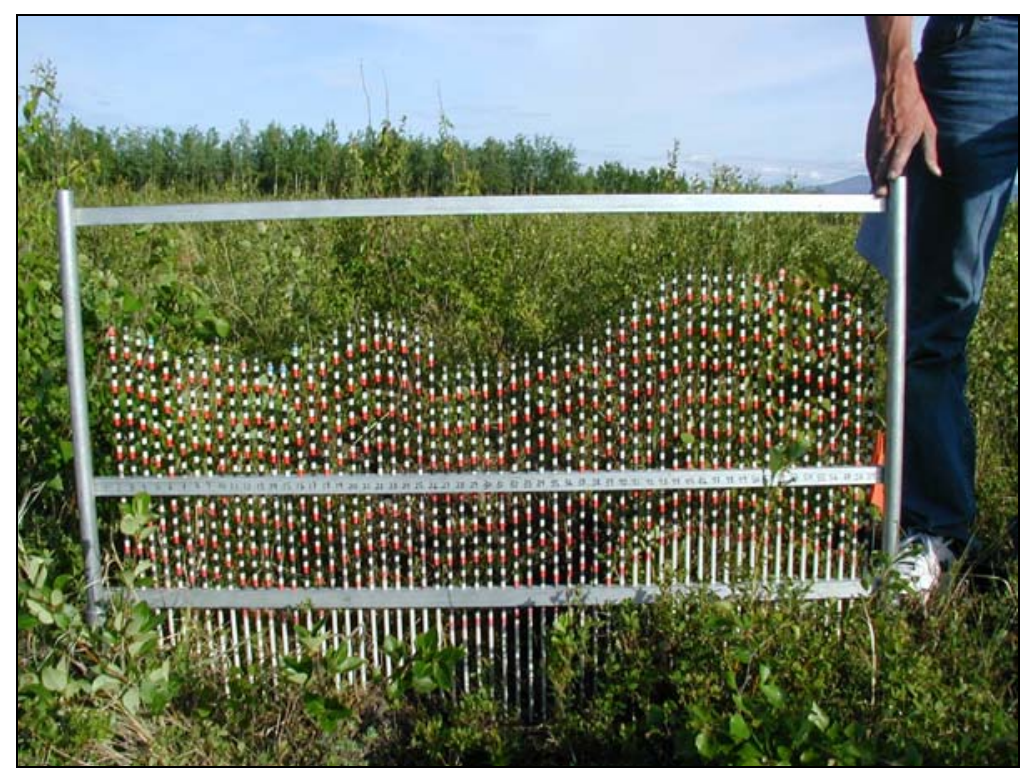

b. Right track.

Figure A8. Rut profiles on point ES-2C on spiral section at the Eddy Drop Zone. 


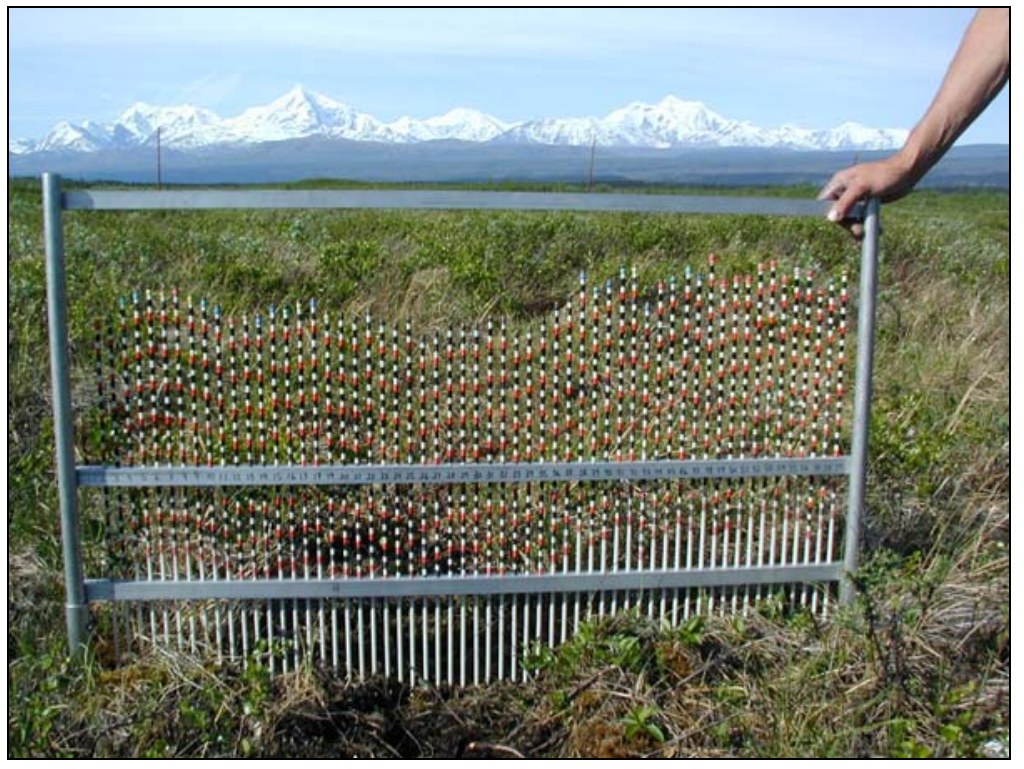

a. Left track.

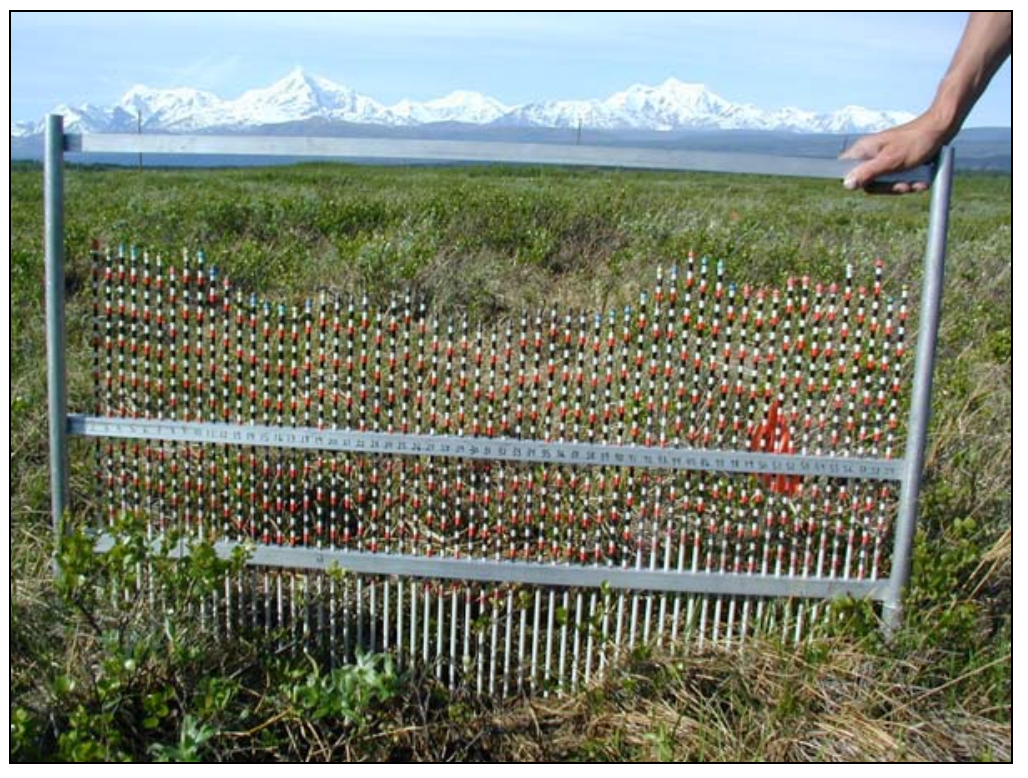

b. Right track.

Figure A9. Rut profiles on point TSS4A on spiral section at the Texas Range. 


\section{APPENDIX B: CALCULATION OF FROST DEPTH}

\begin{tabular}{|c|c|c|c|c|}
\hline \multirow[b]{3}{*}{ Parameters } & \multicolumn{4}{|c|}{ Sites and season } \\
\hline & \multicolumn{3}{|c|}{$\begin{array}{c}\text { DTA, Alaska } \\
1 \text { August 2002-31July } 2003\end{array}$} & \multirow{2}{*}{$\begin{array}{l}\text { Fort McCoy, } \\
\text { Wisconsin } \\
1 \text { August } 1994- \\
\text { 31July } 1995\end{array}$} \\
\hline & $\begin{array}{l}\text { Arkansas } \\
\text { Range }\end{array}$ & $\begin{array}{l}\text { Eddy Drop } \\
\text { Zone }\end{array}$ & $\begin{array}{l}\text { Texas } \\
\text { Range }\end{array}$ & \\
\hline Dry density, $\rho_{\mathrm{d}}, \mathrm{kg} / \mathrm{m}^{3}$ & 1634 & 1356 & 559 & 1800 \\
\hline Water content, $\omega, \%$ & 30 & 39 & 157 & 15.6 \\
\hline Air freezing index, $l_{\text {af }},{ }^{\circ} \mathrm{C}$-days & $1589^{\mathrm{a}}$ & $1589^{\mathrm{a}}$ & $1589^{\mathrm{a}}$ & $608^{b}$ \\
\hline $\begin{array}{l}\text { Temperature difference between } \\
\text { mean annual air temperature and } \\
\text { freezing temperature, } v_{0},{ }^{\circ} \mathrm{C}\end{array}$ & $0.8^{\mathrm{a}}$ & $0.8^{\mathrm{a}}$ & $0.8^{\mathrm{a}}$ & $6.8^{\mathrm{b}}$ \\
\hline $\begin{array}{l}\text { Surface } n \text {-factor for freezing, } \\
n_{\mathrm{f}} \text {, dimensionless }\end{array}$ & 0.33 & 0.33 & 0.29 (peat) & 0.33 \\
\hline $\begin{array}{l}\text { Unfrozen thermal conductivity, } \\
k_{\mathrm{u}}, \mathrm{J} / \mathrm{s}-\mathrm{m}-{ }^{\circ} \mathrm{C}\end{array}$ & 2.0 & 1.2 & 0.55 & 2.4 \\
\hline $\begin{array}{l}\text { Frozen thermal conductivity, } \\
k_{\mathrm{f}}, \mathrm{J} / \mathrm{s}-\mathrm{m}-{ }^{\circ} \mathrm{C}\end{array}$ & 4.2 & 2.0 & 1.3 & 3.5 \\
\hline Latent heat of the soil, $\mathrm{L}, \mathrm{J} / \mathrm{m}^{3}$ & $9.39 \times 10^{7}$ & $16.36 \times 10^{7}$ & $17.65 \times 10^{7}$ & $29.3 \times 10^{7}$ \\
\hline Thermal ratio, $\alpha$, dimensionless & 0.23 & 0.23 & 0.26 & 3.97 \\
\hline $\begin{array}{l}\text { Fusion parameter, } \mu, \\
\text { dimensionless }\end{array}$ & 0.06 & 0.05 & 0.03 & 0.04 \\
\hline $\begin{array}{l}\text { Correction coefficient, } \lambda \text {, } \\
\text { dimensionless }\end{array}$ & 0.98 & 0.98 & 0.96 & 0.70 \\
\hline Frost depth, $X^{\mathrm{C}}, \mathrm{m}(\mathrm{ft})$ & $0.34(1.14)$ & $0.23(0.76)$ & $0.14(0.45)$ & $0.30(0.86)$ \\
\hline Frost depth, $X^{\mathrm{d}}, \mathrm{m}$ & 1.3 & 0.9 & $0.5^{\mathrm{e}_{*}}$ & 0.7 \\
\hline \multicolumn{5}{|c|}{ a Air temperature data from 1 August 2002 to 31 July 2003} \\
\hline \multicolumn{5}{|c|}{ b Air temperature data from 1 August 1994 to 31 July 1995} \\
\hline \multicolumn{5}{|c|}{ c Denotes results from Stefan equation } \\
\hline \multicolumn{5}{|c|}{ d Denotes results from modified Berggren equation } \\
\hline e Not accounting for the influence & depth of pern & & & \\
\hline
\end{tabular}

Two numerical methods to calculate frost depth penetration include the Stefan equation and the modified Berggren equation. The Stefan equation does not account for the volumetric heat of the frozen and unfrozen soil, which estimates a higher value frost depth than modified Berggren equation. The equations are written 


$$
\begin{aligned}
& X=\left(\frac{48 k I_{\mathrm{sf}}}{L}\right)^{1 / 2}(\text { Stefan equation, in English units) } \\
& X=\lambda\left(172,800 \frac{k I_{\mathrm{sf}}}{\mathrm{L}}\right)^{1 / 2}(\text { modified Berggren equation, in SI units) }
\end{aligned}
$$

where $X$ is the frost depth, $I_{\mathrm{sf}}$ is the surface freezing index, $L$ the latent heat of the soil, $k$ the soil thermal conductivity, and $\lambda$ the correction coefficient. 


\section{APPENDIX C: OFF-ROAD VEHICLE GUIDELINES AND RATINGS FROM STUDIES IN ALASKA}

\begin{tabular}{|c|c|}
\hline \multicolumn{2}{|r|}{ Impact category } \\
\hline \multicolumn{2}{|c|}{$\begin{array}{l}\text { Compression to tundra surface: Refers to the bending and compressing of live and standing de } \\
\text { vegetation to the tundra surface so that it becomes flattened and oriented to the direction of travel }\end{array}$} \\
\hline Score & \\
\hline 0 & No observable compression vegetation to tundra surface. \\
\hline 1 & Slight compression of vegetation (1-10\% of plants affected). \\
\hline 2 & Moderate compression of vegetation (11-50\% of plants affected). \\
\hline 3 & Severe compression of vegetation ( $>50 \%$ of plants affected) \\
\hline
\end{tabular}

Displacement: Refers to several categories of disturbance, including tussocks of moss or cottongrass moved and overturned, displacement of wet mosses by splashing action, and exposure of bare soil by removal of vegetation mat.

\begin{tabular}{|c|l|}
\hline Score & \\
\hline 0 & No displacement of vegetation. \\
\hline 1 & Some displacement of vegetation (1-10\% of plants affected). \\
\hline 2 & Moderate displacement of vegetation (11-50\% of plants affected). \\
\hline 3 & Severe displacement of vegetation ( $>50 \%$ of plants affected). \\
\hline \multicolumn{2}{|c|}{ Impact category } \\
\hline Breakage: Refers to breakage of plant stems or flowering stalks. \\
\hline Score & \\
\hline 0 & No breakage observed. \\
\hline 1 & Some breakage observed (1-10\% of plants affected). \\
\hline 2 & Moderate breakage observed (11-50\% of plants affected). \\
\hline 3 & Severe breakage observed ( $>50 \%$ of plants affected). \\
\hline \multicolumn{2}{|c|}{ Impact category } \\
\hline Deposition: Refers to accumulation at sides of tracks. \\
\hline Score & \\
\hline 0 & No mud or moss accumulation at sides of tracks. \\
\hline 1 & Few shallow patches of mud or mud or moss. \\
\hline 2 & Many shallow patches of mud or mud or moss. \\
\hline 3 & Continuous thick deposit of mud or mud or moss. \\
\hline
\end{tabular}


Table C2. Summary of documented off-road vehicle impacts in Alaskan arctic and subarctic terrain. (After Slaughter et al. 1990.)

\begin{tabular}{|c|c|c|c|c|c|}
\hline \multirow{2}{*}{$\begin{array}{l}\text { Location (source) and } \\
\text { vehicle type }\end{array}$} & \multirow{2}{*}{$\begin{array}{c}\text { Setting and number } \\
\text { of passes } \\
\text { made by vehicle }\end{array}$} & \multicolumn{3}{|c|}{$\begin{array}{l}\text { Subjective impact rating } \\
\qquad(1=\text { low; } 8=\text { high })\end{array}$} & \multirow{2}{*}{$\begin{array}{l}\text { Cumulative } \\
\text { impact* }\end{array}$} \\
\hline & & Microrelief & Soils & Vegetation & \\
\hline $\begin{array}{l}\text { Prudhoe Bay, Alaska } \\
\text { (Walker et al. 1987) }\end{array}$ & $\begin{array}{l}\text { Moist, nontussock sedge; } \\
\text { dwarf-shrub tundra }\end{array}$ & & & & \\
\hline \multirow{5}{*}{ Rolligon } & 1 & 2 & 1 & 2 & 5 \\
\hline & 30 & 5 & 5 & 5 & 15 \\
\hline & Wet sedge tundra & & & & \\
\hline & 1 & 4 & 4 & 6 & 13 \\
\hline & 30 & 7 & 8 & 9 & 24 \\
\hline $\begin{array}{c}\text { Barrow, Alaska } \\
\text { (Abele et al. 1984) }\end{array}$ & $\begin{array}{l}\text { Wet sedge meadow } \\
\text { (drained lake bed) }\end{array}$ & & & & \\
\hline \multirow{2}{*}{ Rolligon (Houston) } & 5 & 4 & 2 & 2 & 8 \\
\hline & 15 & 7 & 5 & 5 & 17 \\
\hline \multirow{2}{*}{ Weasel } & 5 & & & & \\
\hline & 50 & & & & \\
\hline $\begin{array}{l}\text { Nebesna, Alaska (Racine } \\
\text { and Ahlstrand 1985) }\end{array}$ & $\begin{array}{l}\text { Moist, tussock sedge; } \\
\text { dwarf-shrub tundra }\end{array}$ & & & & \\
\hline \multirow{3}{*}{ Three-wheel Honda } & 10 & 2 & 1 & 3 & 6 \\
\hline & 50 & 3 & 1 & 3 & 7 \\
\hline & 150 & 4 & 3 & 5 & 12 \\
\hline \multirow{3}{*}{ Six-wheel Sidewinder } & 10 & 2 & 1 & 3 & 6 \\
\hline & 50 & 5 & 3 & 6 & 14 \\
\hline & 15 & 7 & 6 & 8 & 23 \\
\hline \multirow{3}{*}{ Weasel } & 10 & 2 & 2 & 5 & 9 \\
\hline & 50 & 5 & 4 & 6 & 15 \\
\hline & 150 & 8 & 7 & 8 & 23 \\
\hline \multicolumn{6}{|c|}{ Denali Highway Region, Alaska (Sparrow et al. 1978) } \\
\hline \multirow{6}{*}{$\begin{array}{l}\text { Uncontrolled off-road } \\
\text { vehicles ranging from } \\
\text { three-wheeler up to } \\
\text { Weasel-size vehicles }\end{array}$} & Dry tundra (light use) & 5 & 5 & 5 & 15 \\
\hline & Dry tundra (light use) & 7 & 8 & 6 & 21 \\
\hline & $\begin{array}{c}\text { Moist tundra (medium } \\
\text { use) }\end{array}$ & 4 & 4 & 6 & 14 \\
\hline & $\begin{array}{c}\text { Moist tundra (medium } \\
\text { use) }\end{array}$ & 8 & 7 & 8 & 23 \\
\hline & Alpine tundra (heavy use) & 8 & 8 & 8 & 24 \\
\hline & Alpine tundra (heavy use) & 4 & 5 & 6 & 15 \\
\hline Weasel-size & $\begin{array}{l}\text { Open coniferous } \\
\text { woodland }\end{array}$ & 4 & 7 & 8 & 23 \\
\hline
\end{tabular}


Table C3. Representative small off-road vehicle characteristics for personal and industrial use in Alaska. (From Slaughter et al. 1990.)

\begin{tabular}{|c|c|c|c|}
\hline Class & $\begin{array}{l}\text { Weight } \\
\text { (kg) }\end{array}$ & $\begin{array}{l}\text { Ground } \\
\text { pressure } \\
\left(\mathrm{kg} / \mathrm{cm}^{2}\right)\end{array}$ & Remarks \\
\hline \multicolumn{4}{|l|}{ I. Small: Personal use } \\
\hline Three-wheeler all-terrain cycle & $90-120$ & 0.10 & $\begin{array}{l}1 \text { passenger, } 3 \text { wheels, } \\
\text { knobby or cleated tread }\end{array}$ \\
\hline Four-wheeler all-terrain cycle & $110-170$ & 0.10 & $\begin{array}{c}1 \text { passenger, } 4 \text { wheels, } \\
\text { knobby tread }\end{array}$ \\
\hline Goot or Pug & $500-600$ & 0.70 & $\begin{array}{l}\text { 2-4 passengers, } 4 \text { wheels, } \\
\text { four-wheel drive, cleated tread }\end{array}$ \\
\hline Trackster & 450 & 0.04 & 2 passenger, rubber tracks \\
\hline Argo, Huster, Max, Sidewinder & $400-600$ & 0.18 & 2-4 passengers, cleated tread \\
\hline \multicolumn{4}{|l|}{$\begin{array}{l}\text { II. Medium: Personal } \\
\text { and industrial use }\end{array}$} \\
\hline Weasel & 1,200 & 0.07 & $\begin{array}{c}\text { 2-6 passengers, tracked, } \\
\text { skid steering }\end{array}$ \\
\hline Bombardier Bombi & 1,100 & 0.06 & $\begin{array}{l}2 \text { passengers, tracked, } \\
\text { skid steering }\end{array}$ \\
\hline Jeep & 1,180 & 2.24 & $\begin{array}{l}4 \text { passengers, four-wheel drive, may } \\
\text { be equipped with oversized tires }\end{array}$ \\
\hline Thiokol IMP & 1,200 & 0.06 & $\begin{array}{l}\text { Rubber track, steel cleated, } \\
\text { skid steering }\end{array}$ \\
\hline Pasquali 993 tractor & 815 & 0.84 & $\begin{array}{l}4 \text { wheels, cleated tires, } \\
\text { articulated steering }\end{array}$ \\
\hline \multicolumn{4}{|l|}{ III. Large-industrial use } \\
\hline Norwell RN-110 & 5,400 & 0.09 & $\begin{array}{c}\text { Rubber tracks, steel cleats, } \\
\text { skid steering }\end{array}$ \\
\hline Rolligon (Houston) & 6,800 & 0.25 & 6 wheels, ribbed tires \\
\hline Bombardier Muskeg Tractor & 3,200 & 0.09 & $\begin{array}{l}\text { Rubber tracks, steel cleated, } \\
\text { skid steering }\end{array}$ \\
\hline Rolligon (CATCO) & 11,700 & 0.35 & 8 wheels, smooth tires \\
\hline Caterpillar D-7 & 15,800 & 0.70 & Prime mover, steel cleated tracks \\
\hline
\end{tabular}


Table C4. Static contact pressure estimates for selected harvesting equipment. (From Stone 2002.)

\begin{tabular}{|c|c|c|}
\hline \multirow{2}{*}{ Equipment type } & \multicolumn{2}{|c|}{ Static ground pressure } \\
\cline { 2 - 3 } & $\mathbf{( k P a )}$ & $\mathbf{( p s i )}$ \\
\hline Flexible tracked skidders & $20-40$ & $3-6$ \\
\hline Rigid tracked crawlers & $40-70$ & $6-10$ \\
\hline Forwarder with 3 to 4 axles & $55-70$ & $8-10$ \\
\hline Rubber-tired skidders & $80-110$ & $12-16$ \\
\hline Forwarder with 2 axles & $100-125$ & $14-18$ \\
\hline
\end{tabular}




\section{APPENDIX D: METHODS TO CALCULATE VEHICLE SPEED AND TURNING RADIUS FROM GPS DATA. (AFTER AYERS ET AL. 2000.)}

A Global Positioning System (GPS) unit was mounted on the vehicle for tracking its position during the Stryker maneuver tests at DTA. This was similar to a GPS unit used by Ayers et al. (2000). The GPS unit recorded the position data at the $1-\mathrm{Hz}$ frequency in latitude and longitude coordinates. The data then were converted to Universal Transverse Mercator (UTM) system coordinates to calculate the vehicle speed and turning radius.

The distance between the position points is equal to the speed of the vehicle. Distance in meters from Position Point A to Position Point B (on northing versus easting axis) is

$$
\text { Distance }_{\mathrm{A}-\mathrm{B}}=\sqrt{\left(A_{\mathrm{N}}-B_{\mathrm{N}}\right)^{2}+\left(A_{\mathrm{E}}-B_{\mathrm{E}}\right)^{2}} \text {. }
$$

Since the GPS recorded at the 1-Hz frequency, the time from Position Point A to Position Point B was one second. Velocity in meters per second from Position Point A to Position Point B is

$$
\text { Velocity }(\mathrm{m} / \mathrm{sec})=\frac{\text { Distance }_{\mathrm{A}-\mathrm{B}}}{\text { Time }_{\mathrm{A}-\mathrm{B}}}
$$

Turning radius was calculated using five data points with plane geometry referencing the northing and easting of each point. The equations used to calculate the turning radius for the points are illustrated in Figure D1. Perpendicular bisects to lines connecting the first to the third, and third to the fifth, data points were calculated from the coordinates of those points. The intersection of those two perpendicular bisects was determined by solving two equations with two unknowns. Turning radii greater than and equal to $150 \mathrm{~m}$ are assigned a value of $150 \mathrm{~m}$, and are considered as straight path. 


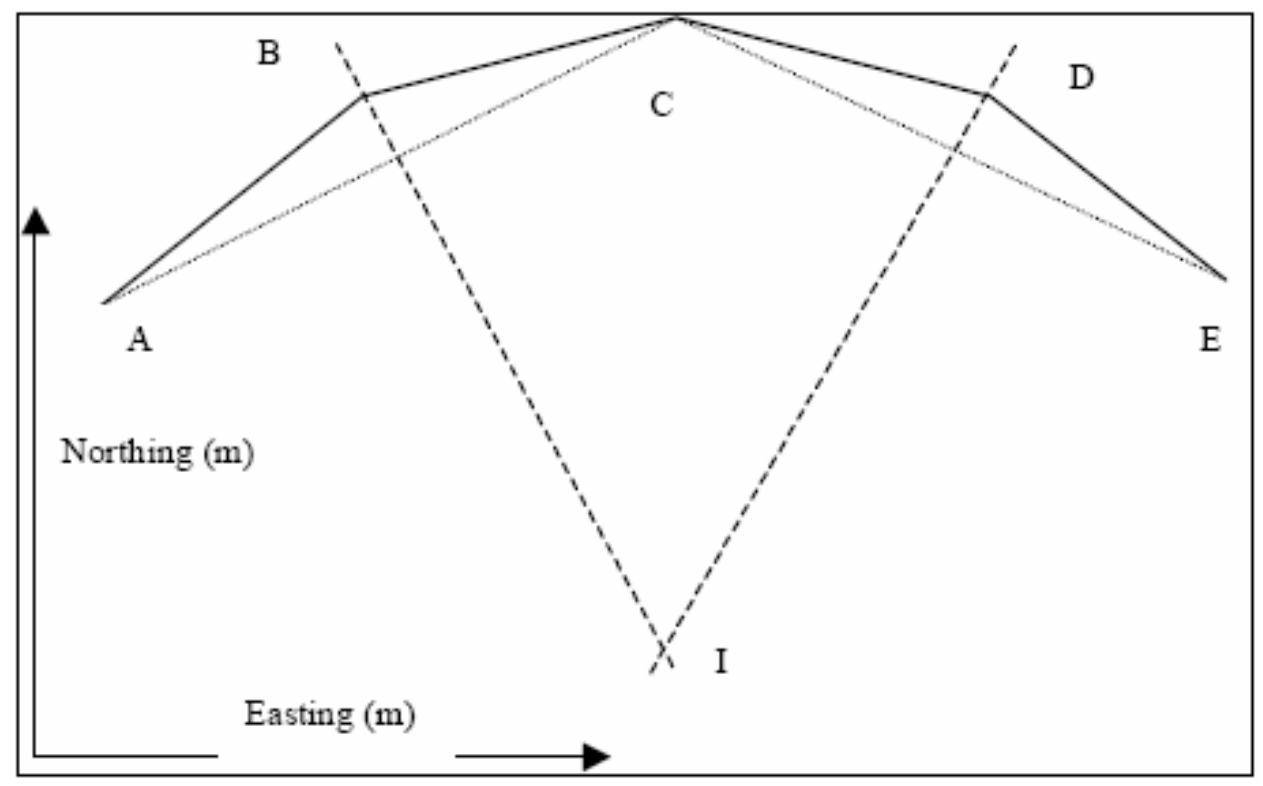

Figure D1. Turning radius.

The slope of the line from position A to position C is

$$
m_{\mathrm{A}-\mathrm{C}}=\frac{C_{\mathrm{N}}-A_{\mathrm{N}}}{C_{\mathrm{E}}-A_{\mathrm{E}}} .
$$

The slope of the line from position $\mathrm{C}$ to position $\mathrm{E}$ is

$$
m_{\mathrm{C}-\mathrm{E}}=\frac{E_{\mathrm{N}}-C_{\mathrm{N}}}{E_{\mathrm{E}}-C_{\mathrm{E}}} .
$$

The slope of the perpendicular bisect to line A-C at position B is

$$
m_{\mathrm{B}-\mathrm{I}}=\frac{-1}{m_{\mathrm{A}-\mathrm{C}}} .
$$

The slope of the perpendicular bisect to line $\mathrm{C}-\mathrm{E}$ at position $\mathrm{D}$ is

$$
m_{\mathrm{D}-\mathrm{I}}=\frac{-1}{m_{\mathrm{C}-\mathrm{E}}} .
$$


Equations to determine the intercepts of the perpendicular bisects are

$$
\begin{aligned}
& b_{\mathrm{B}-\mathrm{I}}=B_{\mathrm{N}}-m_{\mathrm{B}-\mathrm{I}} B_{\mathrm{E}} \\
& b_{\mathrm{D}-\mathrm{I}}=D_{\mathrm{N}}-m_{\mathrm{D}-\mathrm{I}} D_{\mathrm{E}} .
\end{aligned}
$$

Equations to determine the positions of the intersection I of the two bisects are

$$
\begin{aligned}
& I_{\mathrm{N}}=m_{\mathrm{B}-\mathrm{I}} I_{\mathrm{E}}+b_{\mathrm{B}-\mathrm{I}} \\
& I_{\mathrm{N}}=m_{\mathrm{D}-\mathrm{I}} I_{\mathrm{E}}+b_{\mathrm{D}-\mathrm{I}} .
\end{aligned}
$$

The equation to determine distance from point $\mathrm{C}$ to intersection $\mathrm{I}$ is

$$
\text { TurningRadius }(m)=\sqrt{\left(I_{\mathrm{N}}-C_{\mathrm{N}}\right)^{2}+\left(I_{\mathrm{E}}-C_{\mathrm{E}}\right)^{2}} \text {. }
$$




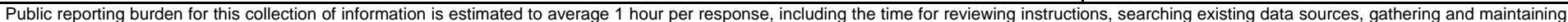

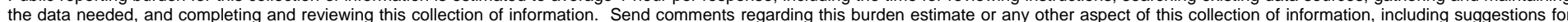

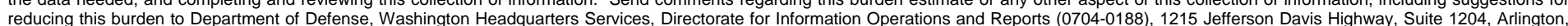

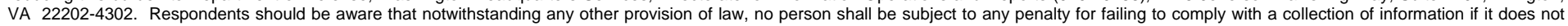
display a currently valid OMB control number. PLEASE DO NOT RETURN YOUR FORM TO THE ABOVE ADDRESS.

\begin{tabular}{l|l}
$\begin{array}{l}\text { 1. REPORT DATE (DD-MM-YYYY) } \\
\text { July } 2005\end{array}$ & $\begin{array}{l}\text { 2. REPORT TYPE } \\
\text { Technical Report }\end{array}$ \\
\hline
\end{tabular}

4. TITLE AND SUBTITLE

Disturbance Measurements from Off-Road Vehicles on Seasonal Terrain

3. DATES COVERED (From - To)

5a. CONTRACT NUMBER

5b. GRANT NUMBER

5c. PROGRAM ELEMENT NUMBER

6. AUTHOR(S)

5d. PROJECT NUMBER

Rosa T. Affleck

5e. TASK NUMBER

5f. WORK UNIT NUMBER

7. PERFORMING ORGANIZATION NAME(S) AND ADDRESS(ES)

8. PERFORMING ORGANIZATION REPORT NUMBER

U.S. Army Engineer Research and Development Center

Cold Regions Research and Engineering Laboratory

ERDC/CRREL TR-05-12

72 Lyme Road

Hanover, New Hampshire 03755-1290

9. SPONSORING / MONITORING AGENCY NAME(S) AND ADDRESS(ES)

10. SPONSOR/MONITOR'S ACRONYM(S)

11. SPONSOR/MONITOR'S REPORT NUMBER(S)

\section{DISTRIBUTION / AVAILABILITY STATEMENT}

Approved for public release; distribution is unlimited.

Available from NTIS, Springfield, Virginia 22161.

13. SUPPLEMENTARY NOTES

\section{ABSTRACT}

Vehicle operations on cross-country terrain for military, commercial or industrial, and recreational purposes can disturb the terrain, especially during spring thaw season. Terrain disturbance from off-road vehicle operations can be measured in terms of rut depth and vegetation damage. Ruts occur when vehicle load is greater than the terrain's bearing capacity, especially in soft soils. Rutting is the physical disturbance of the soil, including compaction and deformation. Estimates of rut depth for wheeled and tracked vehicles in soft, unfrozen soils can be calculated using an empirical equation based on the vehicle and soil properties. The vehicle parameters include vehicle load, tire or tracked footprint area, and wheel slip. The terrain soil properties are very important elements for estimating rut depth, including soil type and strength. Rut depth measurements were collected from military vehicles during Stryker (wheeled) vehicle impact tests at three locations at Donnelly Training Area, Alaska, and from M60A3 (tracked) and HEMTT (wheeled) vehicles at Fort McCoy, Wisconsin, during spring thaw seasons. These rut depth data are coupled with information about vehicle maneuvers (multiple passes and turning) and soil properties, such as soil type, moisture content, and soil strength. The scope of this report is to compare the actual rut depth measurements with the empirical equations to relate the physical disturbance of the soil and vegetation to a severity index, quantify the volumetric soil displacement, and assess disturbance on winter operations.

\begin{tabular}{|c|c|c|c|c|c|}
\hline \multirow{3}{*}{\multicolumn{2}{|c|}{$\begin{array}{l}\text { 15. SUBJECT TERMS } \\
\text { Cumulative impact } \\
\text { Rut depth }\end{array}$}} & Rutting & \multicolumn{3}{|c|}{ Terrain disturbance } \\
\hline & & Severity index & \multicolumn{3}{|c|}{ Vehicle impact } \\
\hline & & Sinkage & \multicolumn{3}{|c|}{ Volumetric soil displacement } \\
\hline \multicolumn{3}{|c|}{ 16. SECURITY CLASSIFICATION OF: } & $\begin{array}{l}\text { 17. LIMITATION } \\
\text { OF ABSTRACT }\end{array}$ & $\begin{array}{l}\text { 18. NUMBER } \\
\text { OF PAGES }\end{array}$ & $\begin{array}{l}\text { 19a. NAME OF RESPONSIBLE } \\
\text { PERSON }\end{array}$ \\
\hline $\begin{array}{r}\text { a. REPORT } \\
\mathrm{U}\end{array}$ & $\begin{array}{c}\text { b. ABSTRACT } \\
U\end{array}$ & $\begin{array}{c}\text { c. THIS PAGE } \\
\text { U }\end{array}$ & $\mathrm{U}$ & 99 & $\begin{array}{l}\text { 19b. TELEPHONE NUMBER (include } \\
\text { area code) }\end{array}$ \\
\hline
\end{tabular}

